\title{
HIGH-ENERGY AIR SHOCK STUDY IN STEEL AND GROUT PIPES
}

H. D. Glenn, H. R. Kratz, D. D. Keough,

D. A. Duganne, D. J. Ruffner, R. P. Swift, and D. Baum

October 5, 1979

Work performed under the auspices of the US Department of Energy by the UCLLL under contract number W-7405-ENG-48
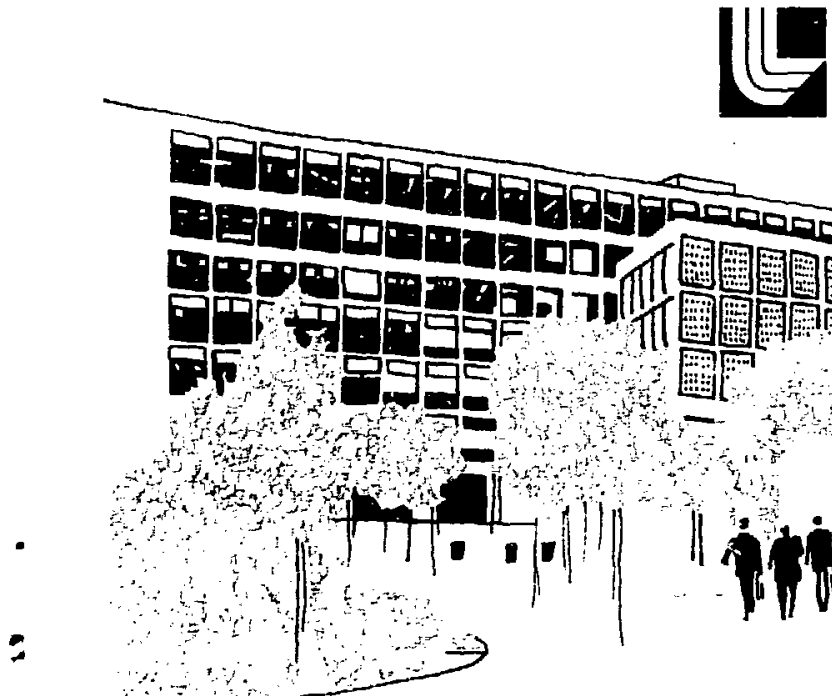
IAWRENCE LIVERMORE LABORATORY

Unversityol Cahtomia Livermore
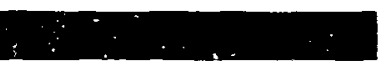


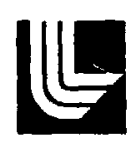

\title{
LAWRENCE LVERMORE LABORATORY
}

University of Calitornia/Livermore, Calitomia, 94550

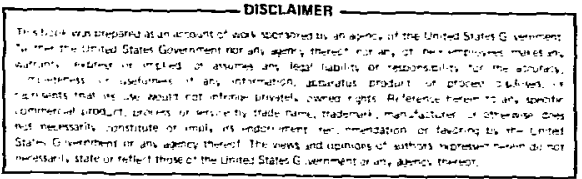

UCRL-52826

\section{HIGH-ENERGY AIR SHOCK STUDY IN STEEL AND GROUT PIPES}

\author{
H. D. Glenn, H. R. Kratz,* D. D. Keough, ${ }^{\dagger}$. \\ D. A. Duganne, D. J. Ruffner, R. P. Swift, and D. Baum
}

Manuscript date: October 5, 1979

-Systems, Science \& Software. La Jolla, CA

tSRI International, Menlo Park, CA

¥Artec Associates, Hayward, CA 


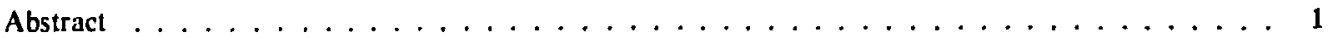

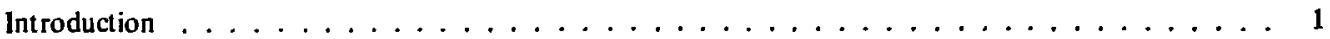

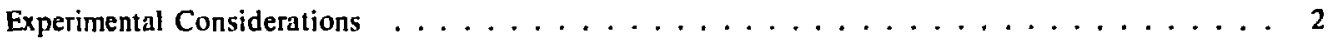

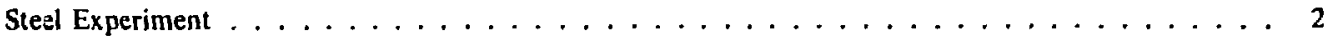

Experimental Procedures and Diagnostic Coverage . . . . . . . . . . . . . 3

Optical Coverage with Framing Camera . . . . . . . . . . . . . . . . . 3

Optical Coverage with Streaking Cameras . . . . . . . . . . . . . . . 4

Electronic Diagnostics ..........................4 4

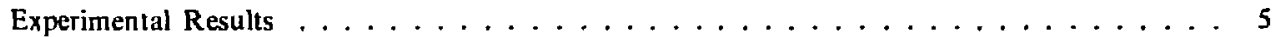

Framing Camera Coverage ...................... 5

TOA Data and Air Shock Velocity ..................... 5

Pressure Profiles .......................... 6

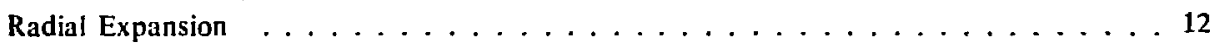

Condensation ............................. 13

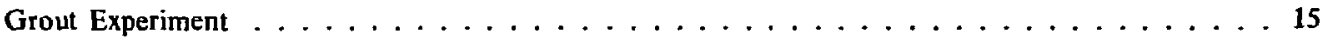

Experimental Procedure and Diagnostic Coverage . . . . . . . . . . . . . . . 15

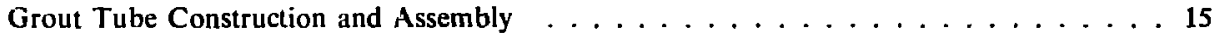

Optical Coverage with Framing Cameras . . . . . . . . . . . . . . . 17

Optical Coverage with Streaking Cameras ..................... 17

Electronic Diagnostics .......................... 17

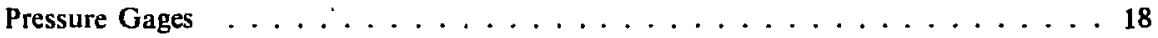

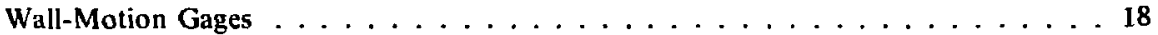

Plasma Flow and Conductivity Diagnostics .................. 18

Differences between Steel and Grout Experiments . . . . . . . . . . . . . . . 18

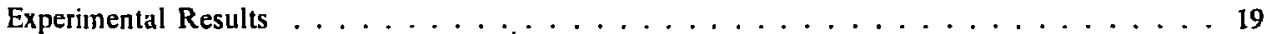

Framing Camera Coverage ........................ 19

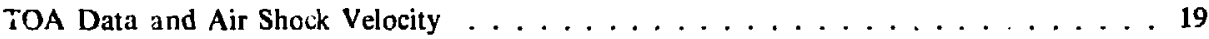

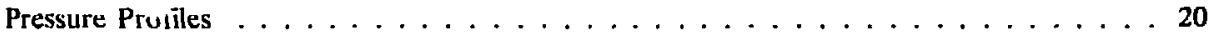

Radial Wall Motion ............................ 26

Plasma Flow Velocity and Conductivity Measurements . . . . . . . . . . . . . 28

Comparison of Experimental Results . . . . . . . . . . . . . . . . . . . . . 29

TOA and Velocity Results . . . . . . . . . . . . . . . . . . . . . 29

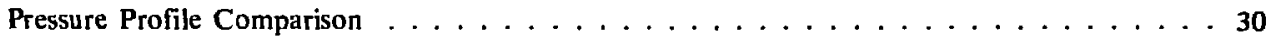

Summary and Conclusions $\ldots \ldots \ldots \ldots \ldots$

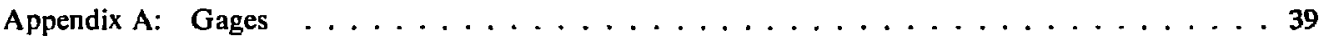

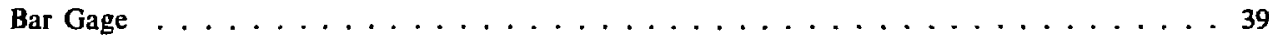

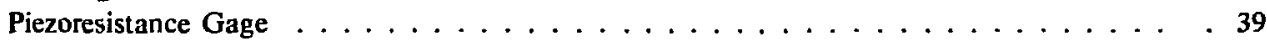

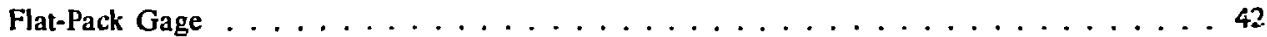

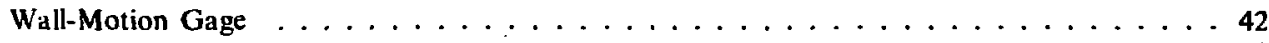

Appendix B: Grout Shock-Tube Construction . . . . . . . . . . . . . . . . 46

Appendix ,C: Plasma Flow Velocity and Conductivity Gages . . . . . . . . . . . . . 48

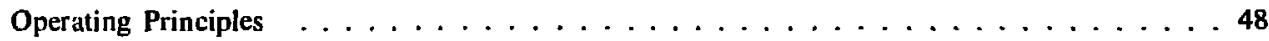

Plasma-Velocity Gage . . . . . . . . . . . . . . . . . . . . . 51

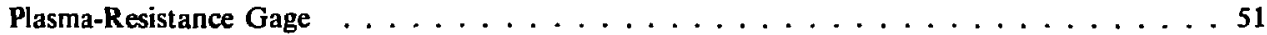

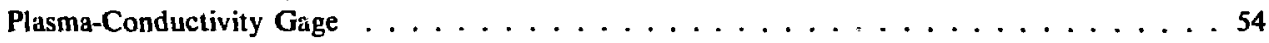

Acknowledgments ..............................54

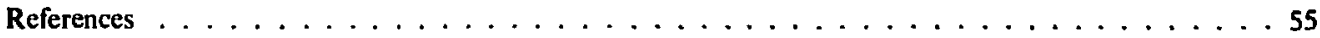




\section{HIGH-ENERGY AIR SHOCK STUDY IN STEEL AND GROUT PIPES}

\section{ABSTRACT}

Voitenko compressors are used to generate $43 \mathrm{~mm} / \mu \mathrm{s}$ air shocks in both a steel and a grout outlet pipe containing ambient atmospheric air. Fiber-optic ports provide diaphragm burst times, time-of-arrival (TOA) data, and velocities for the shock front along the $20-\mathrm{mm}-\mathrm{i}$.d. exit pipes. Pressure profiles are obtained at higher enthalpy shock propagation than ever before and at many locations along the exit pipes. Numerous other electronic sensors and postshot observations are described, as well as experimental results. The primary objectives of the experiments are as follows: 1) provide a data base for normalization/improvement of existing finite-difference codes that describe high-energy air shocks and gas propagation; 2) obtain quantitative results on the relative attenuation effects of two very different wall materials for high-energy air shocks and gas flows. The extensive experimental results satisfy both objectives.

\section{INTRODUCTION}

For nearly a decade, theoretical studies have indicated that ablation of wall material was the principal attenuation mechanism for high-velocity $(>10 \mathrm{~mm} / \mu \mathrm{s})$ air-shock propagation. ${ }^{1-3}$ This conclusion was primarily based on agreement between calculational and experimental results for time-ofarrival (TOA) of the shock front at specific locations in open pipes containing air at ambient conditions. In the study ${ }^{1}$ using the Voitenko compressor, ${ }^{4}$ postshot inspection of the pipe wall clearly indicated that considerable erosion of the surface had taken place. In the Marvel experiment, ${ }^{2}$ different chemical tracer sections were located in the wall of the Marvel tunnel at specific locations to provide an estimate of ablation thickness. A final distribution of the chemical tracers was obtained from core samples along the tunnel in a postshot drilling program. This final tracer distribution confirmed that significant ablation or mass entrainment in the gas flow occurred.

In a literal sense the term ablation, as related to high-energy flow, is generally confined to the vaporization of wall material and subsequent addjtion of that vaporized material to the gas flow. However, other processes exist by which wall material may be entrained in the gas flow. For an open pipe in a nuclear explosion the deposition of radiant energy ( $x$ rays, $\gamma$ rays, and thermal) ahead of the shock front may be sufficient to vaporize wall material and/or produce a thin melt layer at the wall of the pipe. In addition, a thin melt layer may be produced by high-temperature gases behind the shock front. Then, as the shock propagates down the pipe, turbulence behind the shock front may be effective in scouring off this thin liquid layer and adding mass to the flow in the form of droplets. This scouring model was first postulated ${ }^{5}$ in an attempt to explain the results of dynamic ablation measurements associated with plasma flow in a lineof-sight pipe during a nuclear test. ${ }^{6}$ The scouring model has been incorporated into a numerical code for simulating high-energy gas flow in open pipes. ${ }^{7}$ Other considerations for mass entrainment are irregularities in the pipe wall or the wall composition that may result in sizeable wall fragments being entrained in the gas flow. Whether or not these processes are present depends upon the experiment being considered.

Although considerable evidence exists that ablation plays an important role in the attenuation of high-energy gas flows, the principal uncertainty concerns the rate at which ablation or wall material enters the flow and affects conditions in and behind the shock front. The early computer $\operatorname{codes}^{1,2}$ and 
subsequent modified versions $\mathrm{s}^{7.8}$ contain parameters and prescriptions to quantify the rate of ablation. Unfortunately, these finite-difference codes lacked sufficient dynamic experimental data to determine whether the present formulations accurately describe the physical processes of ablation. An accurate measurement of the ablation rate would provide the most direct experimental basis for evaluating the present theory. However, the cstimated ablation rate is so small ${ }^{l}(<10 \mu \mathrm{m} / \mu \mathrm{s})$ and the typical environment so severe (e.g., pressures $>1 \mathrm{GPa}$, temperatures $\gg 1 \mathrm{eV}$, and wall motion $>0.1 \mathrm{~mm} / \mu \mathrm{s})$ that survival of a credible ablationrate measurement is extremely difficult. For- tunately, other measurements are possible in the above environment to aid in evaluating the ablation rate and its subsequent effect on conditions in and behind the shock front.

In the following sections we describe two experiments that used a modified 9,10 Voitenko compressor $^{4}$ to study air-shock propagation in both a steel and a grout outlet pipe. Comparison of these results provides a measure of the effect of variation of wall material. In addition, the results from each experiment can be used in evaluating and/or improving existing high-energy air shock propagation codes.

\section{EXPERIMENTAL CONSIDERATIONS}

Some of the hardware, diagnostics coverage, and modes of operation are common to both experiments. For example, the high-explosives (HE) assembly, compressor section, and first $15 \mathrm{~cm}$ of the outlet pipe in both experiments are identical to within tight machine tolerances. The detonated HE drives the stainless-steel plate into the chamber, compressing the $\sim 1.1-\mathrm{MPa}$ air (initially in the chamber) to high pressures $(>100 \mathrm{GPa})$, densities $\left(>1.0 \mathrm{Mg} / \mathrm{m}^{3}\right)$, and temperatures $(>10 \mathrm{eV})$ before the diaphragm breaks. ${ }^{1} 11$ The expansion and motion of this compressed air down the exit pipe generates a high-velocity $(\approx$ Mach 130$)$ air shock.

Fiber-optic ports in the outlet pipes transmit luminosity associated with the high-energy air shock and gas flow to external display boards that are scanned by streaking cameras. These optical records are then reduced to give TOA information about air-shock propagation down the outlet pipes. Electronic sensors provide pressure profiles at many. corresponding locations in both experiments. The grout experiment is designed to provide wherever possible a duplication of sensors located in the steel experiment, so that a direct comparison of experimental results is possible. However, the grout experiment enabled us to obtain diagnostic measurements not feasible on the steel experiment.

Although similar, the two experiments do contain differences in design, fabrication and execution. Each experiment represents a significant advancement in the state of the art for high-energy shock studies. The stcel experiment is the first Voitenkogenerated air shock and gas-flow study that provides detailed pressure profiles and for a much greater length-to-diameter ratio than ever before obtained. The grout experiment is the first time that a Voitenko-generated air-shock st udy has ever been attempted with this type of wall material. Thus, each experiment and its results will be presented in a separate section before a comparison of experimental results is given in a subsequent section.

\section{STEEL EXPERIMENT}

Figure 1 illustrates the physical features and diagnostics coverage of the compressor-outlet pipe assembly. Table I summarizes the diagnostics used and their relative locations with respect to the diaphragm. The optical diagnostics employed are similar to previous air-shock ${ }^{10}$ and gas-jet ${ }^{3,11}$ studies but will be reviewed for details particular to this experiment. Most of the elect ronic diagnostics are relatively new to the present application and thus will be described in greater detail in this section and in Appendix A. The rest of this section covers the experimental results for this test. 


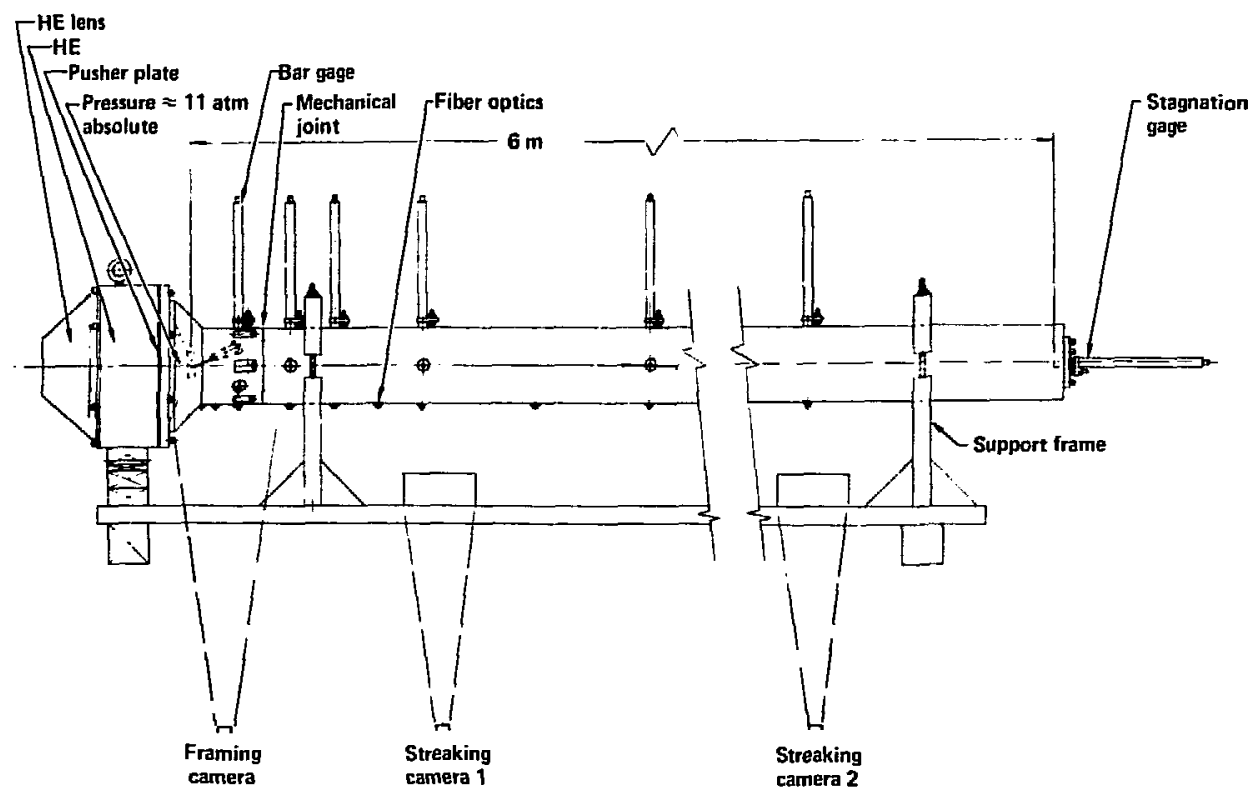

FIG. 1. Compressor assembly, steel outlet pipe, and diagnostics systems for the steel-pipe experiment.

\section{EXPERIMENTAL PROCEDURES AND DIAGNOSTIC COVERAGE}

\section{Optical Coverage with}

Framing Camera

A framing cumera (Model 189B) was focused on the first $\sim 0.20 \mathrm{~m}$ of the steel outlet pipe to detect the location, duration and extent of possible venting. The delayed detonation of $1.8-\mathrm{kg}$ HE pads attached to the back of two $1.2 \mathrm{-m}$ long argon candles provided supplementary lighting for the framing camera's field of view. Bridge wires were mounted on the steel outlet pipe and detonated at preselected times to provide optical fiducials. Such fiducials are necessary for timing resolution of the framing coverage and as an aid in determining the interframe time.

Although venting was not expected to occur in tine time frame that would affect propagation of the shock front, venting may affect pressures well behind the shock front. Since a goal of this study is to numerically simulate the compressor generation of the air shock and pressure profile for some distance behind the shock front, a knowledge of venting is crucial. In a previous air-shock study, ${ }^{12}$ venting from the HE driver region was observed,
TABLE 1. Diagnostic3 for the steel pipe experiment.

\begin{tabular}{ll}
\hline $\begin{array}{c}\text { Distance from diaphragm }(\mathrm{m}) \\
0\end{array}$ & Diagnostics $^{\mathrm{a}}$ \\
\hline 0.02 & F \\
0.05 & F \\
0.10 & F \\
0.20 & F, B, PM \\
0.30 & F, B, PM \\
0.40 & F, B \\
0.50 & F \\
0.75 & F, B, PY \\
1.00 & F \\
1.25 & F, B, PY \\
1.50 & F \\
1.75 & F, B \\
2.00 & F \\
2.50 & F, B, P \\
3.00 & F, B \\
3.50 & F, B \\
4.00 & F, B \\
4.50 & F, B \\
5.00 & F, B \\
5.50 & F, B, P \\
6.00 & F, B \\
\hline 6 & B \\
\hline
\end{tabular}

${ }^{\mathrm{a}} \mathrm{F}=$ fiber optics; $\mathrm{B}=$ bar gage (SSS); PM = pressure-Manganin (SR1); PY = pressure-ytterbium (SRI); P = LLL 80,000-psi PCB gage 109A(D). 
but a venting criterion was applied to the numerical simulation which helped to explain the experimental results.

\section{Optical Coverage with Streaking Cameras}

Twenty-one 1.80-m-long light pipes were emplaced along the outlet pipe. The light-pipe emplacement design is describeed in detail in Ref. 11. To increase timing resolution for the streaking records, the light pipes were divided between two display boards. One end of each light pipe in the first $2.0 \mathrm{~m}$ of the outlet pipe was located in the first display board and those beyond $2.0 \mathrm{~m}$ were located in the second board. The detonation of bridge wires located in the display boards at predetermined times provided the optical fiducials to correlate air-shock luminosity data for the streaking cameras. The two streaking cameras (Models 132) and the framing camera (Model 189B) were synchronized. Another fruming (Model 6) and streaking (Model 136) camera, not shown in Fig. I, were used as backup to the other cameras and operated in a free-running mode. Rewrite was prevented by the delayed detonation of small HE pads attached to the back of the turning mirrors above the optic ports. Opaque plastic tents were used to shield the bunker-optic ports and display boards. This procedure and delayed closure of electromechanical shutters on the cameras significantly reduced exposure to ambient light and lowered the fogging level of the film. Low fog levels become important for the air shock near the end of the pipe where shock luminosity is low and high contrast is desirable. No optical filters were used on any of the cameras.

\section{Electronic Diagnostics}

The electronic diagnostics for this experiment consisted of three types of pressure gages. The three types and their relative locations are given in Table 1. A total of 15 bar gages, 4 piezoresistance gages, and 2 PCB quartz gages were installed. The bar gages represent the primary electronic sensors since they were used extensively in both experiments. The other six gages ivere installed as backup and as an independent check of the pressure profiles obtained with the bar gages. Gages similar in design to the bar and PCB quartz gages have been used to measure pressures in other gas flow experiments. ${ }^{[1-13}$ The piezoresistant gages were specifically designed for this experiment and had never been used in a similar application.

The following is a brief description of how the bar gages functioned. One end of each bar gage was exposed to flow conditions in the pipe. The end of the bar gage at $6.0 \mathrm{~m}$ was flush with the end wall to record stagnation flow. The input ends of the other 14 gages were machined to a $10-\mathrm{mm}$ radius so they conformed to the curvature of the pipe wall. As the air shock passes each gage a compression shock propagates down the input (signal) bar for $\sim 0.15 \mathrm{~m}$ before impacting the $x$-cut quartz crystal. Compression of the crystal induces polarization and subsequently produces a free charge on the electrodes, which is recorded as a voltage pulse on the associated electronics. The voltage signal is directly proportional to the degree of compression or amplitude of the incident shock wave. ${ }^{14}$ The sh.ock wave transits the crystal into a second (dump) bar where propagation continues. The amplitudes of the transmitted and reflected waves across this impedance discontinuity depend upon the material of the two bars. ${ }^{15.16}$ For the bar gages at 0.10 and $0.20 \mathrm{~m}$ the signal and dump bars are tungsten carbide and titanium, respectively. At the other locations the signal and dump bars are tungsten and aluminum, respectively. The recording duration of the bar gages is limited by the time for reflections to arrive back at the crystal from the end of the dump bar. The useful recording duration of the bar gages used in these experiments was in the range 55-60 $\mu \mathrm{s}$.

The sensitive elements for the piezoresistance gages were composed of either Manganin or ytterbium. These gages were designed to provide a record of the pressures behind the shock front with a minimum of intervening material. The primary difficulty in obtaining measurements of the flow parameters is in retaining the integrity of the sensor when subjected to high pressures, high temperatures, large displacements, and strain effects. ${ }^{17}$ The gages met these requirements except for survival of the recording time, where success was marginal. A more detailed description of the construction and operation of bar and piezoresistance gages is given in Appendix A.

The PCB gages (Model 109A) are standard commercial gages commonly employed to measure gits shock pressures. These gages were located at 2 and $5 \mathrm{~m}$ from the diaphragm where the pressures behind the shock front were expected to be well 
within the calibrated $0.55 \mathrm{GPa}$ range for this gage. Pressure profiles in excess of $100 \mu \mathrm{s}$ were obtained with both gages.

\section{EXPERIMENTAL RESULTS}

To correlate the optical and electronic measurements, a common time reference was provided by the electrical pulse that initiated detonation of the plane-wave lens. The time interval between detonation of the plane-wave lens and air shock breakage of the Mylar diaphragm was $58.1 \mu \mathrm{s}$. This time was determined by using a light pipe oriented to view the center of the diaphragm. This value was $1.6 \mu \mathrm{s}$ earlier than obtained in a previous experiment. ${ }^{10} \mathrm{~A}$ discussion of this difference for the time of diaphragm break and its effect will be given in a later section where air-shock propagation from these two experiments and the earlier esneriment are compared. The above diaphragm breaking time is taken as the new zero time reference for all experimental results in this test.

\section{Framing Camera Coverage}

The framing camera (Model 189B) gave photographic evisence that no venting of highenergy gases in the outlet pipe occurred for the first $39.3 \mu \mathrm{s}$ after breakage of the diaphragm. After this time gaseous HE products from the driver bypassed the plywood blast shield provided and began to obscure the field of view. Although venting after this time would undoubtedly reduce pressures well behind the shock front, it would have negligible effect on propagation of the shock front. The bar gage located $0.10 \mathrm{~m}$ was felt to be especially susceptible to venting since the bar gages depend solely on close machine tolerances, an $\mathbf{O}$-ring, and vacuum grease to achieve a pressure seal. The second experiment confirmed that concern about this gage was warranted.

\section{TOA Data and Air Shock Velocity}

Table 2 summarizes TOA results of the shock front for the fiber optics and pressure sensors. The TOA values given for the fiber optics correspond to the time that the first luminosity peak was recorded at each location. The TOA values for the pressure sensors are the times at which the initial rise for the first pressure peak is very steep. This time was chosen instead of the peak pressure because the pressure sensors have two inherent effects that tend to spread the risetimes and delay the peak. The first is related to the transit time for the shock front to traverse the end of the pressure sensor. As an example, the end of the bar gages and PCB quartz disks are $\sim 6.5 \mathrm{~mm}$ in diameter. For those locations where the shock velocities are 20 and $10 \mathrm{~mm} / \mu \mathrm{s}$, the transit times across the sensors would be $\sim 0.32$ and $0.65 \mu \mathrm{s}$, respectively. Thus, even a step pressure pulse at the above two locations would be recorded with these risetimes. The second inherent effect is the time required for the gas pressures in the shock front to reach the piezoelectric (or piezoresistive) element in the sensor. For the PCB gage, calculations have shown ${ }^{12}$ that about $0.3 \mu \mathrm{s}$ is required for the shock to transit the $0.5 \mathrm{~mm}$ ablative coating, thin-steel diaphragm, and quartz crystal before conversion to an electrical signal. However, the quartz element in the bar gage is recessed $\sim 0.16 \mathrm{~m}$ from the bore wall, and a $\sim 30-\mu$ s delay occurs for which the data must be corrected. In addition, propagation of the pressure pulse down the signal bar will result in dispersion of a sharp shock front and thus increase the risetime. For the bar gages used in these experiments the inherent increase in risetime for a step pulse due to dispersion is $\approx 3 \mu 5 .{ }^{18}$ In the analysis and interpretation of the experimental results, these inherent effects have been factored into the values given for Table 2. Other inherent effects exist that can affect the experimental results but with respect to TOA values we feel the most significant ones are covered in the above discussion.

Figure 2 shows a TOA plot for propagation of the shock front in the exit pipe. Differentiation of the TOA curve yielded the velocity for the shock front as a function of distarce down the outlet pipe as given in Fig. 3. After a short period of acceleration the shock attains a maximum velocity of $\sim 43 \mathrm{~mm} / \mu \mathrm{s}$ at a distance of $\sim 75 \mathrm{~mm}$ from the diaphragm. Over approximately the first $2 \mathrm{~m}$, ablation and mass entrainment are considered ${ }^{1.3}$ to be the principal attenuation mechanism. Over this distance the velocity has attenuated to less than $10 \mathrm{~mm} / \mu \mathrm{s}$. Beyond the $2.0 \mathrm{~m}$ distance the attenuation rate decreases, with the dominant mechanism for attenuation being convective heat transfer and friction. ${ }^{3,12}$ Significant cooling of gases well behind the shock front occurs beyond the first $2 \mathrm{~m}$ of propagation. This is shown by the signilicant amount of condensation and plating of ablated wall 
TABLE 2. Air shock time-of-arrival (TOA) data from the steel pipe experiment.

\begin{tabular}{|c|c|c|c|c|}
\hline $\begin{array}{l}\text { Axial } \\
\text { distance } \\
\text { (m) }\end{array}$ & $\begin{array}{c}\text { Fiher o } \\
\text { TO } \\
(\mu \mathrm{s})\end{array}$ & $\begin{array}{l}\text { A } \\
\text { ) }\end{array}$ & $\begin{array}{c}\text { Bar } \\
\text { gage TOA } \\
\text { ( } \mu \mathrm{s})\end{array}$ & $\begin{array}{l}\text { SRI and LLL } \\
\text { TOA } \\
\text { ( } \mu \mathrm{s})\end{array}$ \\
\hline 0. & (58.1) & 0.0 & & \\
\hline 0.02 & & 1.2 & & \\
\hline 0.05 & & 2.1 & & \\
\hline 0.10 & & 3.26 & 3.5 & 4.0 \\
\hline 0.20 & & 5.9 & 6.7 & 6.35 \\
\hline 0.30 & & 8.5 & 9.1 & \\
\hline 0.40 & & 11.6 & & \\
\hline 0.50 & & 14.4 & 15.0 & 16.0 \\
\hline 0.75 & & 22.6 & & \\
\hline 1.00 & & 31.7 & 32.3 & 31.8 \\
\hline 1.25 & & 43.3 & & \\
\hline 1.50 & & 57.8 & 57.3 & \\
\hline $1.7 \%$ & & 77.5 & & \\
\hline 2.00 & & 103.8 & 104.5 & 104.0 \\
\hline 2.50 & & 183.0 & 185.3 & \\
\hline 3.00 & & 295.0 & & \\
\hline 3.50 & & 448.0 & & \\
\hline 4.00 & & 611.0 & & \\
\hline 5.00 & & & & 1045.0 \\
\hline
\end{tabular}

material that occurs between 2.5 and $4.5 \mathrm{~m}$, as will be shown later.

\section{Pressure Profiles}

Figures 4-Il give the pressure profiles obtained for this experiment. The pressure records for the bar gages beyond the $2.0 \mathrm{~m}$ location had high noise levels and/or a double trigger of the scope trace in the steel experiment. Other than the shock-front TOA value at $2.5 \mathrm{~m}$, no meaningful data reduction was considered feasible for the bar gages beyond $2.0 \mathrm{~m}$. The bar gages used to record stagnation pressures at the end of the outlet pipe failed to provide pressure profiles or reliable TOA values in either the steel or the grott experiment.

Peak pressures associated with the shock front decayed from $3.5 \mathrm{GPa}$ at $0.10 \mathrm{~m}$ to $0.008 \mathrm{GPa}$ at $5.0 \mathrm{~m}$ from the diaphragm. The duration of the experimentally measurable flow varies from $\sim 50 \mu \mathrm{s}$ at $0.10 \mathrm{nt}$ (Fig. 4) to over $300 \mu \mathrm{s}$ at $5.0 \mathrm{~m}$ (Fig. II).
These two positions represent the only locatic ns where the scope settings were such that the flow duration could be determined with any certainty. The increase in the duration of the flow can be attributed primarily to the delayed entrainment of wall material into the flow, resulting in a relatively greater attenuation of the flow well behind the shock front. Evidence for this effect is the attenuation of the $3.55 \mathrm{GPa}(19 \mu \mathrm{s})$ peak at $0.10 \mathrm{~m}$, to $1.48 \mathrm{GPa}(38.6 \mu \mathrm{s})$ at $0.20 \mathrm{~m}$, to $1.14 \mathrm{GPa}(50.4 \mu \mathrm{s})$ at $0.30 \mathrm{~m}$ and its final disappearance at $0.50 \mathrm{~m}$. The gradual dispersion of the high-energy flow, using the Voitenko compressors, has been observed in jet studies. ${ }^{3,19}$ In those studies the delayed entrainment of wall material was also identified as the primary attenuation mechanism and a major contributor to dispersion and increase in the pressure pulse width.

The piezoresistance gage at $0.10 \mathrm{~m}$ suggests the possible presence of a $0.15 \mathrm{GPa}$ precursor before the sharp rise to its $3.5 \mathrm{GPa}$ peak value (Fig. 4). However, dispersion in the bar gage will reduce the peak pressure and increase the pulse width of the shock front in addition to masking line structures

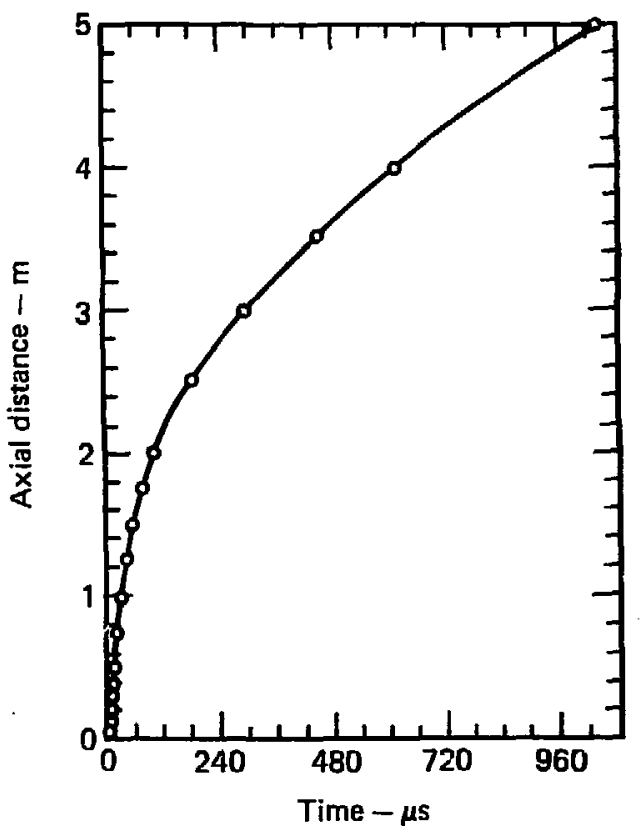

FIG. 2. Air shock TOA data for the steel outlet pipe. 


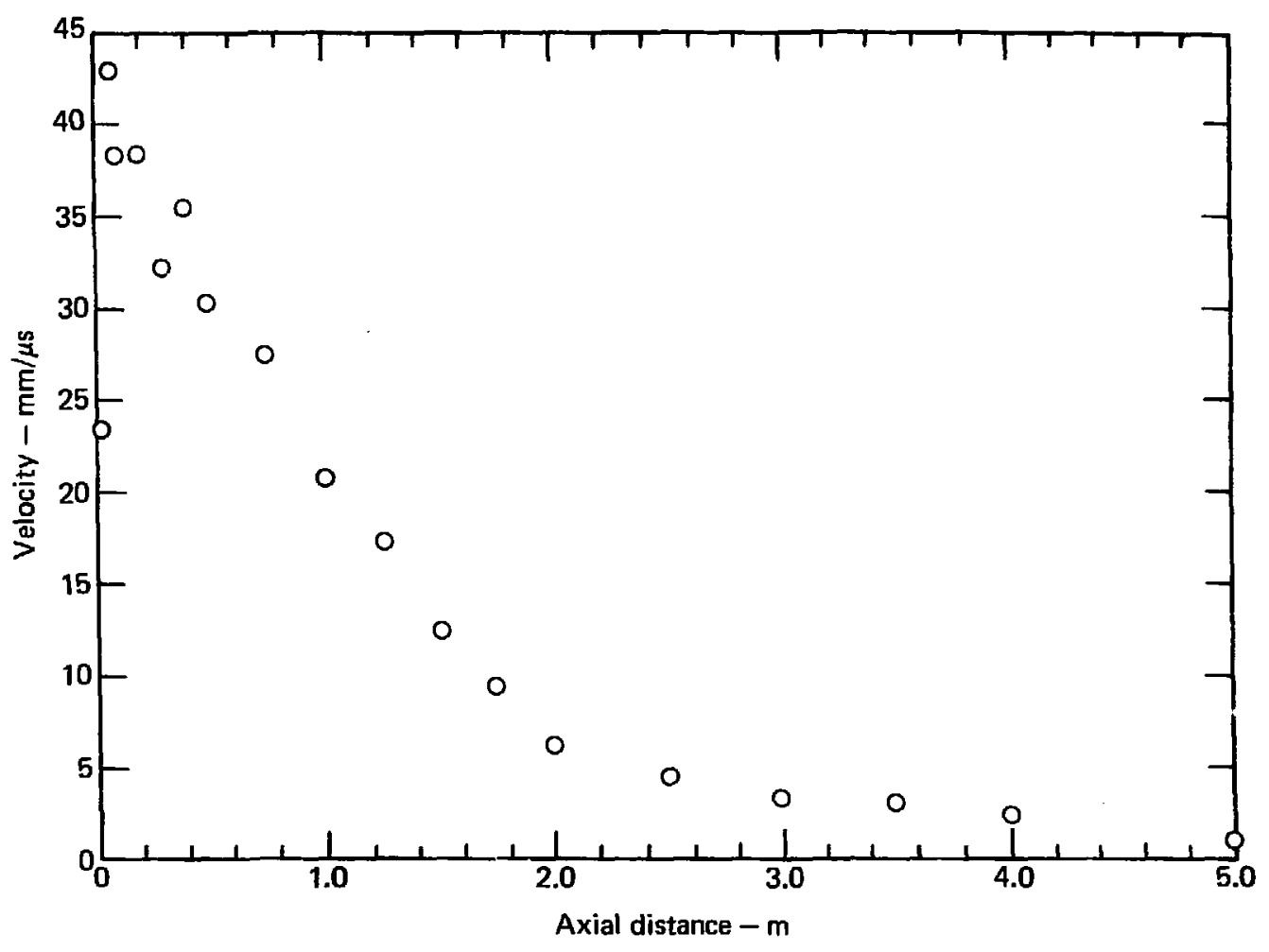

FIG. 3. Shock velocity vs axial distance for the steel shock-tube experiment.

such as the precursor. Thus, the results for the piezoresistance and bar gages are felt to be consistent at $0.10 \mathrm{~m}$. The piezoresistance gage at $0.20 \mathrm{~m}$ failed within $1 \mu \mathrm{s}$ after shock arrival and at $1.00 \mathrm{~m}$ nol even this datum was obtained. Consequently, the only otter location where a similar comparison between these two gage types was at $\sim 9.50 \mathrm{~m}$ (Fig. 7). Only a hint of a precursor was observed at this distance and surprisingly the shock front appearied steeper and the pulse width narrower for the piezoresistance record. The peak pressure appears unusually high with respect to the peak value for the bar gage, even though considerable attenuation of the peak caused by dispersion in the bar gage could be expected, considering the narrow pulse width for the flat-pack gage. However, the poor agreement between pressure profiles of the shock front at the
$0.50 \mathrm{~m}$ location represents the largest disparity between any gage results at the same axial distance for both experiments.

The large pressure oscillations observed result from axial and radial oscillations of the flow that are induced by an early diaphragm break and radial convergence of the driver gas in the compressor section. ${ }^{1.20}$ The face that these oscillations appear to persist for a substantial distance is confirmed by the pressure profiles obtained with the PCB and bar gages at $2.0 \mathrm{~m}$ (Fig. 10). Both gages at $2.0 \mathrm{~m}$ give close agreement, in TOA and amplitude, for the first two large pressure peaks. It is not known whether the following two oscillations for the bar gage are factual or a gage-related problem. Over all, the $\mathrm{p}$ ssure profiles are felt to be in good agreement for the duration of the bar gage record. The PCB 


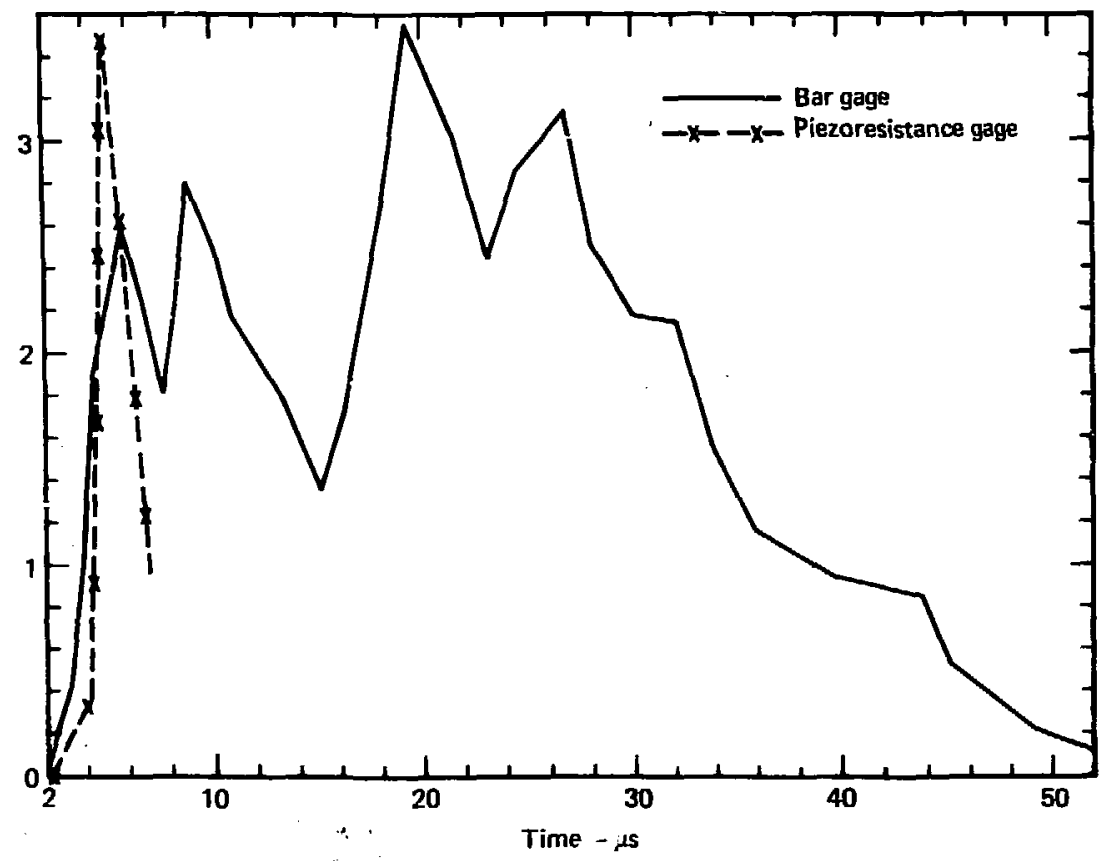

FIG. 4. Pressure profiles at $0.10 \mathrm{~m}$ in steel outlet pipe.

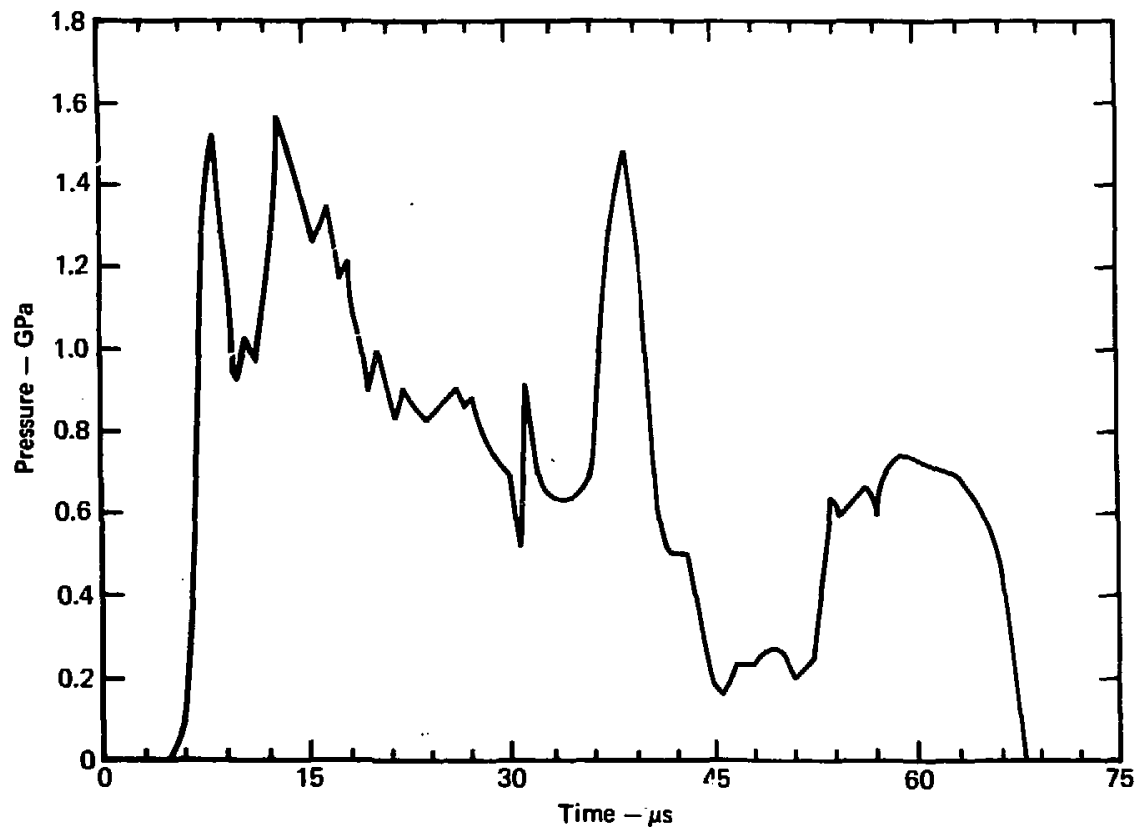

FIG. 5. Pressure proflle obtained with a bar gage at $0.20 \mathrm{~m}$ from the diaphragm (steel pipe). 


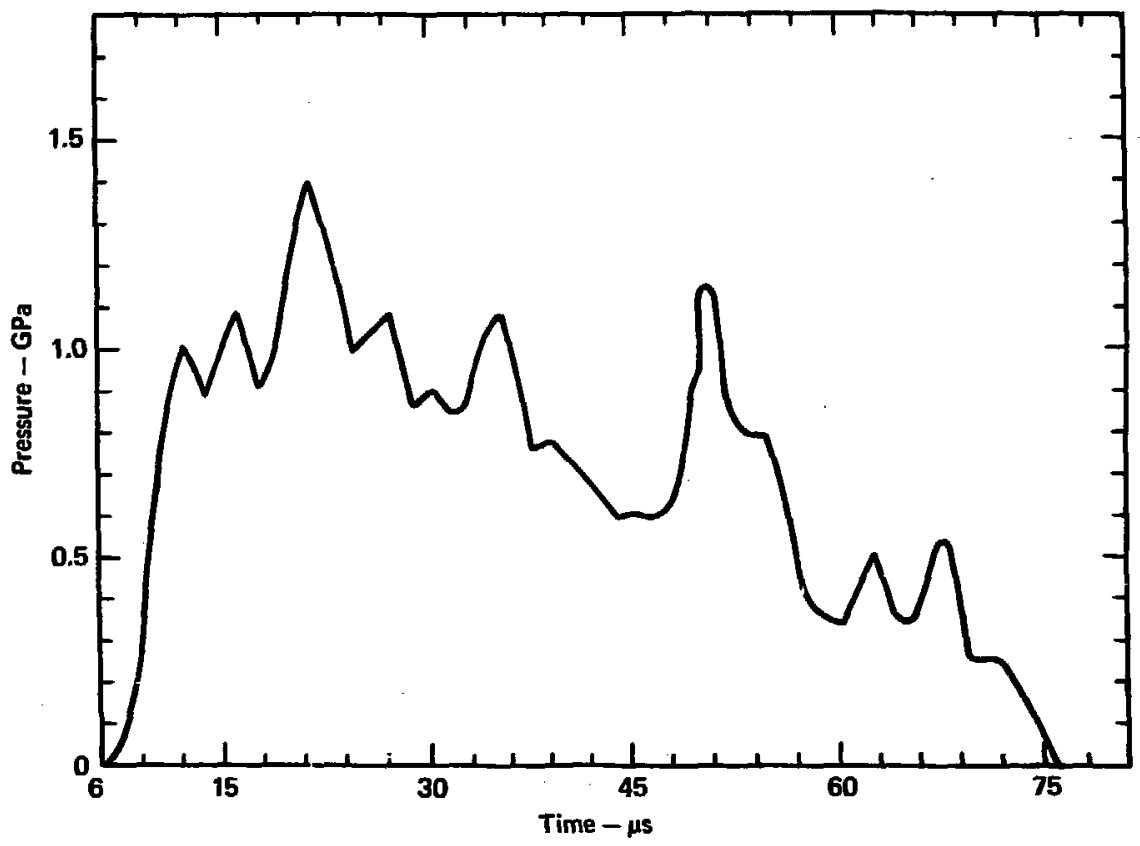

FIG. 6. Pressure profile obtained with a bar gage at $0.30 \mathrm{~m}$ from the diaphragm (steel pipe).

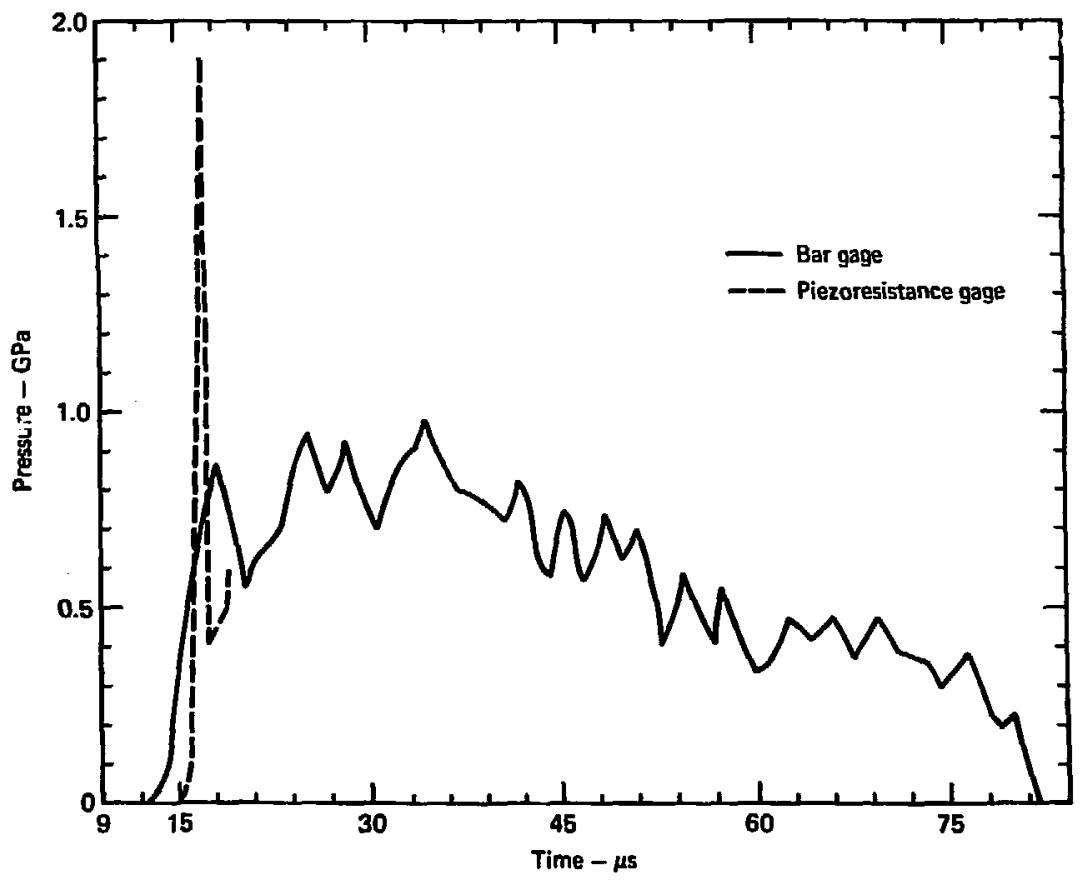

FIG. 7. Pressure profiles at $0.50 \mathrm{~m}$ in the steel outtet pipe. 


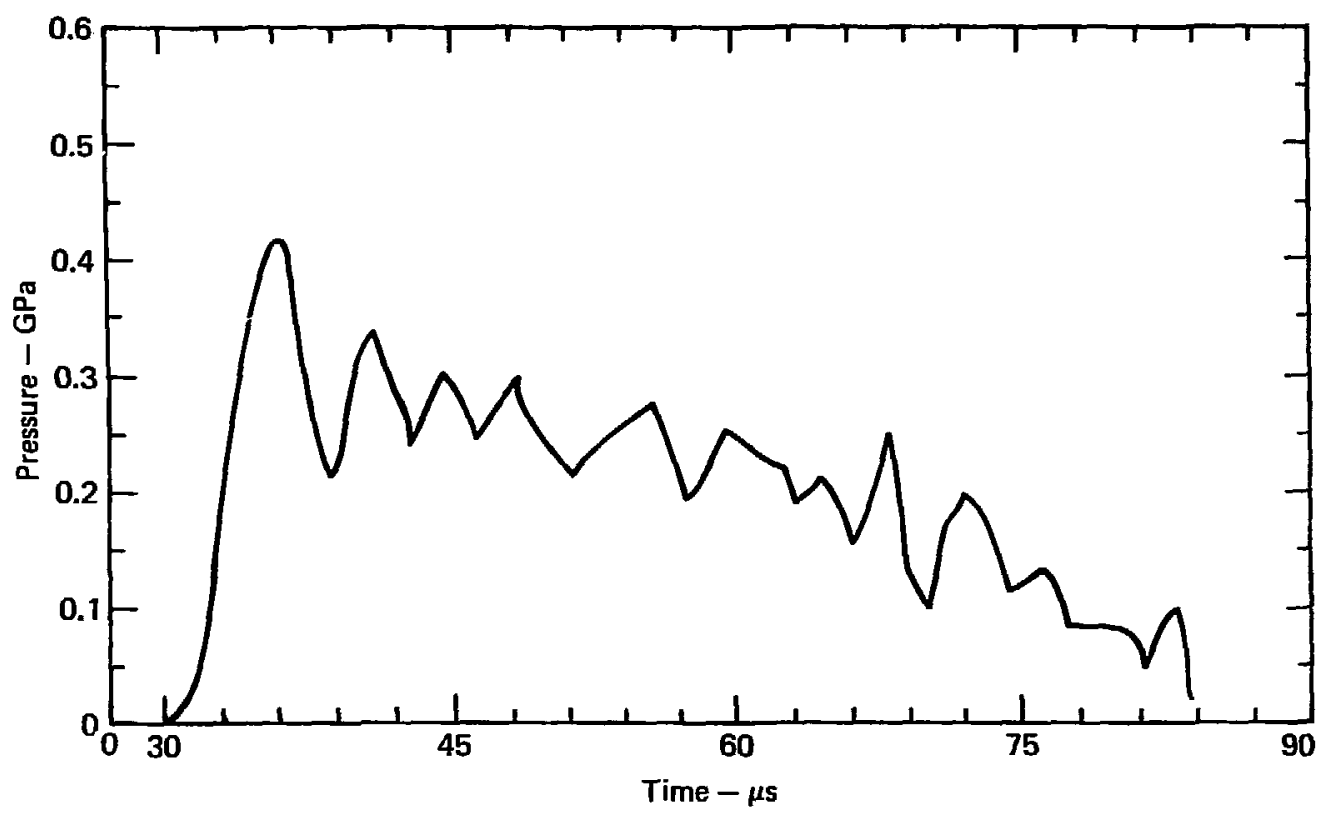

FIG. 8. Pressure profile obtained with a bar gage at $1.0 \mathrm{~m}$ from the diaphragm (steel pipe).

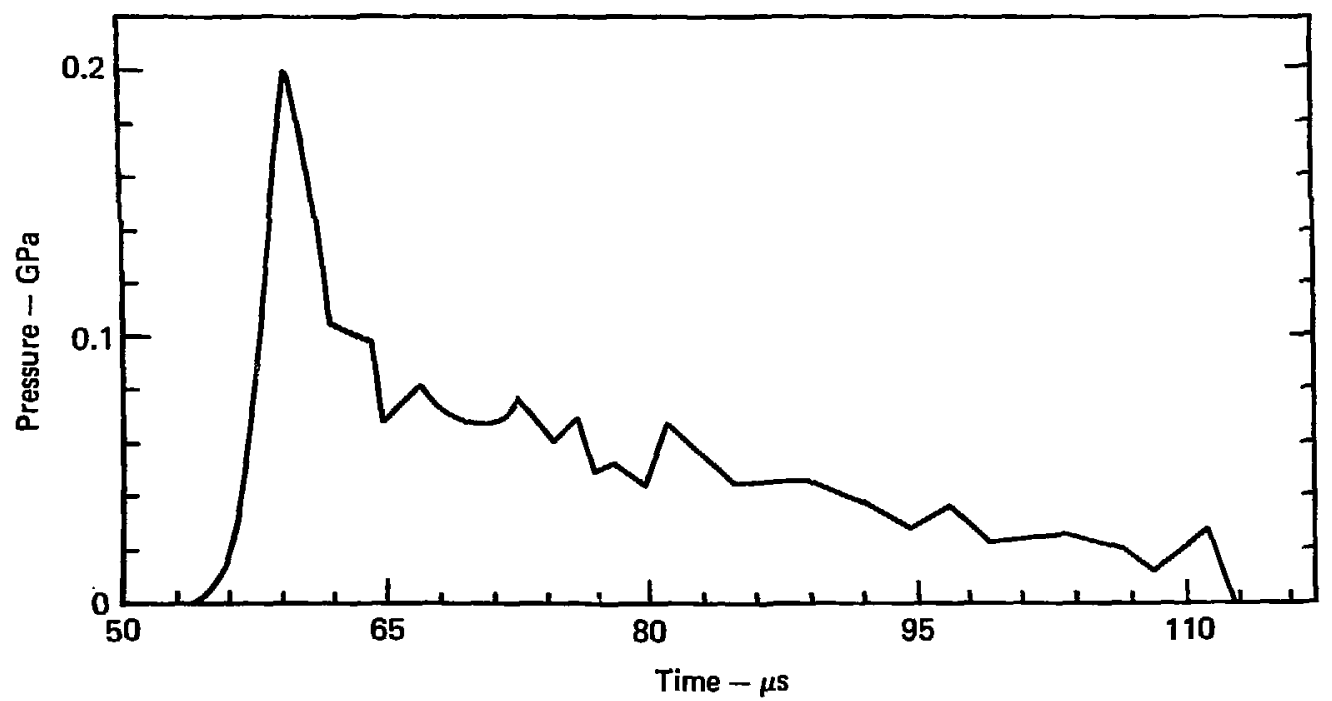

FIG. 9. Pressure profile obtained with a bar gage at $1.50 \mathrm{~m}$ from the diaplragm (steel pipe). 


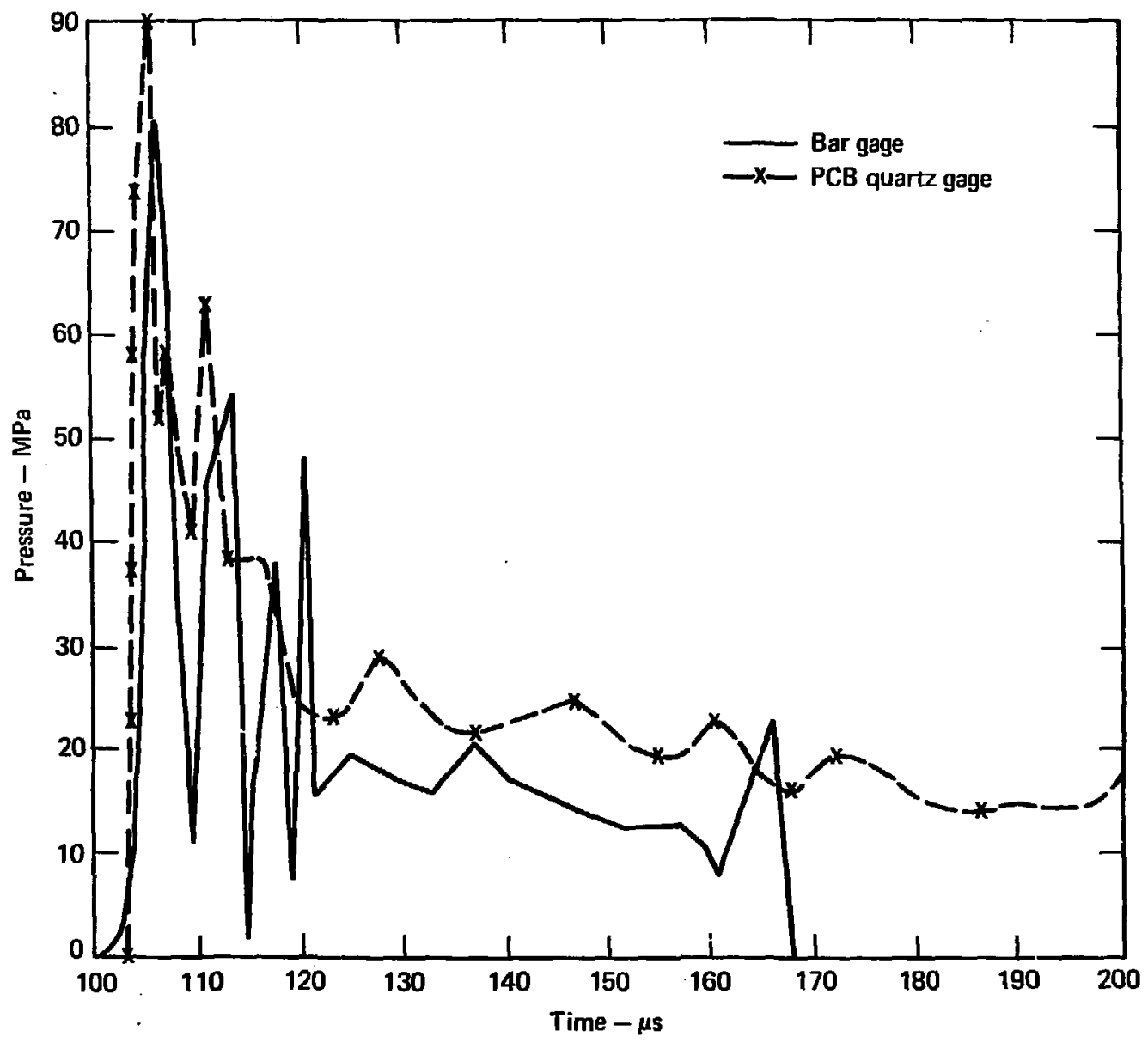

FIG. 10. Pressure profiles at $2.00 \mathrm{~m}$ in steel oullet pipe. 


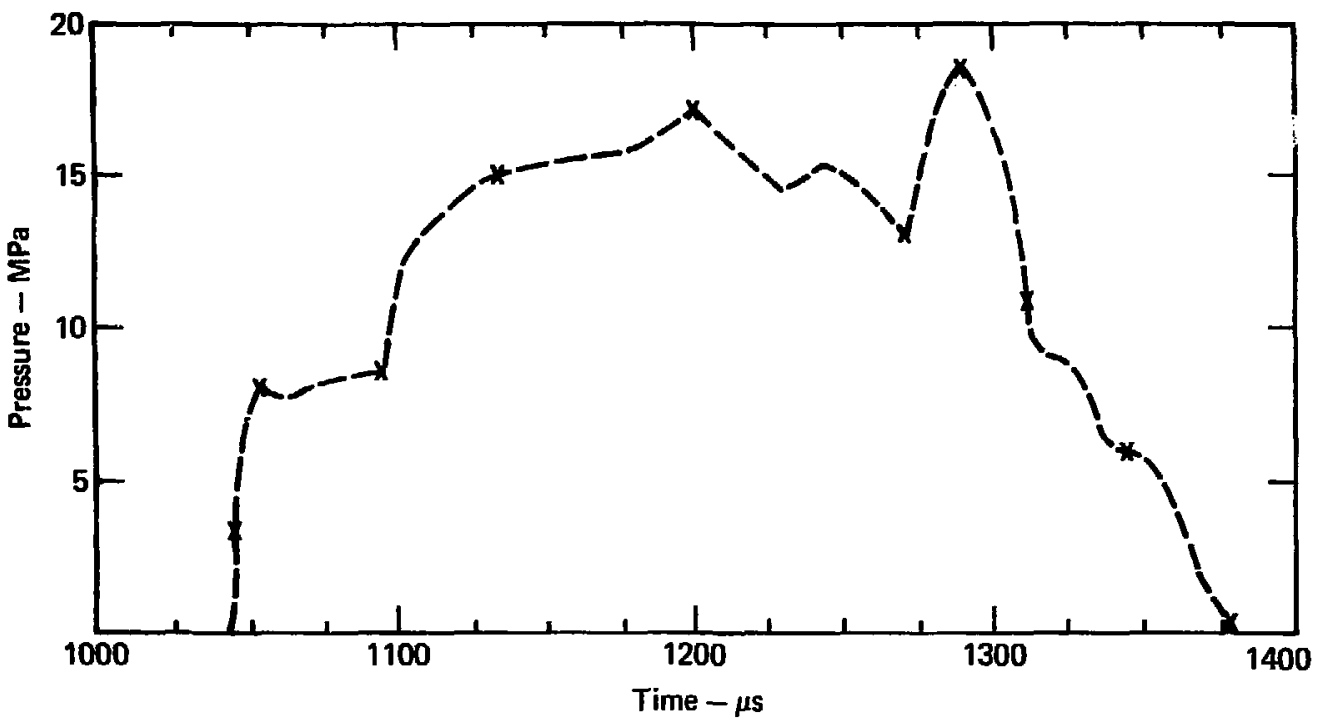

FIG. 11. Pressure profile obtained with PCB quartz gage at $5.0 \mathrm{~m}$ in the stecl outlet pipe.

gage indicates that a flow pressure of $\sim 15 \mathrm{MPa}$ or greater exists well beyond the measurement duration of the bar gage record.

A more complete record of the duration of the flow is provided by the PCB gage at $5.0 \mathrm{~m}$ (Fig. 11). At this distance the rapid oscillations appear to have damped out. Yet the profile is far from that of a classical shock wave, since substantially larger pressures occur well behind the shock front. In addition to damping of the oscillations, a plot of peak pressure in the shock front vs axial distance (Fig. 12) reveals a significant difference. Between 0.10 and $2.0 \mathrm{~m}$ the shock-front pressure is fairly well bounded by the two expressions shown in Fig. 12. Extrapolation to $5.0 \mathrm{~m}$ would predict a shock-front pressure of approximately an order of magnitude lower than measured. The higher pressures at $5.0 \mathrm{~m}$ were partially expected since it has been shown ${ }^{12}$ that for shock velocities below $10 \mathrm{~mm} / \mu$ s ablation ceases, with only heat transfer and friction remaining as the principal attenuation mechanisms. However, another event has occurred in the interval between 2.0 and $5.0 \mathrm{~m}$ that may have a significant influence on the flow. This is the condensation of ablated wall material and will be discussed in the subsection "Condensation."

\section{Radial Expansion}

In these and earlier ${ }^{3,10,11}$ experiments the compressor section and first $0.15 \mathrm{~m}$ of outlet pipe were machined from a single piece of steel stock. This requirement was imposed earlier ${ }^{10}$ to eliminate venting of high-energy gases following diaphragm breakage. The impulse delivered to the compressor by the HE and the high-energy gas flow in the outlet pipe have always been sufficient to highly fragment both the compressor section and first $0.15 \mathrm{~m}$ of outlet pipe. In this experiment the remaining $5.85 \mathrm{~m}$ of outlet pipe was recovered intact and postshot measurements of the bore diameter were obtained as a function of axial distance from the diaphragm.

These measurements indicated that radial expansion occurred over the first $2.5 \mathrm{~m}$ of the outlet pipe. Results from those measurements are plotted in Fig. 13, showing the change in pipe radius as a function of axial distance from the diaphragm. High pressures behind the shock front were the principal factors producing the radial displacement. The other minor contributor is the removal of wall material via ablation and scouring. 5 The HE transferred significant axial momentum to the first $0.15 \mathrm{~m}$ of the outlet pipe, causing it to impact the 


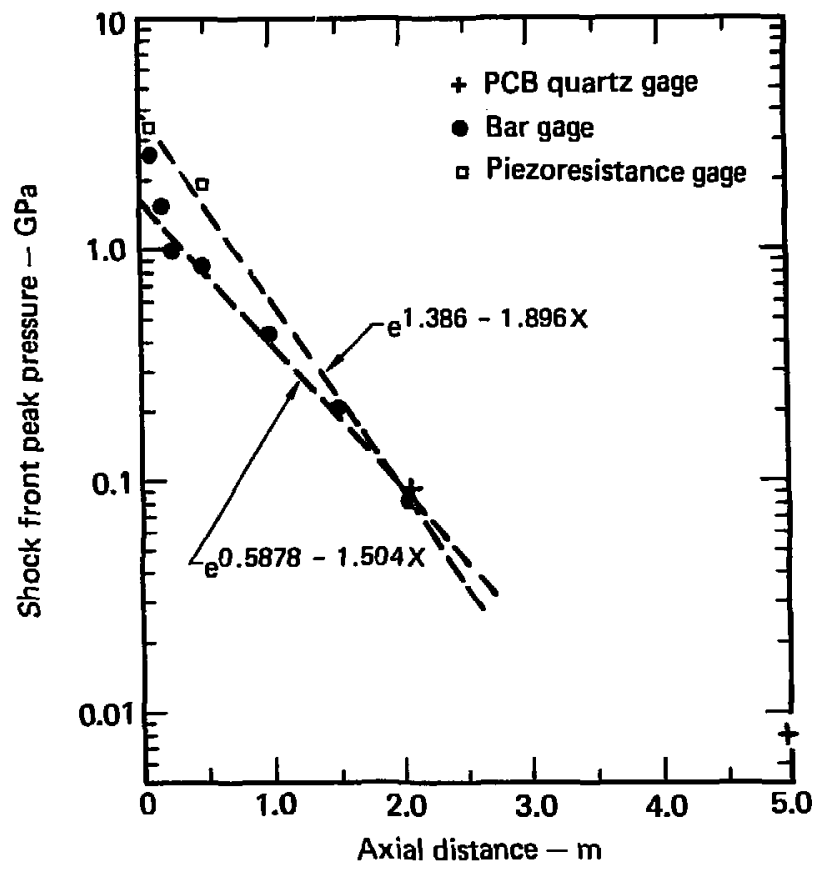

FIG. 12. Peak pressure in the shock front vs axial distance from the diaphragm (steel pipe).

front end of the $5.85 \mathrm{~m}$ section, resulting in some flaring of that end of the surviving section. Consequently, the measurements of bore diameter over the first $0.05-0.10 \mathrm{~m}$ of the surviving section would partially have to be discounted because of the impact and flair effect.

\section{Condensation}

Previous efforts to dynamically record ${ }^{6}$ the rate of ablation in this high-energy flow regime were partially obscured by the presence of prompt radiation $\left(\mathrm{x}\right.$ and $\gamma$ ) deposition. ${ }^{5}$ Passive measuremen $\mathrm{s}^{2}$ and physical observations of wall sections ${ }^{1}$ showing the erosional effects of mass entrainment have been documented. The entrainment of mass from the wall contributes to attenuation and cooling of highenergy gases. As this flow propagates, interaction with the cold wall and other energy losses can be expected to further cool the flow. When the temperature in the flow drops sufficiently, then condensation of the entrained wall material will occur. Figure 14 shows this as a plot of condensation thickness vs axial distance from the diaphragm. Integrating these results indicated that the total en- trained mass condensed out over the distance shown was $\sim 0.34 \mathrm{~kg}$.

In an earlier report $8 \mathrm{MJ}$ of energy was calculated to be imparted to the chamber air that exited down the outlet pipe. The value $0.34 \mathrm{~kg}$ is more than an order of magnitude larger than those calculations predicted to be entrained in the $0.029 \mathrm{~kg}$ of driver and driven gas for that experiment. However, those calculations extended to only $56 \mu \mathrm{s}$ following the diaphragm break and were for an outlet pipe of $\sim 1.4 \mathrm{~m}$ in length. In addition, comparison between calculational predictions and experinental results were limited to TOA values for propagation of the shock front. As a basis for analysis, let us accept $8 \mathrm{MJ}$ as reasonable and assume that all of the chamber air exited down the outlet pipe. The following two options may explain the $0.34 \mathrm{~kg}$ of condensed wall material, since the initial experimental conditions and shock TOA results for the earlier experiment ${ }^{10}$ are not that different for the first $1.4 \mathrm{~m}$ of air shock propagation.

The first option is that the entire $0.34 \mathrm{~kg}$ of condensed wall material was vaporized and entrained in the driver (chamber air) and shocked air 


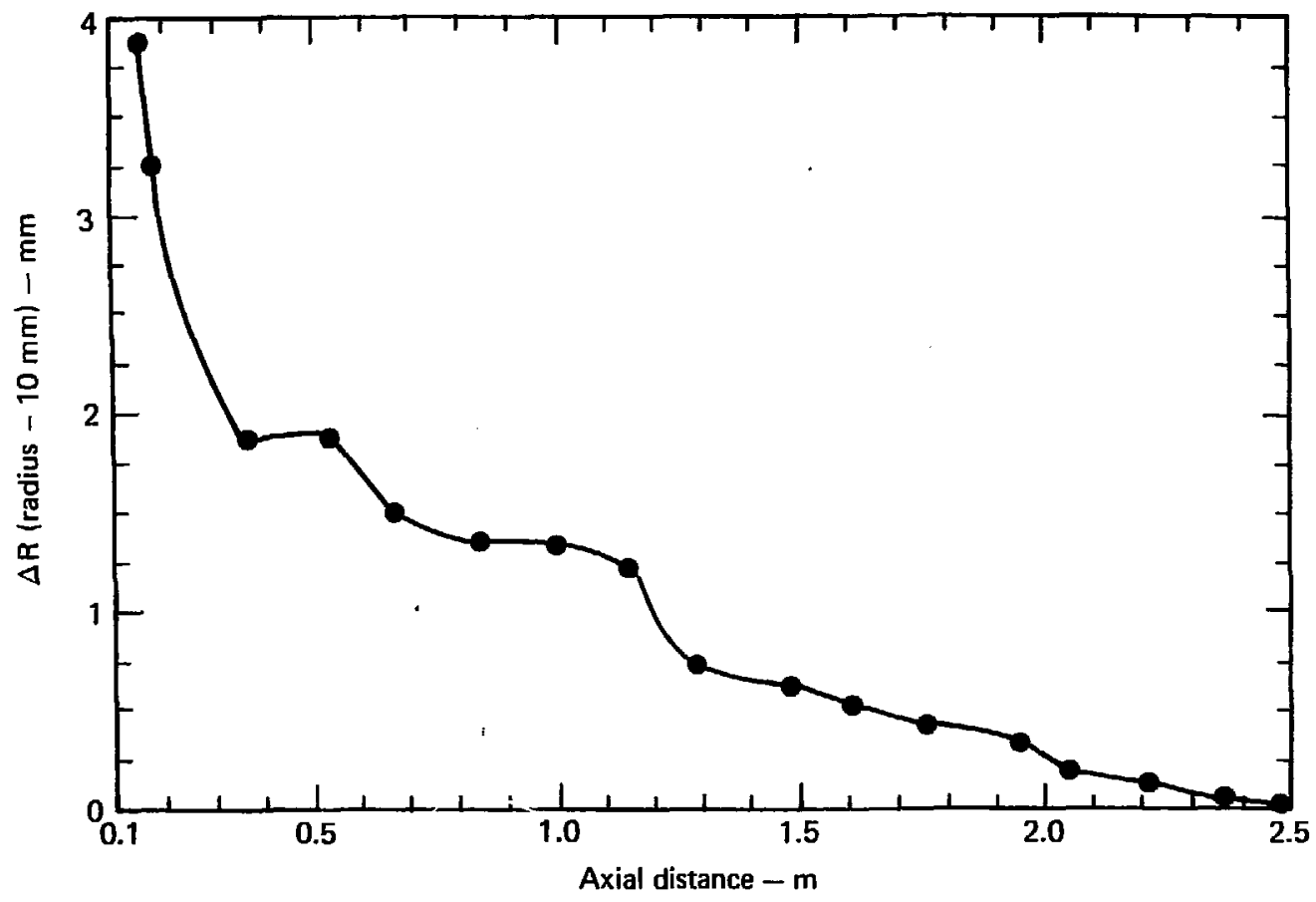

FIG. 13. Radial change vs axial distance from the diaphragm (steel pipe).

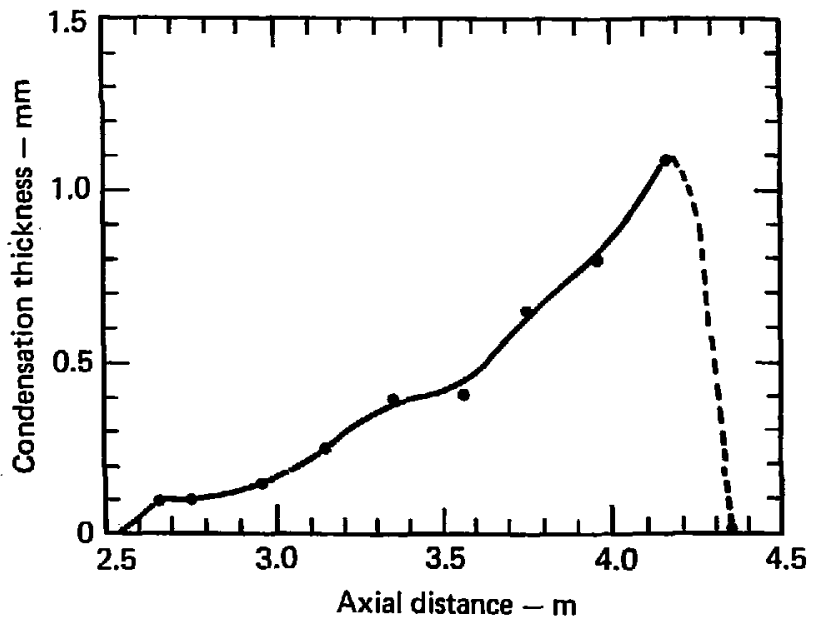

FIG. 14. Condensation thickness vs axial distance from the diaphrogm (steel pipe). 
in the outlet pipe. If only a few grams were entrained in the shocked dir and the major fraction was entrained well behind the contact surface, then attenuation effects on propagation of the shock front would be greatly reduced. Approximately $4.25 \mathrm{MJ}, 53 \%$ of energy in the flow, would be required to vaporize $0.34 \mathrm{~kg}$ of steel assuming a specific energy of vaporization $\left(E_{v}\right)$ of $12.5 \mathrm{MJ} / \mathrm{kg}$.' Of the remaining $47 \%, \sim 14 \%$ was calculated ${ }^{\prime}$ to be lost by the gas doing work on the pipe. The value of $14 \%$ was based on a pipe length of $1.4 \mathrm{~m}$ and flow time of $56 \mu \mathrm{s}$. Figure 13 shows that expansion occurred for a distance of $2.5 \mathrm{~m}$ indicating that the $14 \%$ value is very conservative. Thus, less than $33 \%$ $(2.6 \mathrm{MJ})$ remains in the flow to be partitioned between internal and kinetic energy. Experimental results at $2.0 \mathrm{~m}$ for the pressure profiles (Fig. 10) and gross estimates for flow velocities provide estimates for total energy in the flow that are consistent with the $33 \%$ value.

The second option is 10 introduce some latitude to the figures by reducing the energy necessary for mass entrainment in the flow. This can be done by assuming that a melt layer develops which becomes entrained in the flow and is carried along in the form ol droplets. This entrainment mechanism, known as "scouring," was first postulated" to account for large dynamic ablation rates ${ }^{6}$ that normal ablation models could not explain. The scouring concept is not a substitute for ablition, but is an additional mechanism of mass entrainment. Scouring may be the dominant entrainınent mechanism well behind the shock front where temperatures and specific energies per unit mass in the flow are much lower, Appreciable scouring may occur late in time when HE gases act as a carrier for the droplets.

Numerical simulation of the compressor operation ${ }^{20}$ suggests that more than half the air may be trapped in the chamber and may not flow down the outlet pipe. Although those calculations terminated at $10 \mu \mathrm{s}$ following the diaphragm break, the predictions were in reasonable agreement with the first two peaks of the pressure profile recorded at $0.10 \mathrm{~m}$. If such a reduction in driver gas is realistic, then significantly less energy than $8 \mathrm{MJ}$ can be expected to be contained in the pipe flow. To explain the $0.34 \mathrm{~kg}$ of condensed wall material would require a reduced energy entrainment mechanism for a major portion of the flow. The scouring option is one possible mechanism.

\section{GROUT EXPERIMENT}

Figure 15 shows two orthogonal plan views of the fealures and diagnostics coverage for the compressor-outlet pipe assembly. Table 3 summarizes the diagnostics employed and their relative locations with respect to the diaphragm. The HE assembly, compressor section and first $0,15 \mathrm{~m}$ of the outlet pipe are identical in design to the steel experiment. The remaining $\sim 2.85 \mathrm{~m}$ of wall material for the outlet pipe is constructed of a special grout mix (DR-1) formulated for this experiment. ${ }^{21}$ The grout pipe allowed the use of diagnustic systems not feasible in the steel experiment.

\section{EXPERIMENTAL PROCEDURE AND DIAGNOSTIC COVERAGE}

\section{Grout Tube Construction \\ and Assembly}

It was necessary to mix and pour the grout at reduced pressures to remove air entrained in the grout. This added significantly to the complexity of the design and assembly of grout section. To describe the final configuration shown in Fig. 15 we present in chronological order the assembly procedure used. For more detail on grouting at reduced pressures, grout tube design and assembly, see Appendix B.

Not shown in Fig. 15, but crucial to the assembly, was a rigid cylindrical steel frame designed to support certain electronic sensors and a 20-mm bore tube. The bore tube was a 3-m-long, 19-num-o.d. copper tube covered with 0.5-mm-thick heat-shrink tubing and supported in the center of a cylindrical steel frame by four grout disks. This 20$\mathrm{mm}$ diam bore tube effectively acted as a form for the $20 \mathrm{~mm}$ bore through the grout section. The particle velocity systems, conductivity probes, and flatpack ${ }^{17}$ gages were then installed, supported by welded steel brackets near the circumference of the steel frame. The conductivity probes and piezoresistant segments of the flat packs were installed in 

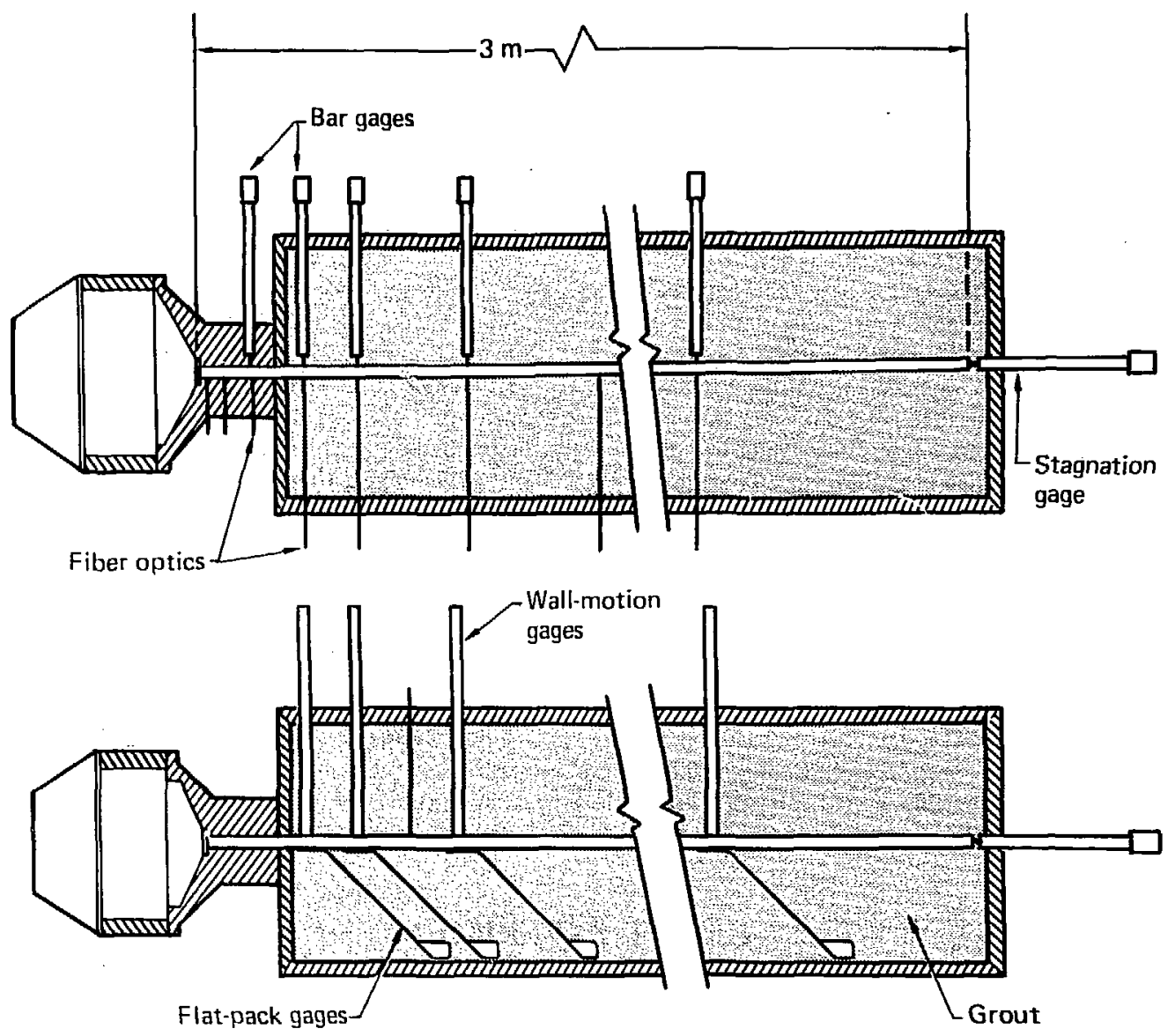

FIG. 15. Orthogonal plan viess of the compressor assembly, grout outlet pipe, and diagnostics systems.

physical contact with the $20-\mathrm{mm}$ bore tube. The eables associnad with the sensors were tied to outer ribs of the steel frame and brought out in a bundie through the back end of the frame. The frane was then inserted into a 0.508 -m-o.d. steel pipe. Adjusting serews through the pipe walls and in contact with the steel frame were used to center the $20-\mathrm{mm}$ bore tube with respect to the pipe walls. Then fiber optics assemblies and bar- and wall-motion gages were all inserted through ports in the pipe walls until the end of each sensor made physical contact with the 20-nm hore tube. End plates were emplaced on the steel pipe and bolted securely. All sensor ports and the cable port in the back end plate were then saled with epoxy to itain a vacuum- secured shock vessel. A vacuum pump was attached to the vessel and the remaining leaks were sealed with epoxy.

At this time DR-1 grout 21 was added to the vessel from a large mixing tank with the vessel and tank nuaintained at a reduced pressure by means of roughing pumps. The grout set up for approximately six weeks between the fill operation and the shot date. The week prior to the shot date a $0.33 \mathrm{~N}$ solution of nitric acid was eireulated through the bore cube to dissolve the 3-m length of copper tubing. The heat shrink tubing was left in place to prevent air from drying out the walls of the $20 \mathrm{~mm}$ bore in the grout. 
TARLE 3. Diagnostics for the grout pipe experiment.

\begin{tabular}{ll}
$\begin{array}{c}\text { Distanice from diaphragm } \\
(\mathbf{m})\end{array}$ & Dingnastics $^{\mathrm{a}}$ \\
\hline 0 & F \\
0.02 & F \\
0.05 & F \\
0.10 & F, B \\
0.20 & F, B, PM, W \\
0.30 & F, B, PY, W \\
0.40 & F \\
0.50 & F, B, PY, W \\
0.75 & F \\
1.00 & F, B, PY, W \\
1.25 & F \\
1.50 & F, B, PY, W \\
1.75 & F \\
2.00 & F, B, PY, W \\
2.50 & F, B, PY, W \\
3.00 & B
\end{tabular}

\footnotetext{
${ }^{\mathrm{a}} \mathrm{F}=$ fiber optics; $\mathrm{B}=$ bar gage (SSS); $\mathrm{PM}=$ pressure-Menganin (SRI); PY = pressure-ytterbium (SRD; $W=$ wall-motion sensor (particle velocity loop) (SRI).
}

Four days before the shot date the grout-filled vessel was transported to a shot table at the Site 300 HE testing facility operated by the Laboratory. Following preliminary setup procedures and bunker preparations the shrink tubing was removed. Visual inspection of the $20 \mathrm{~mm}$ bore indicated a snooth wall along its entire length without any debris or rough surfaces. The compressor section and $0.15 \mathrm{~m}$ of steel outlet pipe were then attached to the front end plate of the grout shock tube. The experiment was successfully fired shortly after installation of the stagnation gage, HE assembly, and pressurization of the compressor chamber.

\section{Optical Coverage with Framing Cameras}

Two framing cameras were focused on the first $\sim 0.25 \mathrm{~m}$ of the steel-grout outlet pipe to detect the location, duration and extent of possible venting. The delayed detonation of $1.8-\mathrm{kg} \mathrm{HE}$ pads attached to the back of two 1.2-m-lang argon candles provided supplementary lighting for the framing cameras' field of view. Of particular interest were the bar gage at $0.10 \mathrm{~m}$ and the junction between the initial steel pipe and grout pipe at $0.15 \mathrm{~m}$. Beyond the junction at $0.15 \mathrm{~m}$ the grout pipe is of sufficient diameter $(0.508 \mathrm{~m})$ that venting was not a concern. Bridge wires were mounted on the short section of the steel outlet pipe and detonated at preselected times to provide optical fiducials. Optical fiducials supply the timing resolution for the framing coverage and act as a backup in determining the interframe time. One of the framing cameras (Model 189B) was operated in a synchronous mode with the two streaking cameras. The second framing camera (Model 6) was operated in a free-running mode and used solely as a backup system.

\section{Optical Coverage with Streaking Cameras}

Fifteen $1.80-\mathrm{m}$-long light pipes were emplaced along the outlet pipe (Table 3). Four of the light pipes were located in the $0.15-m$ section of steel outlet pipe according to the emplacement design described in Ref. 11. The other 11 light pipes were located in the grout section of the outlet pipe with one end of the fiber optics in direct contact with the shrink tubing around the copper bore tube. The grouting operation, removal of copper tubing with nitric acjd solution and preliminary preparations prior to firing the $\mathrm{HE}$ are described in Appendix B. The fact that all the light pipes were in optical communication with the bore of the tube was determined just before final assembly on the chot table following removal of the shrink tubing.

One end of each of the 15 light pipes was terminated in an optics display board for scanning by two streaking cameras (Models 75 and 132) running in a synchronous mode. The other streaking camera (Model 132) was used as a backup. The detonation of bridge wires located in the display board at predetermined times provided the optical liducia:s to correlate air-shock luminosity data for the streaking camera. Rewrite was prevented by the delayed detonation of small $\mathrm{HE}$ pads attached to the back of the turning mirrors above the optic ports. Opaque plastic tents were used to shield the display board and the bunker optic ports to the cameras. This procedure and delayed closure of electro-mechanical shutters on the cameras significantly reduced exposure to ambient lighı and lowered the fogging levels of the streaking camera films. No optical filters were used on any of the cameras.

\section{Electronic Diagnostics}

The electronic diagnostics in this experiment consisted of two types of pressure gages, wallmotion sensors, and plasma-flow velocity and conductivity sensors. Detailed descriptions of the 
pressure gages and wall-motion sensors are given in Appendix $A$ and their locations are given in Table 3. A more detailed description of the coriductivity and particle flow measurements is presented in Appendix C.

Pressure Gages. The nine bar gages in this experiment are identical in design and operation to those used in the steel experiment as described in the previous section. The first bar gage was emplaced at $0.10 \mathrm{~m}$ in the steel pipe (Fig. 15). The next seven bar gages were all located in the grout section (Table 3 ) with one and in contact with the shrink tubing covering the copper tubing. The input ends of the first eight bar gages were machined to a $10-\mathrm{mm}$ radius to conform to the curvature of the bore radius. The end of the bar gage at $3.0 \mathrm{~m}$ was flush with the end wall to record stagnation pressures associated with the flow.

A total of seven flat-pack gages ${ }^{17}$ was installed in the grout section with the center of the piezoresistant elements at the same axial locations (Table 3) as the bar gages. Thus, at each of the seven locations in the grout section, two types of pressure gages are used to compare pressure proliles generated by the air shock and gas flow.

Wall-Motion Gages. Pressures in and behind the shock front are sufficient to induce rapid radial expansion of the grout walls. This radial wall motion was monitored using a mutual-inductance particle velocity gage $22-24$ at several different axial locations ulong the bore (Table 3). Each gage consists of a closely wound primary and secondary conducting wire forming a rectangle with length large compared to the lateral dimensions. Initially the primary loops are driven by a large de current; the secondary loops are linked by the magnetic field produced by the primary loops and produce a signal output from the secondary loop during gage operation. Both rectangular sets of primary and secondary loops are embedded in the grout section of the shock tube. One end of both sets is exposed to pressures behind the shock front. Radial motion of the walls results in alteration of mutual inductance between the loops, and this can be related to particle or wall motion. This gage has been successfully employed for particle-velocity measurements in previous experiments.

Plasma Flow and Conductivity Diagnostics. Diagnostic sensors were emplaced in this experiment to record the time history for plasma now velocity, plasma resistance, and plasma electrical conductivity. The diagnostic stations (Appendix C) for these measurements were located at 367,427 , and $735 \mathrm{~mm}$ downstream from the diaphragm, respectively. The theory and experimental techniques used in this experiment have been under development ${ }^{25-27}$ and have been applied successfully over several years to other high-energy plasma experiments. Experimental results are given later, and Appendix $C$ provides further details of the diagnostics and a brief description of the underlying theory. See Ref. 28 for additional details on the theory, diagnostic sensors, calibration procedures, and experimental results.

\section{DIFFERENCES BETWEEN STEEL AND GROUT EXPERIMENTS}

The following will not only provide a better understanding of the experimental results, but also will illustrate some effects that directly impact the measurements themselves. Neglecting the difference between strength of the wall materials, the initial radiai-wall motion should be about 5 times as great for the grout experiment based on just inertial effects. Taking strength into account would further exaggerate this difference in relative initial wall motion for grout and steel. Such wall motion should reduce pressures well behind the shock front but in turn may reduce mass-entrainment effects, particularly if appreciable delay occurs in the addition of wall material to the flow. This assumes that radial wall motion is uniform and Taylor instabilities can be neglected. As the wall moves out the bar gage remains relatively stationary and the end of the input bar will protrude into the flow. The effect of such protrusion may be a minor perturbation on the flow, but its effect is unknown not only on the flow, but also on the pressure measurement being recorded by the tur gage. Fortunately significant wall motion occurs for only the lirst three bar gages in the grout section. If we assume that the specific energy of vaporization $\left(E_{v}\right)$ of rock; $\sim 10 \mathrm{MJ} / \mathrm{kg}$, is a reasonable value ${ }^{2}$ for our DR-1 grout, then this value does not differ appreciably from the one assumed for steel, i.e., $12.5 \mathrm{MJ} / \mathrm{kg}$. However, $E_{y}$ is just one parameter in the ablation formulation.

Other differences exist that may affect the dynamic description of the ablation process for the two experiments. Examples of such differences are (1) atomic masses and opacities for steel and grout 
differ appreciably: (2) DR-I grout has a large water content ( $\sim 25 \%$ by weight) with relatively low $E_{v}$ $(\sim 2.6 \mathrm{MJ} / \mathrm{kg})^{29}$; and (3) large differences exist in the constitutive relations for steel and DR-1 grout. The above list is by no means exhaustive, but does highlight some of the difficulties to be encountered in future numerical simulation efforts, particularly with respect to the grout experiment.

\section{EXPERIMENTAL RESULTS}

The optical and electronic measurements were time correlated by reference to the electronic signal used to initiate detonation of the plane-wave lens. The time interval between detonation of the pianewave lens and diaphragm breakage was $57.6 \mu \mathrm{s}$. This time was determined with a iight pipe oriented to view the center of the diaphragm and the streaking camera focused on the display board. This value was $0.5 \mu$ s earlier than obtained in the steel experiment and the difference will be discussed in the following section. The diaphragm breaking time is taken as the new zero time reference for all experimental results in this test.

\section{Framing Camera Coverage}

The framing camera (Model 189B) coverage of the first $0.25 \mathrm{~m}$ of the outlet pipe indicated that a small amount of venting around the bar gage at $0.10 \mathrm{~m}$ began at $25 \mu \mathrm{s}$ after the diaphragm broke. This venting continued until high-explosive gases from the driver section obscured the field of view approximately $20 \mu$ s later. This venting may explain the reduction in the pressure profile at $0.10 \mathrm{~m}$ for late times in the grout experiment compared with the steel experiment at this location. This will be discussed in greater detail in the next section. No venting was detected for the grout experiment other than that noted for the bar gage at $0.10 \mathrm{~m}$.

\section{TOA Data and Air Shock Velocity}

Table 4 summarizes TOA results of the shock front for the fiber optics and electronic sensors. The TOA values for the fiber optics are the times that the first luminosity peak was recorded at each location. The TOA values for the bar gages are times at which the initial rise for the first pressure peak was very steep. The basis for this choice was presented in the TOA data discussion of the previous section for the steel experiment. The TOA data for the flat- pack gages correspond to where the initial rise for the first peak is very steep. The piezoresistance elements for the flat-pack gage are $10 \mathrm{~mm}$ in length and lie along the axis of the tube. Thus a limiting factor on the risetime is related to the transit time for the shock front to traverse the $10-\mathrm{mm}$ length of the piezoresistant element. Over most of the tube the velocities are in excess of $10 \mathrm{~mm} / \mu \mathrm{s}$ and the risetimes are very steep; peak pressures occur within $1-2 \mu \mathrm{s}$ of the start of the signal. A similar argument applies to the TOA values given in Table 4 for the wall motion gages. The TOA values in Table 4 are in good agreement, with no apparent anomalies.

Figure 16 presents a TOA plot for propagation of the shock front in the exit pipe. Differentiation of the TOA curve provided a plot of the velocity for the shock front as a funr:ion of distance down the outlet pipe as given in Fig. 17. After a short period of acceleration the shock attains a maximum velocity of $\sim 43 \mathrm{~mm} / \mu \mathrm{s}$ at a distance of $\sim 100 \mathrm{mr}$. from the diaphragm. At this point we can only speculate about the attenuation of the air shock propagation seen in Figs. 16 and 17. Unlike the

TABLE 4. Air shock time-of-arrival (TOA) data from the grout pipe experiment.

\begin{tabular}{|c|c|c|c|c|c|}
\hline $\begin{array}{c}\text { Axial } \\
\text { distance } \\
\text { (m) }\end{array}$ & $\begin{array}{l}\text { Fibe } \\
\text { optic } \\
\text { To } \\
(\mu \mathrm{s})\end{array}$ & $\begin{array}{l}\text { ics } \\
\text { s) }\end{array}$ & $\begin{array}{l}\text { Bar } \\
\text { gage } \\
\text { TOA } \\
\text { ( } \mu s)\end{array}$ & $\begin{array}{c}\text { SRI } \\
\text { flat-pack } \\
\text { sensor } \\
\text { TOA } \\
(\mu s)\end{array}$ & $\begin{array}{c}\text { SRI } \\
\text { wall- } \\
\text { motion } \\
\text { sensor } \\
\text { TOA } \\
(\mu s)\end{array}$ \\
\hline 0 & $(57.6)$ & 0.0 & & & \\
\hline 0.02 & & 1.3 & & & \\
\hline 0.05 & & 2.13 & & & \\
\hline 0.10 & & 3.45 & 3.9 & & \\
\hline 0.20 & & 5.74 & 6.6 & 6.5 & 5.6 \\
\hline 0.30 & & 8.6 & 9.6 & 9.8 & 9.4 \\
\hline 0.40 & & 11.4 & & & \\
\hline 0.50 & & 14.6 & 13.3 & 142 & 13.4 \\
\hline 0.75 & & 22.9 & & & \\
\hline 1.00 & & 31.8 & 32.5 & 32.8 & 32.6 \\
\hline 1.25 & & 43.0 & & & \\
\hline 1.50 & & 57.4 & 57.4 & 57.5 & 56.8 \\
\hline 1.75 & & 76.9 & & & \\
\hline 2.00 & & 107.7 & 108.6 & 108.4 & 107.4 \\
\hline 2.50 & & 208.0 & 209.3 & 193.4 & \\
\hline
\end{tabular}


Voitenko steel experiment, there is no comparable previous air-shock calculational study for the grout experiment. The only other documented studies in the open literature are for the Marvel experiment ${ }^{2}$ which indicated that the principal mechanism for air-shock attenuation was ablation of the 1 -m-diam pipe walls. That study incorporated a model to simulate the delayed entrainment of wall material into the llow behind the shock front. In Marvel, the pipe walls were of transite surrounded by a grout medium similar to our present experiment. Future studies of this grout experiment will probably show that delayed entrainment of wall material is the dominant attenuation mechanism.

\section{Prescure Profiles}

Figures 18-25 are the pressure profiles obtained for this experiment; none were obtained for the stagnation gage. For the grout experiment no pressure profiles were obtained for the flat-pack gages at the $0.20,2.0$, and $2.5 \mathrm{~m}$ locations. The flat pack at $0.20 \mathrm{~m}$ experienced a significant negative deflection with the arrival of the shock front. Such a deflection makes data reduction uncertain since it's

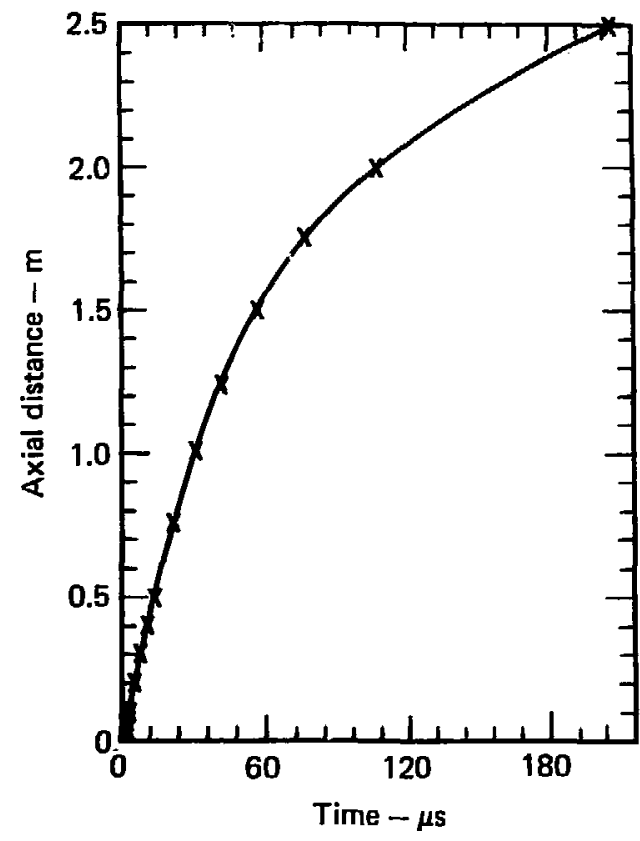

FIG. 16. Air shock TOA data for the grout outlet pipe. difficult, if not impossible, to determine a baseline for the signal trace on the scope. The signal levels for the hat packs at 2.0 and $2.5 \mathrm{~m}$ were too low to obtain pressure profiles.

Ptak pressures associated with the shock front decayed from $2.28 \mathrm{GPa}$ at $0.10 \mathrm{~m}$ to $0.024 \mathrm{GPa}$ at $2.5 \mathrm{~m}$ from the diaphragm. The value for $0.10 \mathrm{~m}$ was obtained with a bar gage since for this experiment no piezoresistance gage was used at this location. For those locations where bar gages and hat packs provided pressure profiles, there appears to be agreement in timing and amplitude for the first two peaks. In general the first two pressure oscillations for the hat packs are much larger and probably more indicative of the pressures exerted at the walls for the gage locations. Dispersion in the input bar for the bar gage will tend to broaden the pressure pulses that arrive at the quartz crystal. The observed oscillaticns result from axial and radial oscillation in the flow induced by early diaphragm break and radial convergence of driver gas in the compressor chamber. 1,20 Examination of the pressure profiles at $1.5 \mathrm{~m}$ (Fig. 23) and $2.0 \mathrm{~m}$ (Fig. 24) indicates that, although the peak amplitudes may attenuate appreciably, the relative degree of the oscillations persists over a substantial distance. Another interesting feature is that (in the time frame) the width for the pressure pulse at half maximum $(\sim \mid \mu \mathrm{s})$ and distance between first two peaks $(\sim 3 \mu \mathrm{s})$ remain relatively constant for the flat-pack profiles. Because of velocity attenuation for the flow, this implies that spatially the pressure pulses become progressively narrower and closer together as the flow propagates down the exit pipe. Although an analogous argument can be forwarded for the bar-gage profiles, the numbers must be modified due to broadening by dispersion of the pulse by the input bar.

A major implication of the above discussion on oscillations is that it's a strong argument for delayed entrainment to the flow of wall material. The entrainment of relatively cold wall material should rapidly damp such oscillations and destroy the stable fine-structure configuration that persists in and for some distance behind the shock front. If the correlation is limited to the first two pressure oscillations, then mass entrainment does not appear to be an important factor for 4-6 $\mu \mathrm{s}$ behind the shock front. Following a somewhat different line of reasoning in a former jet study, ${ }^{19}$ a case was made for an $\sim 8-\mu$ s delay in mass entrainment. 


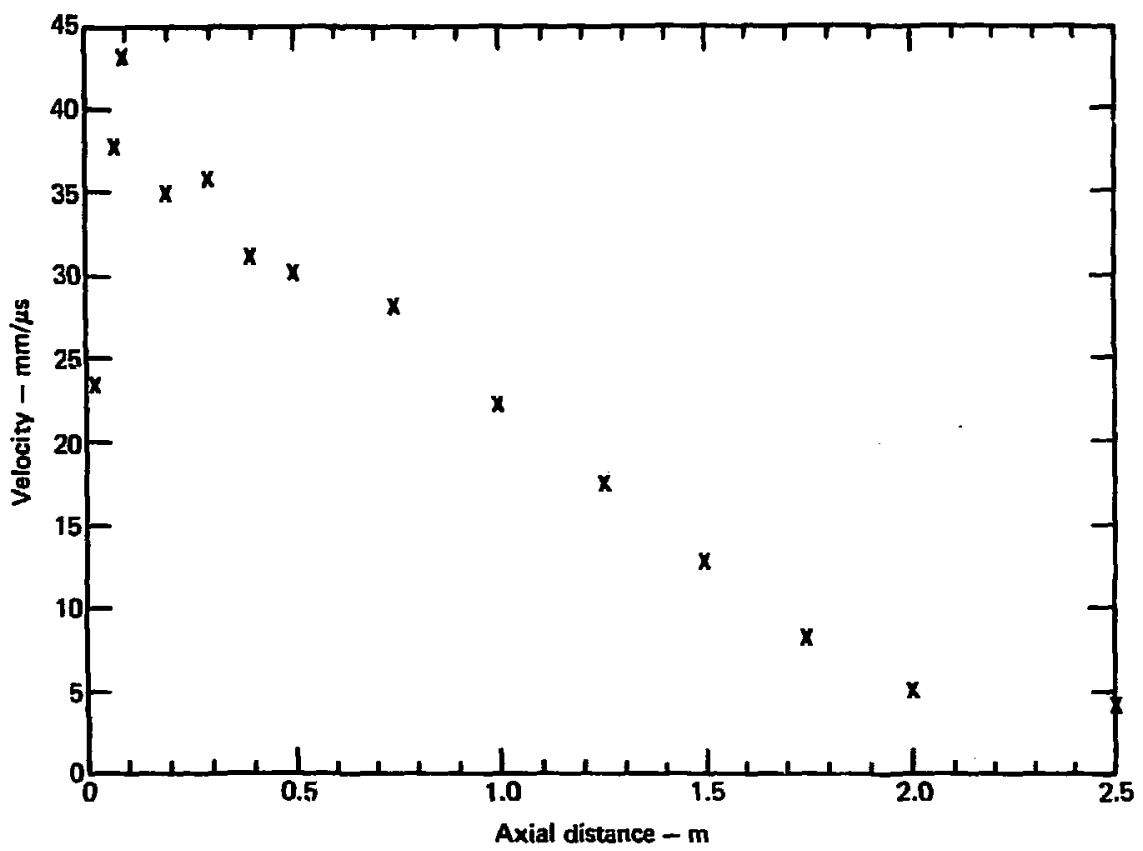

FIG. 17. Shock velocity ys axial distance for the grout shock-tube experiment.

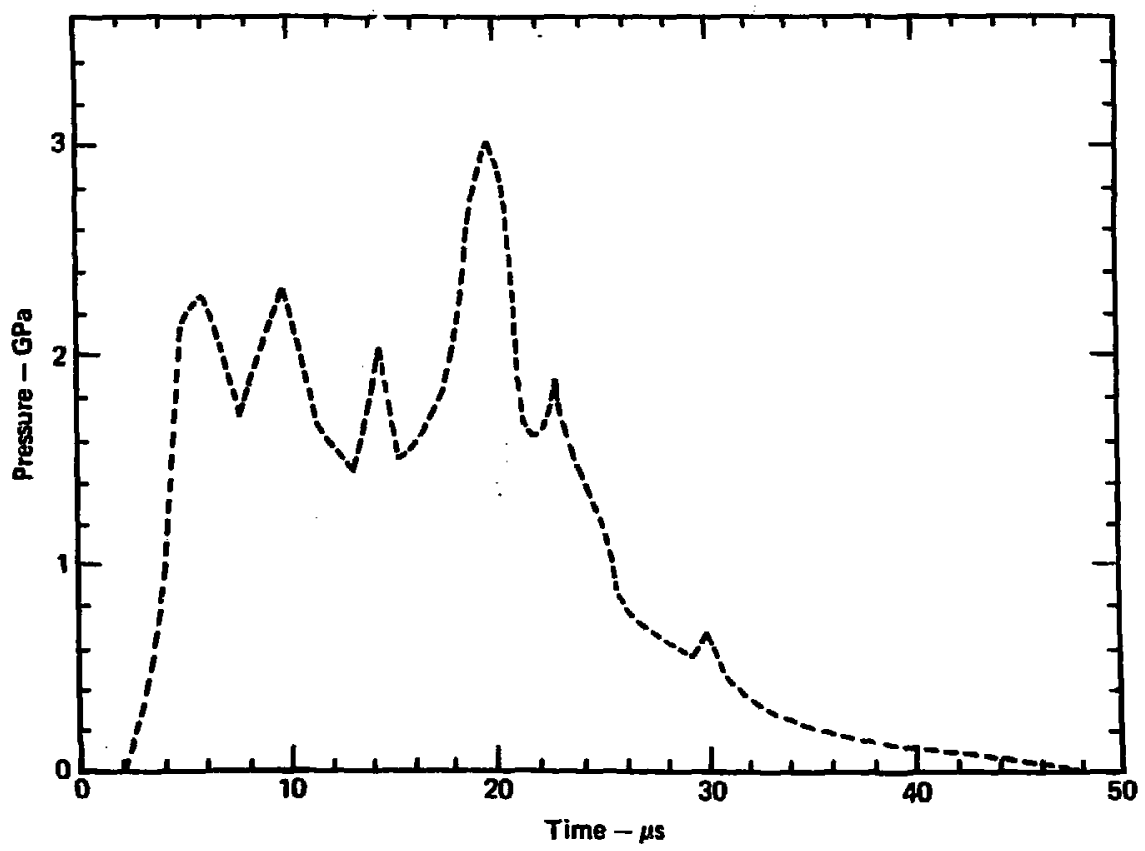

FIG. 18. Pressure profile obtained with the bar gage at $0.10 \mathrm{~m}$ from the diaphragm (grout pipe). 


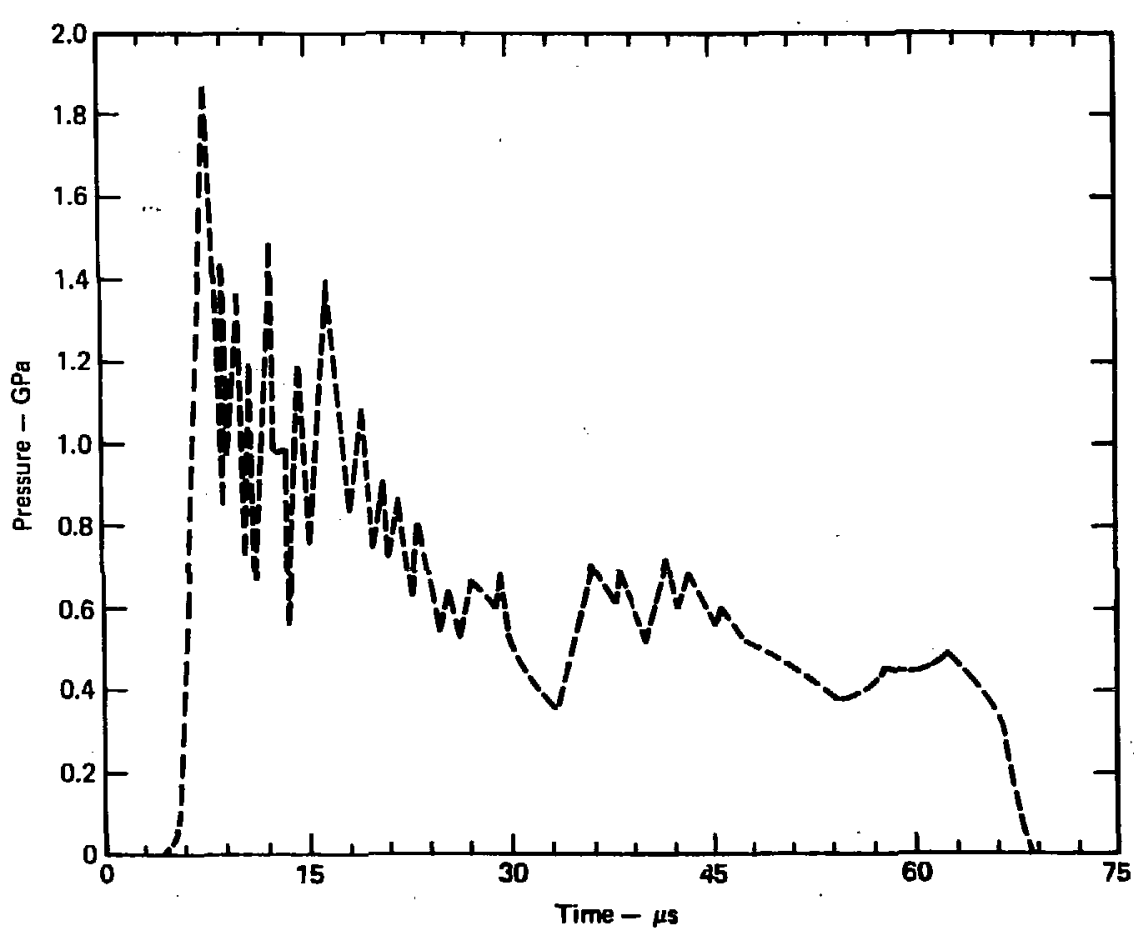

FIG. 19. Pressure profile obtained with a bar gage at $0.20 \mathrm{~m}$ from the diaphragm (grout pipe).

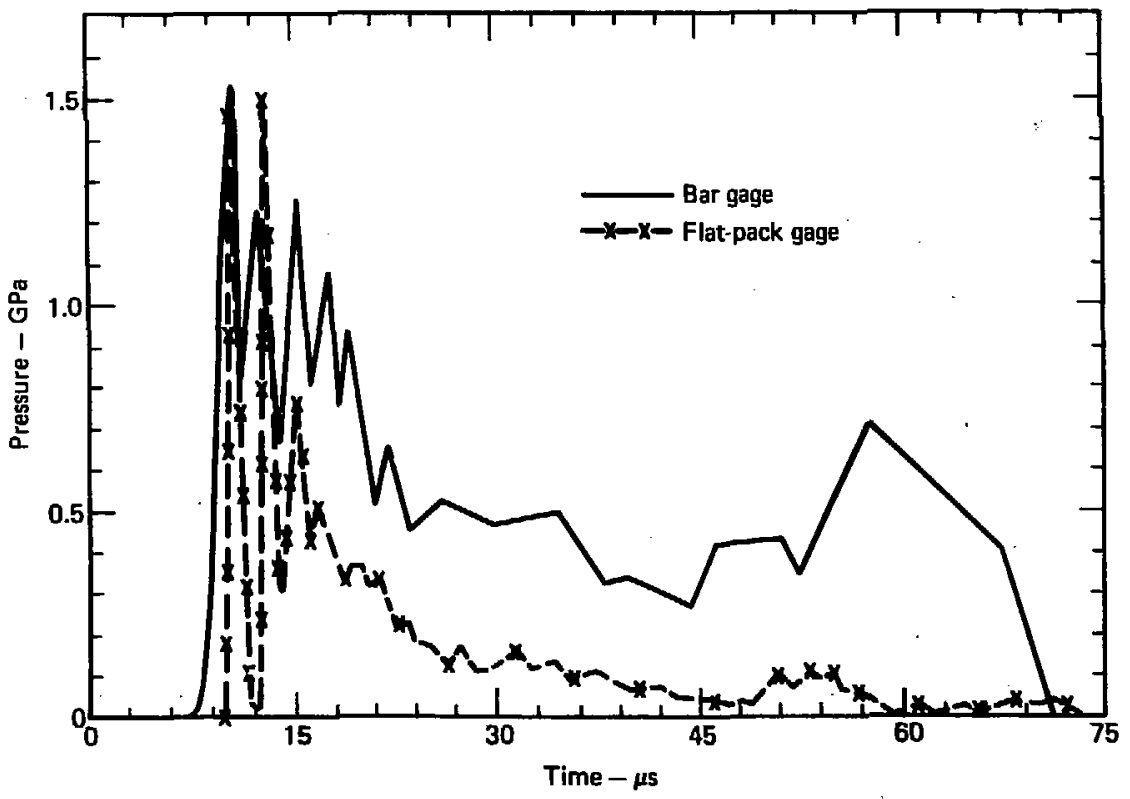

FIG. 20. Pressure profiles at $0.30 \mathrm{~m}$ in the grout pipe. 


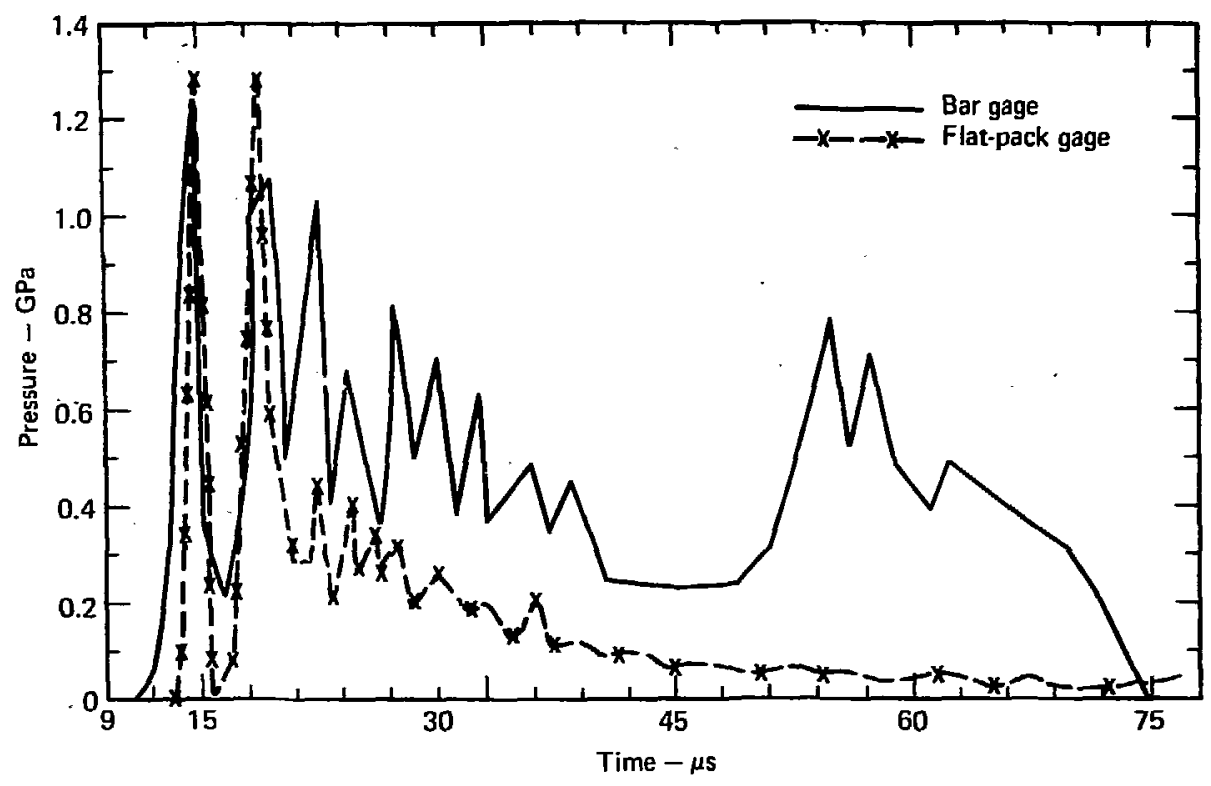

FIG. 21. Pressure profiles at $0.50 \mathrm{~m}$ in the grout pipe.

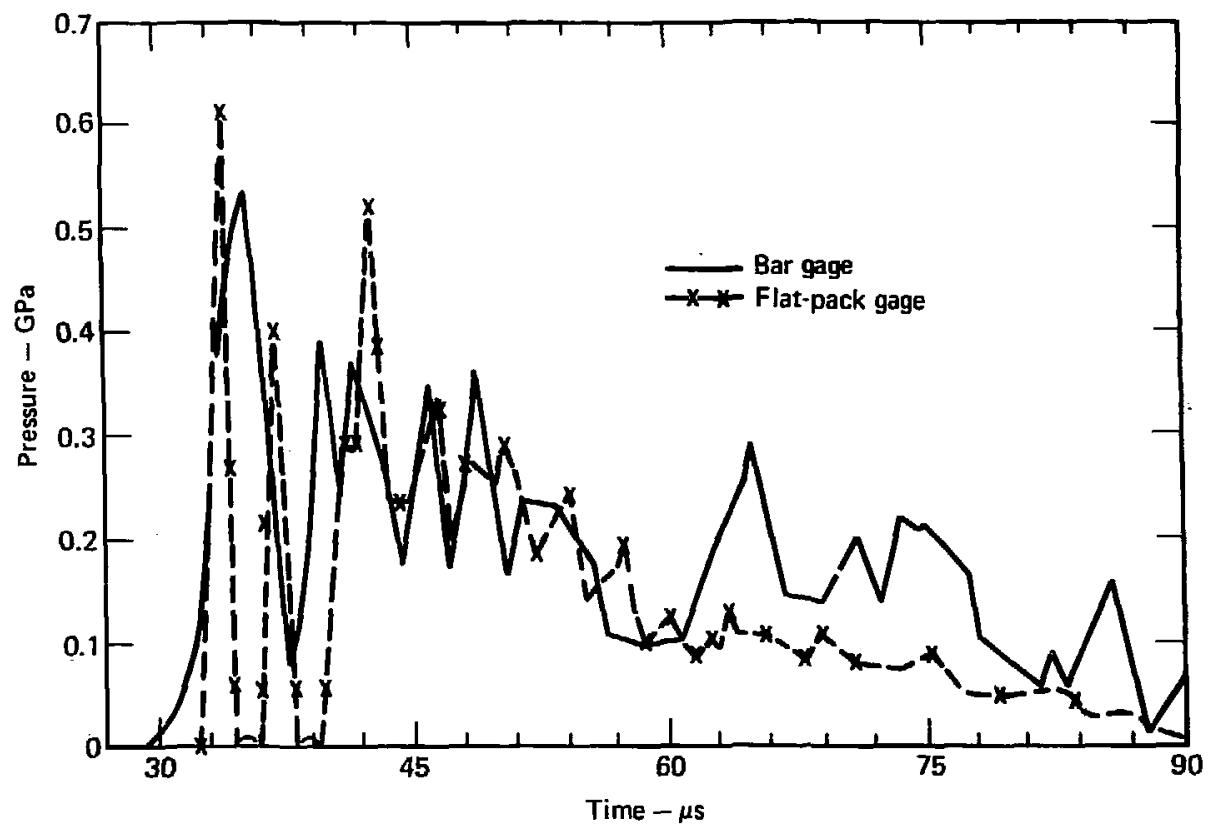

FIG. 22. Pressure profiles at $1.0 \mathrm{~m}$ in the grout pipe. 


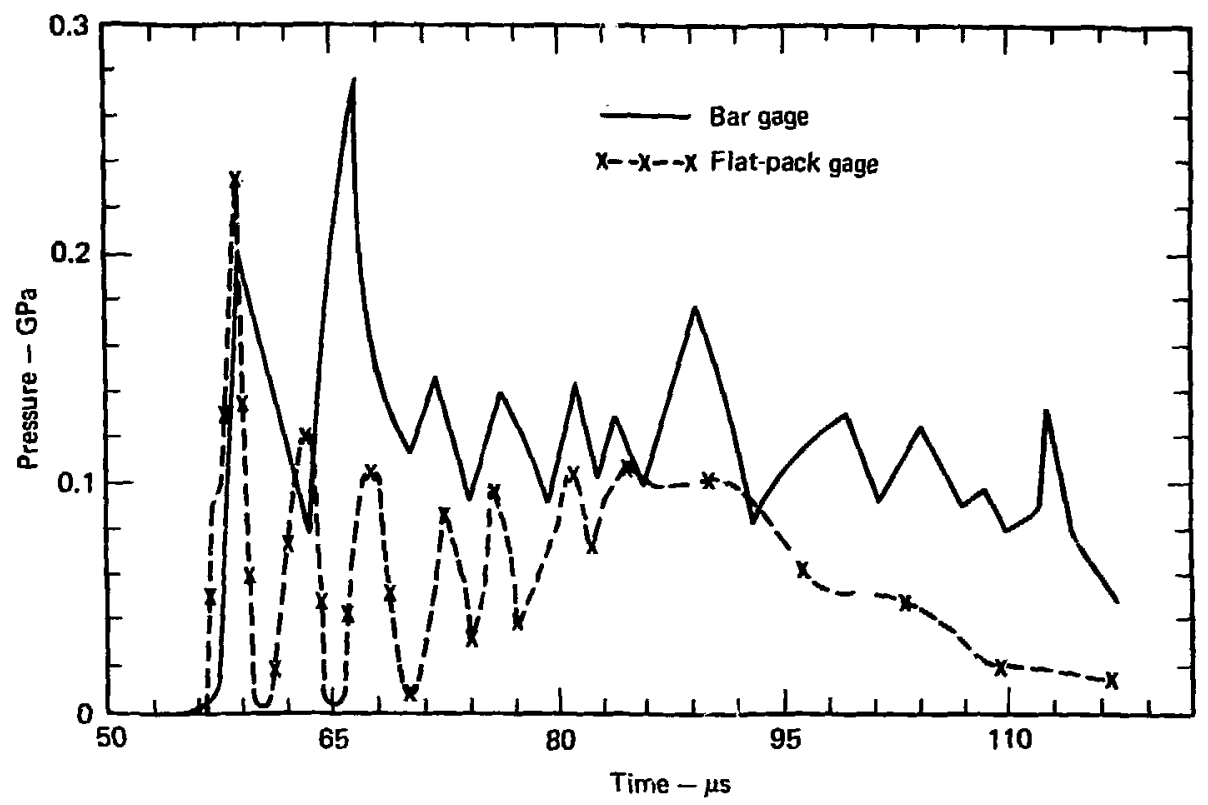

FIG. 23. Pressure profiles at $1.5 \mathrm{~m}$ in the grout pipe.

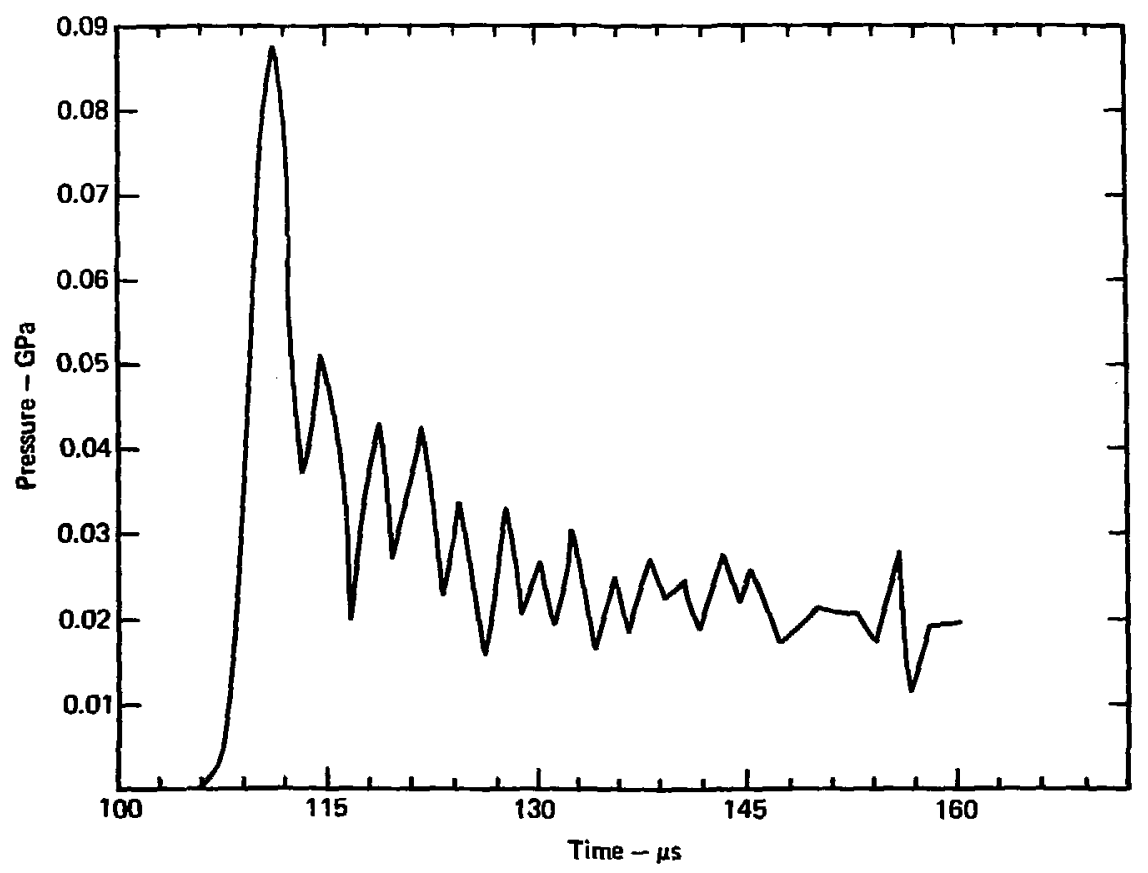

FIG. 24. Pressure profile obtained with the bar gage at $2.0 \mathrm{~m}$ from the diaphragm (grout pipe). 


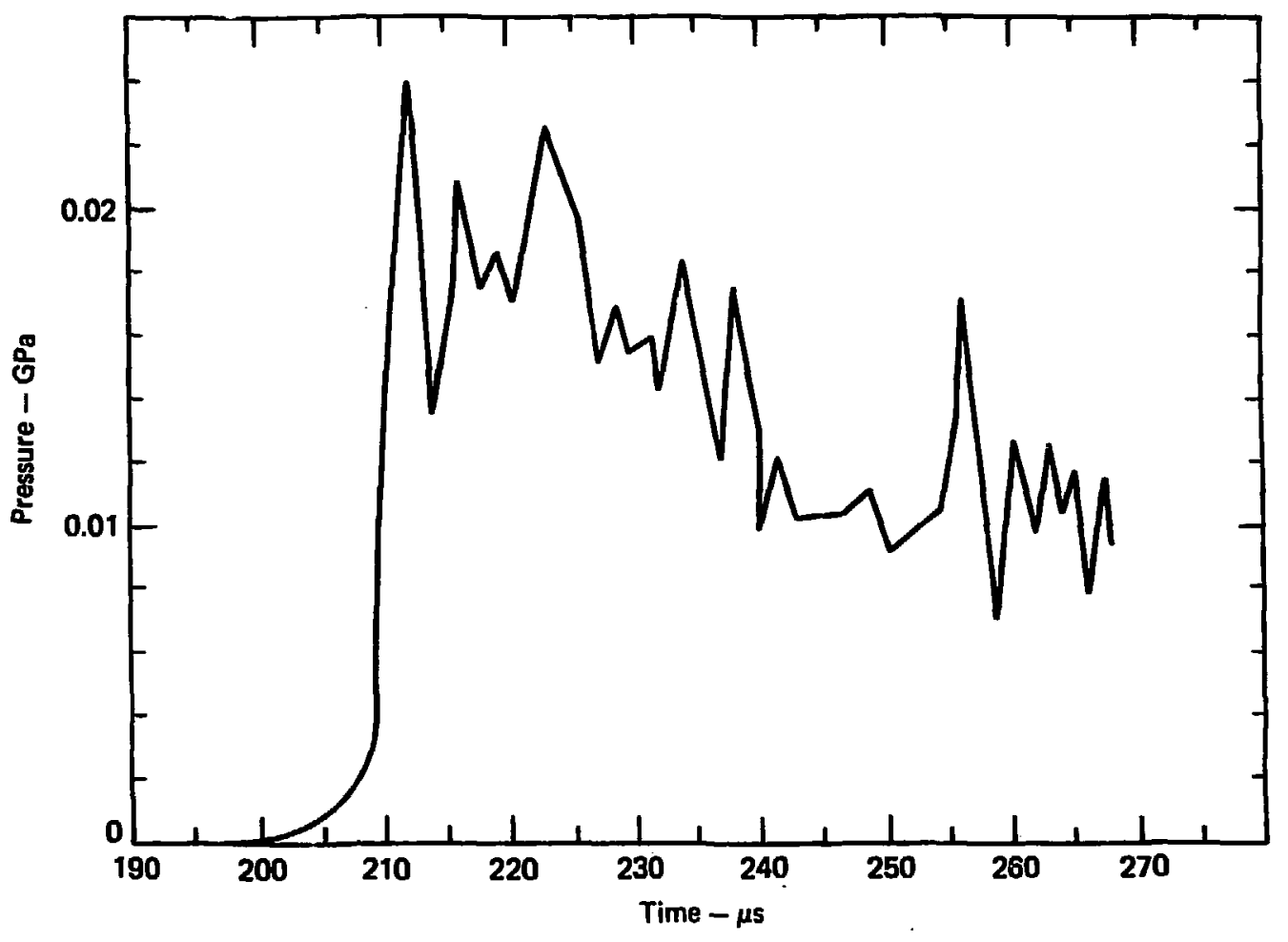

FIG. 25. Pressure profile cbtained with the bur gage at $2.5 \mathrm{~m}$ from the diaphragm (grout pipe). 
In general the peak pressure measurements for the shock front recorded with the bar and flat-pack gages were in excellent agreement, both in amplitude and TOA. If we examine the pressure profiles well behind the shock front the agreement is rather erratic. At $0.3 \mathrm{ml}$ (Fig. 20) and $0.5 \mathrm{~m}$ (Fig. 21) the flat-pack gages indicate consistently lower pressures than the bar gages. At $1.0 \mathrm{~m}$ they track onc another fairly well, while at $1.5 \mathrm{~m}$ the agreement is mediocre. The low-pressure readings for flat-pack gages at 0.3 and $0.5 \mathrm{~m}$ are attributed to a combination of low signal levels and uncertainty regarding time dependence of hysteresis values for ytterbium when unloading from high pressures. The low signal levels create a problem since the reading error becomes progressively greater as the signal level decreases. The flat-pack scope records were reduced with uniaxial strain shock data using a double shock technique in gas gun studies. ${ }^{30}$ These studies indicate that ytterbium exhibits a residual resistance (hysteresis effect) following unloading from high shock levels. The flat-pack signals were reduced using calibration values and residual resistance measurements from the above study. However, the residual resistance can only be observed in gas gun studies for a few microseconds before rarefaction. from the edges of the target produces significant strain effects. Yet some of the nal-pack signal records returned to their baseline after $\sim 100 \mu \mathrm{s}$, indicating no hysteresis effect at that time. This suggests a time dependence for relaxation of the residual resistance for ytterbium. If such a time-dependent relaxation is realistic, then subtraction of the initial residual resistance, which is the current practice, would tend io suppress the pressure levels below their actual values at late times.

\section{Radial Wall Motion}

Radial wall motion was monitored with seven gages (Appendix A) located in the grout section (Table 3). Figure 26 shows radial displacements vs time with the gages at $0.30,0.50,1.00,1.50$, and $2.00 \mathrm{~m}$ from the diaphragm. The time axis for each radial displacement shown in Fig. 26 has been shifted so that zero time corresponds to TOA of the shock front (Table 4) at the respective location for each wall-motion gage. The records for $0.20 \mathrm{~m}$ indicated a gage malfunction, and those for $2.00 \mathrm{~m}$ (after $12 \mu \mathrm{s}$ ) and $2.50 \mathrm{~m}$ were too low for reliable data reduction.
The results shown in Fig. 26 are consistent with the pressure profiles of Figs. 20-24. The rate of wall expansion is the largest for the first $10 \mu \mathrm{s}$, corresponding to the early high-pressure oscillations. The rate of wall expansion uniformly decreases like the pressure decay behind the shock front, then asymptotically approaches some final radial value. Most of the radial expansion is complete by $\sim 60 \mu \mathrm{s}$, and by that time the pressures behind the shock front have decayed considerably. The exception to this is the result at $0.50 \mathrm{~m}$. At approximately $35 \mu \mathrm{s}$ behind the shock front (Fig. 26), the rate of radial expansion increases dramatically. The bar-gage pressure profile (Fig. 21) indicates that a substantial high-pressure flow also occurs at $\sim 35-40 \mu$ s behind the shock front and remains high for $20 \mu \mathrm{s}$ or longer. These two results appear to agree, although this may be accidental since this late-time pressure pulse was not seen on the flatpack pressure profile (Fig. 21).

The grout tube section of this experiment was severely fragmented out to a distance of $0.80 \mathrm{~m}$ from the diaphragm. Expansion of the grout walls due to high-pressure gas flow was partially responsible. However, the major damage was caused by the impact of the first $0.15 \mathrm{~m}$ of steel outlet pipe on the grout section. $\Lambda t 0.80 \mathrm{~m}$ and beyond the grout section was recovered almost intact. The final bore diameter at $0.80 \mathrm{~m}$ measured $60 \mathrm{~mm}$, corresponding to a radial expansion of $20 \mathrm{~mm}$. Wall-motion measurements of radial expansion at $100 \mu \mathrm{s}$ behind the shock front at 0.50 and $1.00 \mathrm{~m}$ were 19 and $4.6 \mathrm{~mm}$, respectively. If these values are reasonably accurate, then appreciable radial wall motion occurred after $100 \mu \mathrm{s}$. A measurement of $20 \mathrm{~mm}$ was obtained for the bore diameter at $3.00 \mathrm{~m}$, which implies a minimal $(<1 \mathrm{~mm})$ radial expansion at this distance. Consequently, significant stagnation or attenuation occurred between 2.5 and $3.0 \mathrm{~m}$ from the diaphragm, since measurements at $2.5 \mathrm{~m}$ indicated a shock propagating at $\sim 4.5 \mathrm{~mm} / \mu \mathrm{s}$ with a peak pressure of $23.8 \mathrm{MPa}$ behind the front.

This implies that the radial expansion at $100 \mu \mathrm{s}$ (Fig. 26) is a conservative estimate for the final values of radial expansion. Even this estimate is approximately an order of magnitude greater than those obtained at comparable distances in the steel experiment (Fig. 13). The major portion of the radial expansion occurs well behind the shock front and thus its primary effect would be to reduce late time pressures. Late time pressures are lower for the 


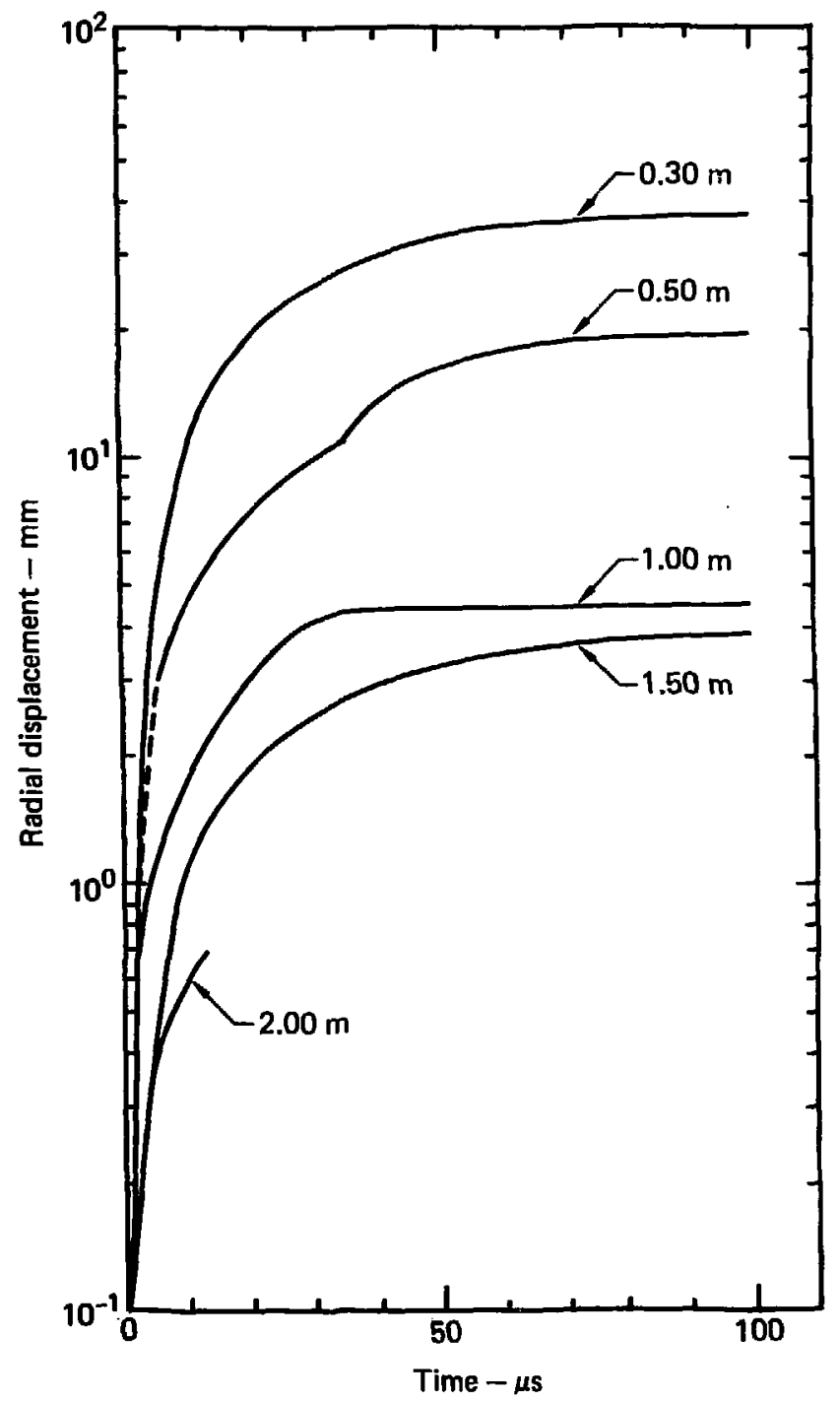

FIG. 26. Radial displacement vs time after arrival of the shock front at $0.30,0.50,1.00,1.50$, and $2.00 \mathrm{~m}$ from the diaphragm (grout pipe). 
grout experiment in the region (first $0.50 \mathrm{~m}$ ) of large radial expansion, compared with the steel experiment. However, this difference is obseured by other factors, which are discussed in the next section.

\section{Plasma Flow Velocity and Conductivity Measurements}

Usable data were obtained from three of the four instrumentation cables used. The velocity gage and the resistance gage (which includes both a voltage and current nieasurement) provided usible records. The conductivity-gage record was extremely noisy and provided no useful data. The cause of the noise was later found to be a broken connection inside of the RC integrator on the output of the search coil.

Analysis of the velocity-gage record Jocated at $367 \mathrm{~mm}$ from the diaphragm produced the flowvelocity time history in Fig. 27(a). The load voltage and load current measurements along with the velocity-gage records were used to produce the effective conductivity vs time plot in Fig. 27(b). The effective plasma conductivity in Fig. 27(b) was surprisingly high for this experiment and resulted in a magnetic Reynolds number slightly greater than 60 . While this magnetic Reynolds number was not higher than the calibrations provided, it was sufficiently high to require correction to both the velocity gage and the plasma-resistance gage. The correction based on the eddy current effects or magnetic Reynolds number effects is shown for the velocity gage in Fig. 27(a) as the dashed line. The conductivity history shown in Fig. 27(b) is already corrected for magnetic Reynolds number effects. The dashed portion at the start of the trace is probably not valid because inductive effects are still important immediately after shock arrival in this measurement.

From the vclocity plot of air-shock propagation in the grout experiment (Fig. 17), the shock velocity was determined to be $\sim 32 \mathrm{~mm} / \mu \mathrm{s}$. The initial flow velocity of the plasma (u) can be obtained from the measured shock speed $U$ using the relation $u=2 U /(\gamma+1)$, where $\gamma$ is the gas equation of state parameter. Using $\gamma=1.208$ for air gives $u=29.0 \mathrm{~mm} / \mu \mathrm{s}$, which is in good agreement with the corrected measured initial flow velocity of $27.4 \mathrm{~mm} / \mu \mathrm{s}$. Whiie the agreement at early times is good, this is not the calse later because of the effects of wall motion and mass entrainment. Data here are referenced to time after shock arrival at a particular diagnostic location. Arrival time data obtained from the velocity gage and resistance gage are consistent with shock arrival time trajectories determined by liber optics and pressure gages (Table 4).

In summary, the flow velocity and conductivity measurements are a reasonable measure of the actual flow conditions. The rate of decay of the flow velocity behind the front is interesting in that it is reduced to one-hall of its initial value by $9 \mu \mathrm{s}$. This rapid decay may indicate mass entrainment from the walls, and should be of considerable importance in future numerical simulation efforts. In future tests these measurements could be repeated with es. sentially the same test setup. One improvement would be the use of longer magnets to reduce the correction required for high magnetic Reynolds numbers.
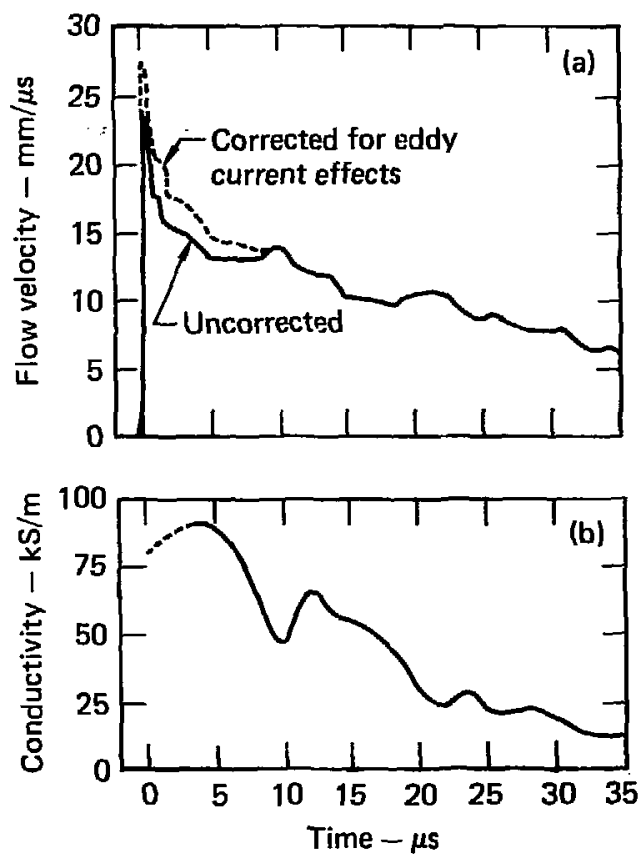

FIG. 27. Results of plasme properties measurements on Voitenko grout shot; (a) plot of plasma now velocity vs time at a distance of $367 \mathrm{~mm}$ from the diaphragm; (b) Plot of plasma effective conductivity vs time at a distance of $\mathbf{4 2 7} \mathbf{~ m m}$ from the diaphragm. 


\section{COMPARISON OF EXPERIMENTAL RESULTS}

One purpose of these experiments was to examine the relative effect of wall material on highenergy shock propagation. The steel and grout wall materials have different properties that should affect the air shock and subsequent gas flow. The density, material strengths, atomic number and atomic mass are all significantly larger for steel than for grout. Such differences in wall materials should affect the rate of radial wall motion, radiation diffusion, convective heat transfer, ablation and mass entrainment. Whether these phenomena combine additively or subtractively will determine their attenuation effect on air shock and gas flow propagation. As an example, a faster radial wall motion may attenuate the shock velocity by reducing pressures behind the shock front, but increase the time for mass entrainment and thus reduce its effect as an attenuator. Although specific uncertainties may not be resolved, comparison of experimental results provides some conclusions.

The fiber optics and bar gages were common to both experiments. Thus we limit the comparison to results obtained with these two systems. Initially TOA results and velocities derived for propagation of the shock front are compared. Then we compare pressure profiles obtained with the bar gages.

\section{TOA AND VELOCITY RESULTS}

The TOA values for the steel and grout experiments were given in Tables 2 and 4, respectively. In Fig. 28 the shock front TOA vs axial distance from the diaphragm are plotted for both experiments. The TOA values were obtained with the fiber optics, but the electronic sensor TOA values also fall within the plotted data points. Over the first $2.0 \mathrm{~m}$ the shock-front propagations are essentially identical, but at $2.5 \mathrm{~m}$ the greater attenuation for the grout experiment is clearly evident.

The velocities for the shock fronts as a function of axial distance are plotted in Fig. 29. They were obtained by taking the slopes of the TOA curves in Fig. 28. As observed previously, ${ }^{10}$ the shock front experiences a short period of acceleration before attaining the maximum velocity of $\sim 43 \mathrm{~mm} / \mu \mathrm{s}$ after approximately $75-100 \mathrm{~mm}$ of travel. The maximum velocity of $45.5 \mathrm{~mm} / \mu$ s obtained earlier ${ }^{10}$ occurred at $30.0 \mathrm{~mm}$ from the diaphragm. This higher velocity closer to the diaphragm is attributed to the diaphragm breaking $\sim 1.6 \mu$ s later than in the steel experiment. The later breakage time gives more time for radial convergence in the compressor: higher radial stagnation pressures are the driving force for the air shock when the diaphragm does break. The earlier diaphragm break is attributed to much lower pressure axial shocks in the compressor section, 1.20 which result in the lower initial shock velocities observed for these two experiments. Although early diaphragm breakage occurs, there still exists the radial stagnation on axis in the throat of the compressor. Radial stagnation generates pressures in excess of $100 \mathrm{GPa}$ and causes highpressure gas flows that overtake the shock front at $75-100 \mathrm{~mm}$ down the pipe. The only consistent explanation for the different diaphragm break times is the variation in initial pressure in the compressor chamber before detonation. Table 5 clearly indicates that higher initial pressures of air in the chamber result consistently in later diaphragm break times.

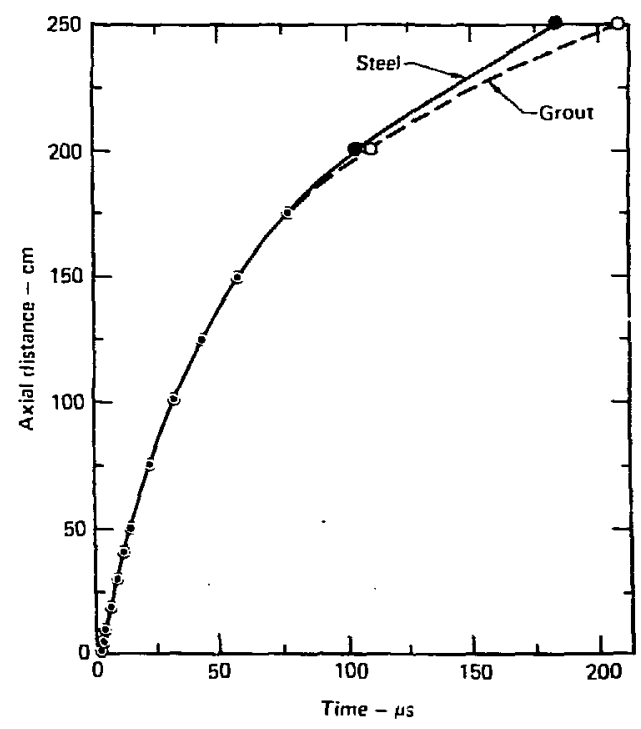

FIG. 28. Air-shock propagation in a steel and a grout pipe. 


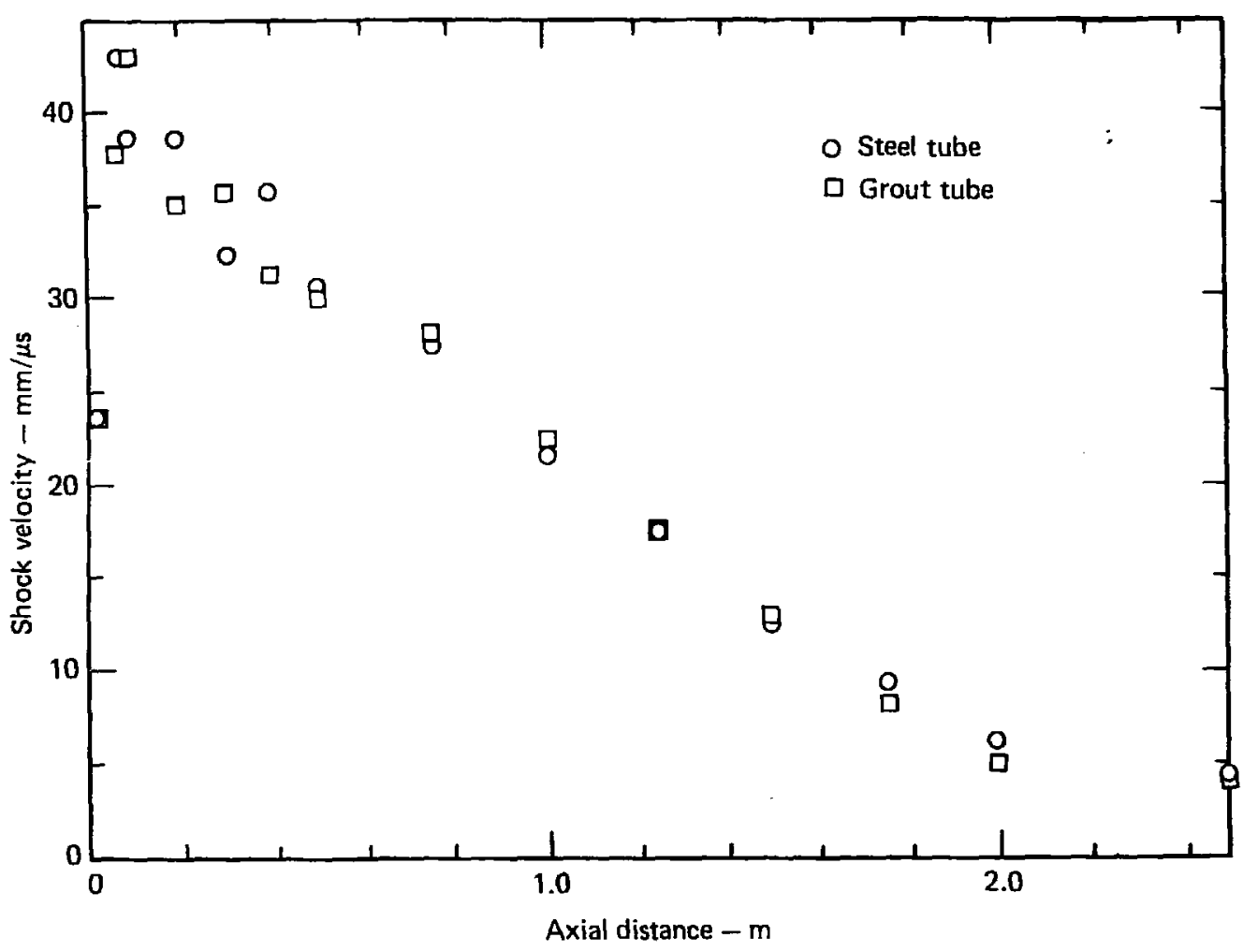

FIG. 29. Shock velocity vs axial distance for the steel and the grout shock-tube experiments.

Figure 29 also shows large variations in the velocity of the shock front between 0.10 and $0.40 \mathrm{~m}$. This appears to be a transient effect related to axial and radial oscillations generated initially in the compressor section. Beyond $0.40 \mathrm{~m}$, the shock velocities decrease in a smooth monotonic fashion. After $1.5 \mathrm{~m}$ of propagation the lower shock velocity in the grout experiment becomes evident, as expected from Fig. 28.

\section{PRESSURE PROFILE COMPARISON}

Other propagation similarities can be seen by comparing pressure profiles from the bar gages. Figure 30 shows the pressure profiles at $0.10 \mathrm{~m}$ from the diaphragm. Not only are the pressure peaks in relatively good agreement, but the general shape appears reproducible for $20 \mu$ s behind the shock front. Framing-camera coverage indicated that a small amount of venting around the bar gage at $0.10 \mathrm{~m}$ in the grout experiment occurred about $25 \mu$ s after the diaphragm burst, continuing until high-explosive gases obscured the field of view approximately $20 \mu$ s later. This may explain the reduction in the pressure profile observed at later times

TABLE 5. Comparison of initial air pressure in the compression chambers with diaphragm times.

\begin{tabular}{|c|c|c|}
\hline Experiment & $\begin{array}{c}\text { Chamber pressure } \\
\text { (MPa) }\end{array}$ & $\begin{array}{l}\text { Dinphragm time } \\
\text { ( } \mu s)\end{array}$ \\
\hline Steel (previous 10 ) & 1.160 & 59.7 \\
\hline Steel (present) & 1.100 & 58.1 \\
\hline Grout & 1.066 & 57.6 \\
\hline
\end{tabular}




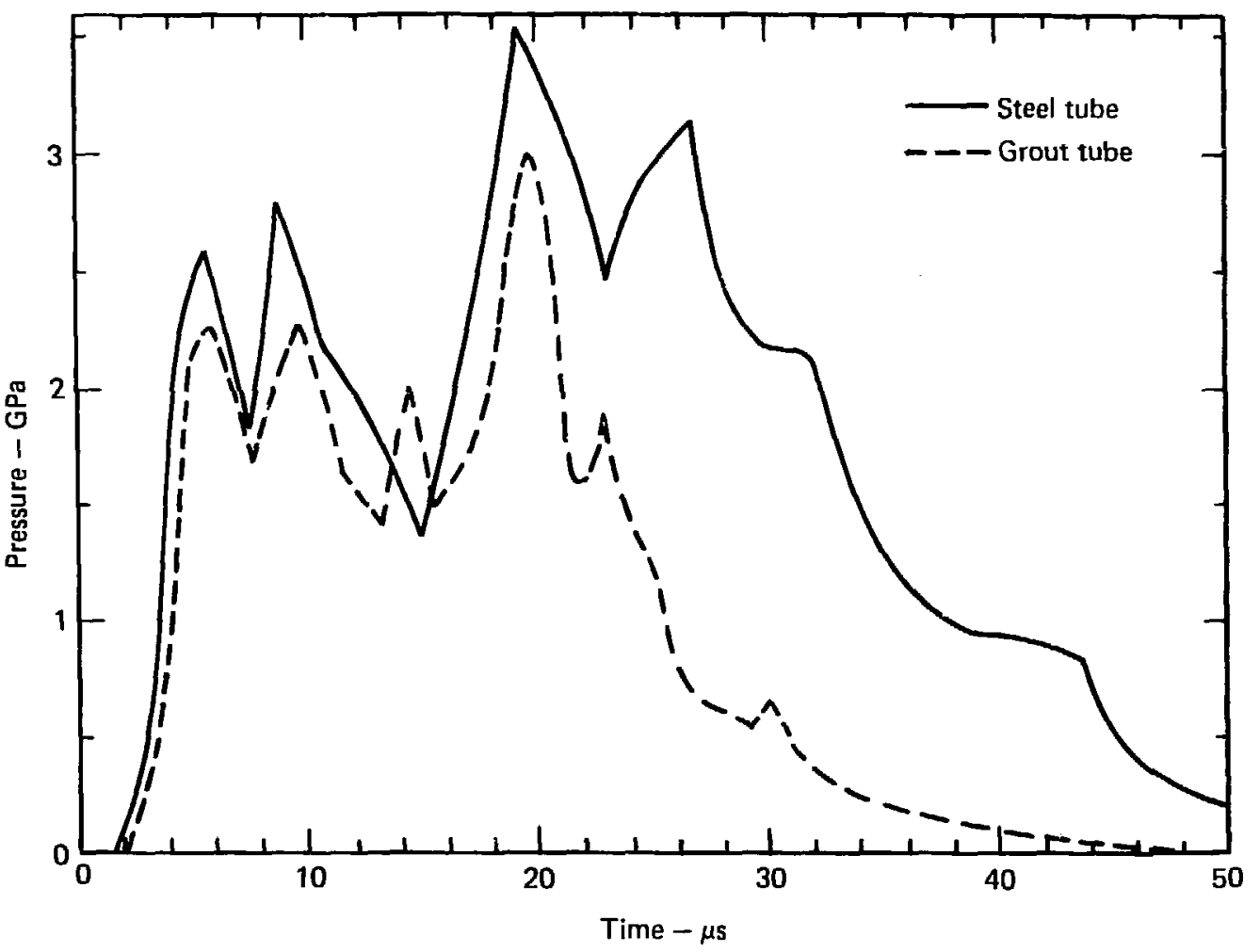

FIG. 30. Pressure profiles obtained with bar gages at $0.10 \mathrm{~m}$ from the diaphragms.

for the grout experiment. At the time venting was first detected, the shock front had reached $\sim 0.80 \mathrm{~m}$, so venting probably had little effect on conditions in and for some distance behind the front. However, this illustrates the similar initial conditions of the flow for both experiments.

Figures 31-36 show pressure profiles for bar

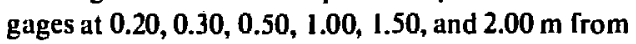
the diaphragm. Peak pressures associated with the shock front are in reasonable agreement, with possible exceptions at $0.30 \mathrm{~m}$ (Fig. 32) and $0.50 \mathrm{~m}$ (Fig. 33). At these locations the peak pressures for the grout experiment are nearly $50 \%$ larger, but have narrow pulse widths. The main difference in the pressure profiles at $0.20 \mathrm{~m}$ (Fig. 31 ) and beyond is that the pressures appear to oscillate far more rapidly for $10-15 \mu$ s behind the shock front in the grout experiment than in the steel experiment. An exception to this is the pressure profiles at $2.0 \mathrm{~m}$.
However, the bar gage at $2.0 \mathrm{~m}$ in the steel pipe was not in agreement with the PCB gage (Fig. 36) pressure profile, indicating a possible problem with the bar gage. One explanation for the rapid oscillations in the grout experiment is that radial wall motion caused a segment of the bar gage to protrude into the flow. This could cause localized flow stagnations that induced additional pressure oscillations. This effect applies only to the first two or three bar gages in the grout, since very little radial wall motion occurred around bar gages at $1.0 \mathrm{~m}$ and beyond. Since the rapid pressure oscillations were also observed in the flat-pack records, they are a real flow phenomenon and not a gage-related problem.

At $0.10 \mathrm{~m}$ much higher pressures were recorded in the steel experiment at late times (Fig. 30). The $35.5 \mathrm{GPa}$ peak at $19 \mu \mathrm{s}$ and the $31.6 \mathrm{GPa}$ peak at $26.7 \mu \mathrm{s}$ are greater in amplitude and broader in 


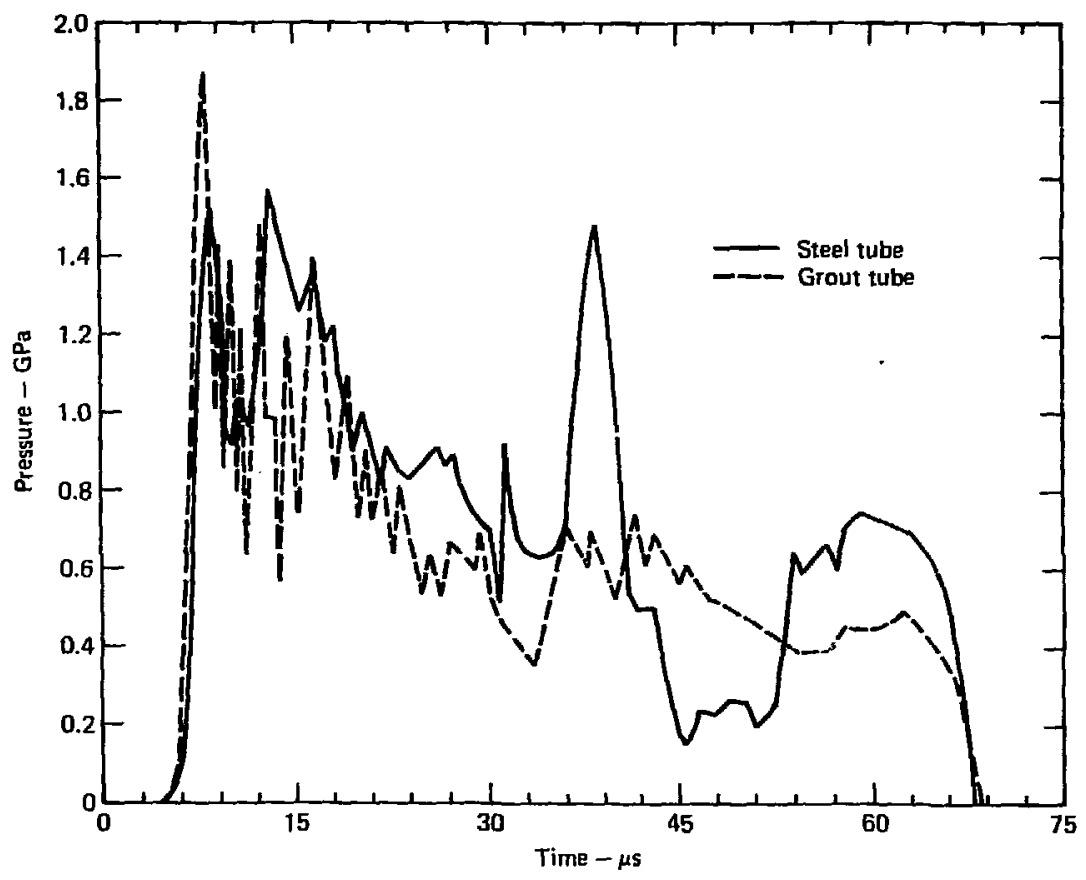

FIG. 31. Pressure profiles obtained with bar gages at $0.20 \mathrm{~m}$ from the diaphragms.

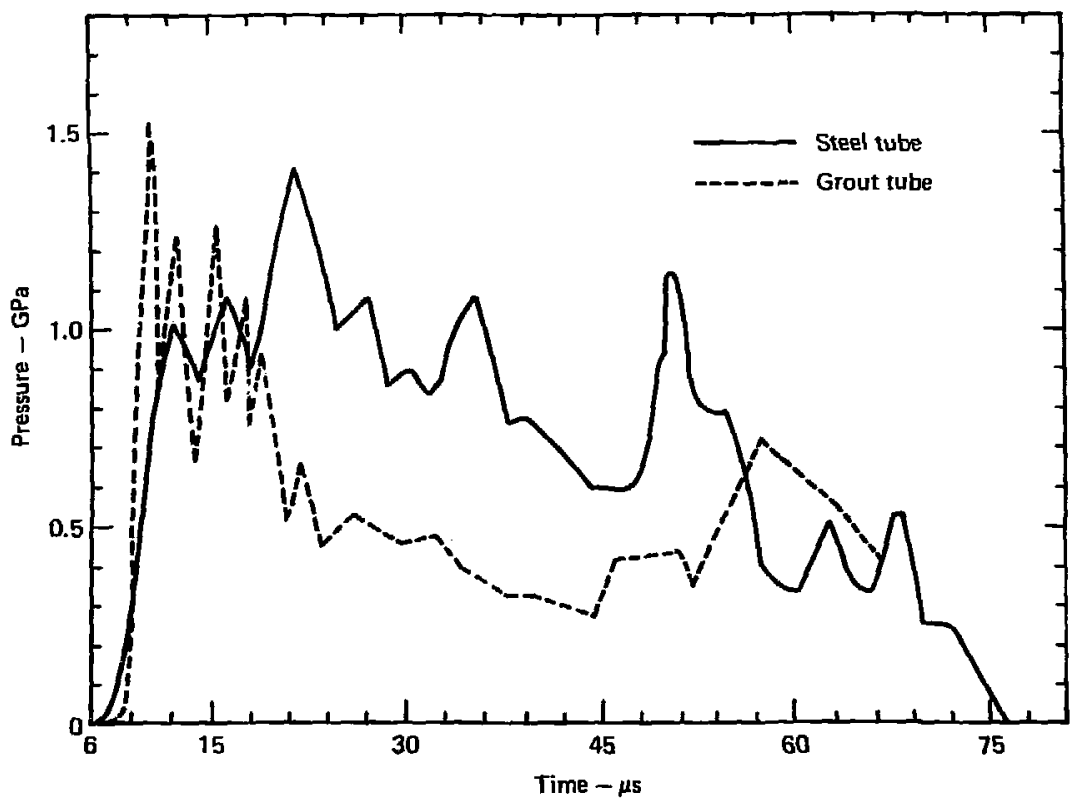

FIG. 32. Pressure profiles obtained with bar gages at 0.30 m from the diaphragms. 


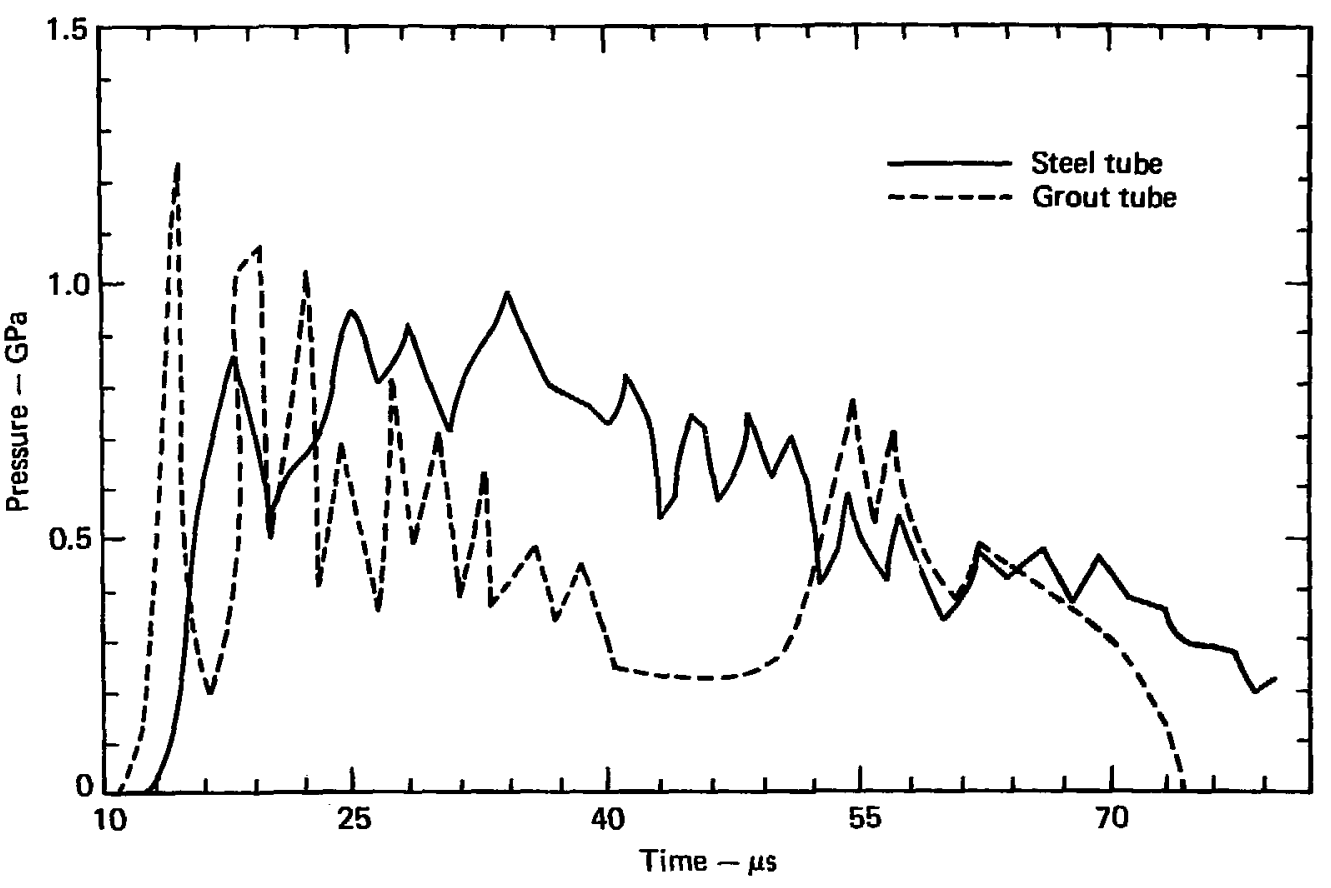

FIG. 33. Pressure profiles obtained with bar gages at $0.50 \mathrm{~m}$ from the diaphragms.

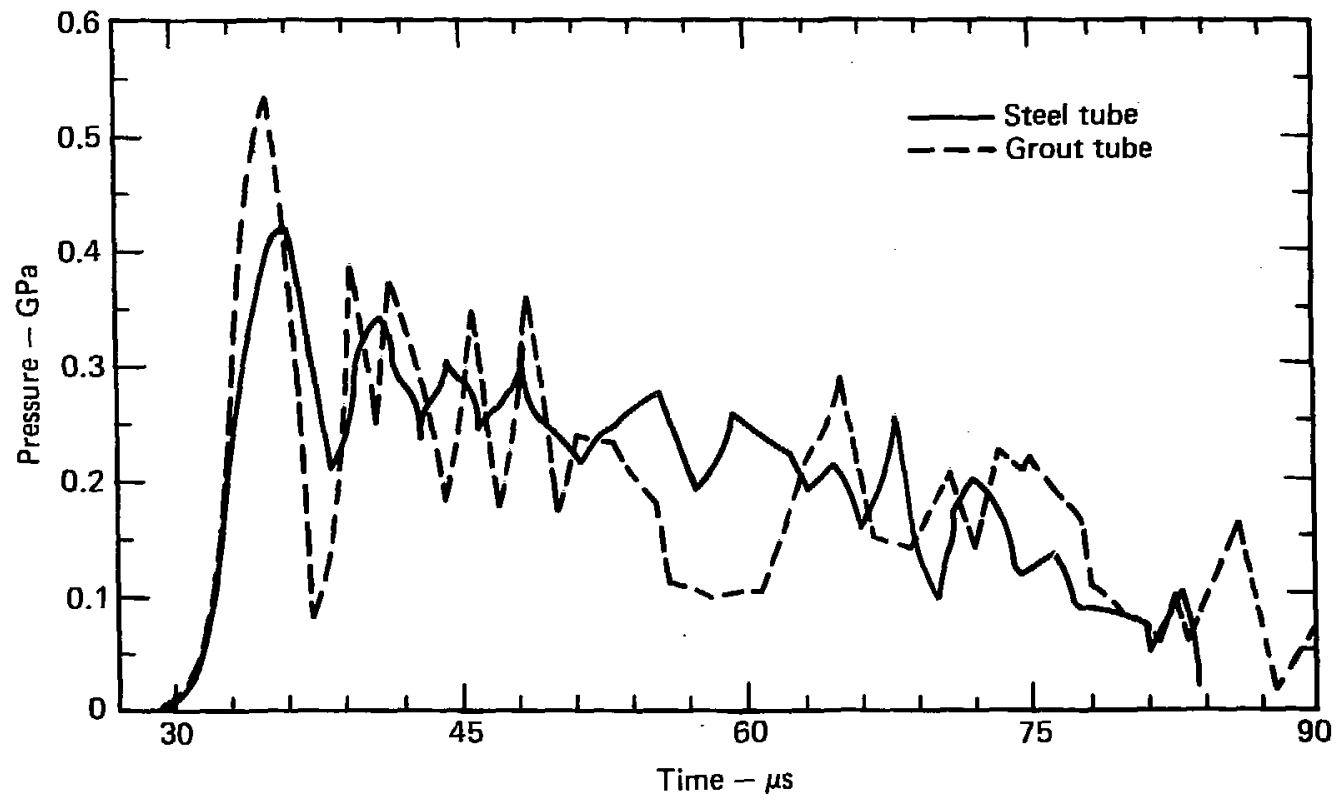

FIG. 34. Pressure profiles ohtained with bar gages at $1.00 \mathrm{~m}$ from the diaphragms. 


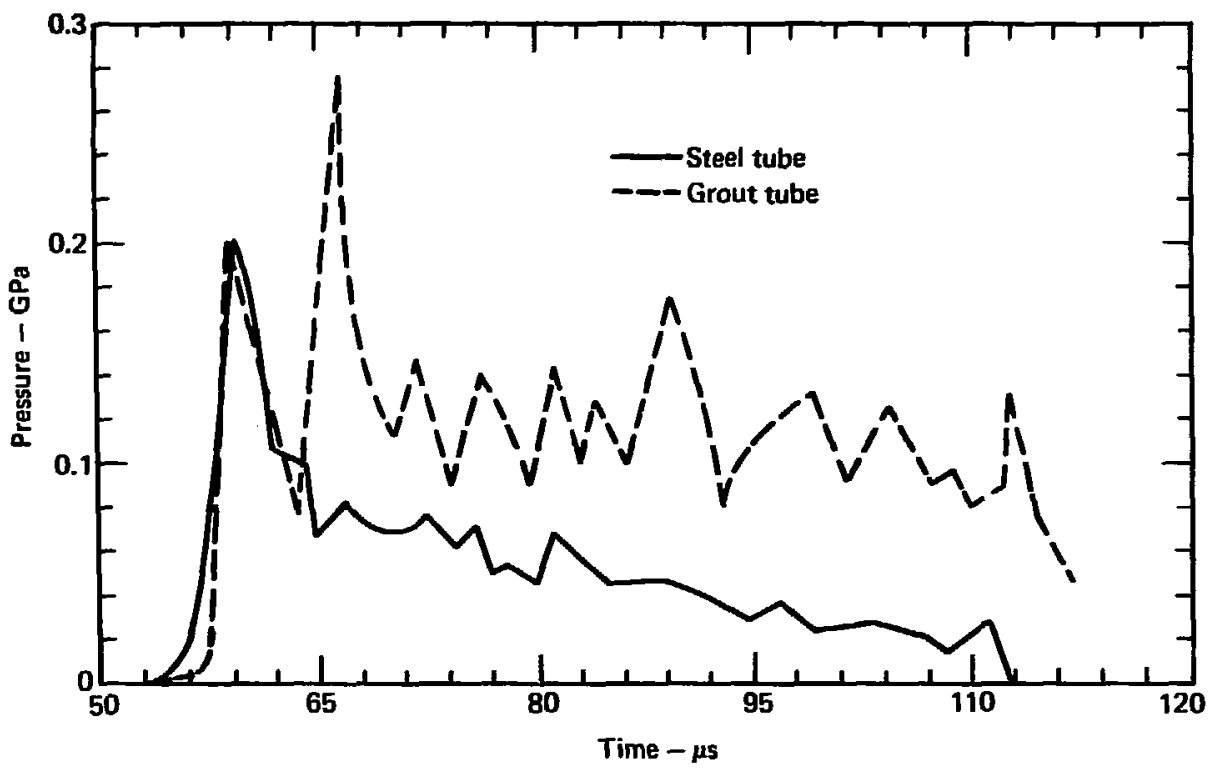

F1G. 35. Pressure profiles obtained with bar gages at $1.50 \mathrm{~m}$ from the diaphragms.

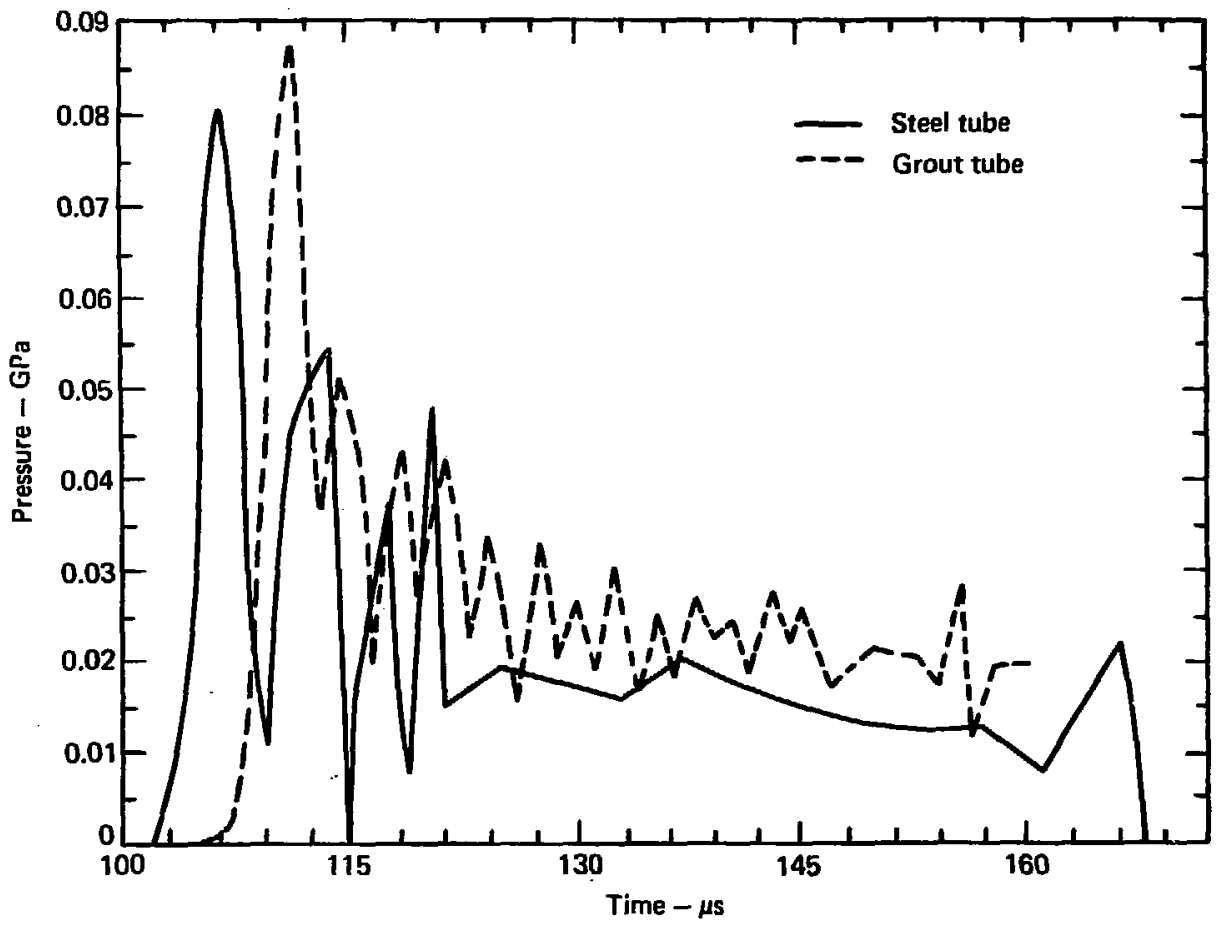

FIG. 36. Pressure profiles obtained with bar gages $\cdot 2.00 \mathrm{~m}$ from the diaphragms. 
pulse width than the corresponding peaks for the grout experiment. However, these peaks rapidly attenuate because of mass entrainment and disappear by $0.50 \mathrm{~m}$. In fact, the $31.6 \mathrm{GPa}$ peak was sufriciently delayed that it does not appear in the $\sim 60-\mu \mathrm{s}$ time window for the bar gage record at $0.50 \mathrm{~m}$. As the shock propagates down the outlet pipes, dispersion and attenuation caused by mass entrainment should slow down the high-pressure peaks behind the shock front so they do not appear in the $60 \mu \mathrm{s}$ time window for the bar gages. Since the first two pressure peaks for the bar gages in both experiments are roughly equal at $0.10 \mathrm{~m}$, we might expect the late time pressures to agree, ignoring the highfrequency oscillations for the grout experiment.
This apparently agrees with the late time profiles observed at $1.0 \mathrm{~m}$ (Fig. 34) and $2.0 \mathrm{~m}$ (Fig. 36). But this approach breaks down at $1.5 \mathrm{~m}$ (Fig. 35). Thus if the bar gage records at $1.5 \mathrm{~m}$ are correct, then a more complex explanation is needed to explain the now between 1.0 and $2.0 \mathrm{~m}$. At this time we have no explanation for this behavior.

Figure 37 illustratcs the iscay of the peak pressure in the shock front as a function of axial distance from the diaphragm. Although the peak pressures in the steel experiment are consistently lower than those for the grout experiment (except for the results at $0.10 \mathrm{~m}$ ), it is not known whether the differences are significant.

\section{SUMMARY AND CONCLUSIONS}

This report describes the experimental results for propagation of a high-energy air sirock in a steel pipe and in a grout pipe. In both experiments a Voitenko compressor was utilized to drive a $43 \mathrm{~mm} / \mu \mathrm{s}$ air shock down the outlet pipes which contained air initially at ambient pressures (0.1 MPa). There were two main reasons for conducting these experiments.

1) Prov te a database for normalization of existing ablation codes.

2) Obtain quantitative results for the relative attenuation effect of high-energy gas flow for two different wall materiais. The results obtained in both experiments are felt to be extensive enough to satisfy both objectives.

In the steel experiment the air shock propagated down a $20-\mathrm{mm}-\mathrm{i}$.d. bore for a distance of $6 \mathrm{~m}$. Fiver optics and pressure gages were installed along the pipe to monitor the air shock and gas flow. Results obtained with fiber optics indicated that the shock-front velocity attenuated from 43.5 to $1 \mathrm{~mm} / \mu$ s over approximately the first $5 \mathrm{~m}$. The greatest attenuation $(18.5 \mathrm{~mm} / \mu \mathrm{s} / \mathrm{m})$ occurred in the first $2 \mathrm{~m}$. Early studies contend that the dominant mechanism for attenuation of shock velocities in excess of $10 \mathrm{~mm} / \mu \mathrm{s}$ is ablation. Over the following $3 \mathrm{~m}$ of propagation the rate of attenuation $(1.83 \mathrm{~mm} / \mu \mathrm{s} / \mathrm{m})$ shows a dramatic decrease. The principal mechanisms for attenuation have been identified earlier as heat losses and fric- tion for velocities below $10 \mathrm{~mm} / \mu \mathrm{s}$, with ablation no longer an important factor.

The pressure profiles provided significant information about conditions in and behind the shock front. For example, the profiles showed that peak pressures in the shock front decay from $3.5 \mathrm{GPa}$ at $0.10 \mathrm{~m}$ to $0.09 \mathrm{GPa}$ at $2.0 \mathrm{~m}$, and to $0.008 \mathrm{GPa}$ at $5.0 \mathrm{~m}$ from the diaphragm. Although results show that the rate of decay for the peak pressure decreases substantially beyond $2 \mathrm{~m}$, there are no pressure records for the interval between 2 and $5 \mathrm{~m}$ to confirm where the break in the decay rate does occur. The large pressure oscillations observed behind the shock front are attributed to axial and radial oscillations of the flow induced by early diaphragm break and radial convergence of the driver gas in the compressor section. Pressure sensors indicate that the duration of the measiable now varied from $50 \mu \mathrm{s}$ at $0.10 \mathrm{~m}$ to over $300 \mu \mathrm{s}$ at $5.0 \mathrm{~m}$. The increase in duration of the flow was attributed primarily to the delayed entrainment of wall material in the flow resulting in a greater attenuation of the flow well behind the shock front.

Postsho: measurements on the surviving $5.85 \mathrm{~m}$ section of steel pipe showed that radial expansion of the $20 \mathrm{~mm}$ bore occurred over the first $2.5 \mathrm{~m}$. This is attributed to fow pressures behind the shock front. As the gas flow continues down the pipe the energy losses further cool the flow and condensation of entri ined wall material occurs. 


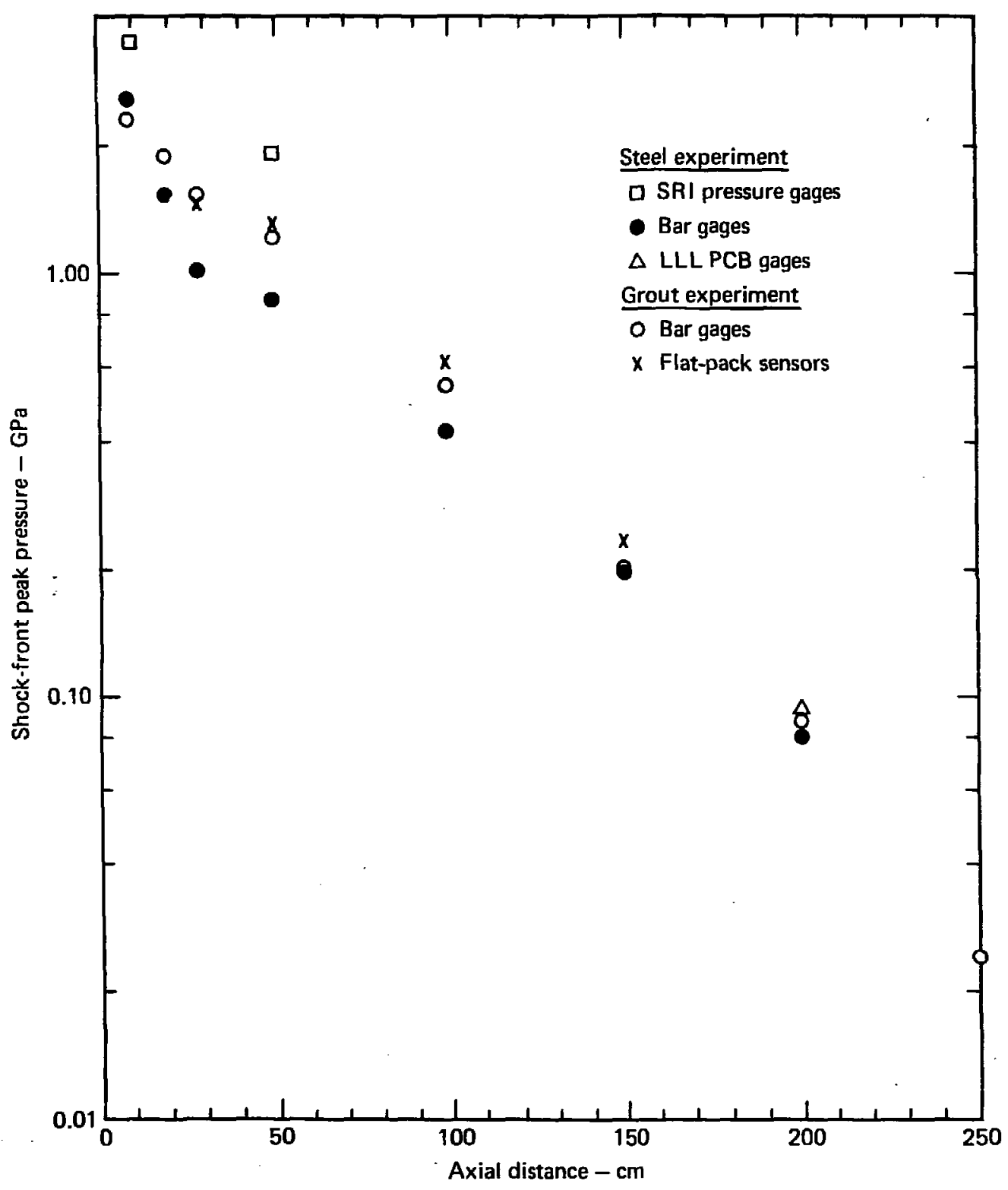

FIG. 37. Peak shock front pressure vs axial distance from the diaphragms. 
Measurements indicated that $\sim 0.34 \mathrm{~kg}$ of entrained wall material was deposited on the pipe walls beIween 2.5 and $4.35 \mathrm{~m}$ from the diaphragm. The value of $0.34 \mathrm{~kg}$ is approximately an order of magnitude greater than earlier ablation calculations predicted. The scouring model is given as a possible entrainment mechanism to explain this discrepancy. This model assumes that turbulence behind the shock front scours melted material off the wall and entrains it in the gas flow as small droplets. Scouring may also be the dominant entrainment mechanism well behind the shock front where temperatures and specific energies are much lower. Significant scouring may even occur late in time when HE gases act as a carrier for the droplets. Estimates of total energy in the gas flow from previous calculations suggest that an entrainment mechanism (e.g., scouring) other than ablation is needed to explain the value of $0.34 \mathrm{~kg}$.

For the grout experiment, the Voitenko compressor and first $0.15 \mathrm{~m}$ of the outlet pipe are identical in design with the steel experiment. Following diaphragm breakage the air shock propagates down the 20-mm-i.d. bore for a distance of $3 \mathrm{~m}$, where the Final $\sim 2.85 \mathrm{~m}$ of outlet pipe is constructed of DR-1 grout. Over the first $2.5 \mathrm{~m}$, fiber optics and bar gages were installed at the same axial distances as used in the steel experiment in order to facilitate a one-to-one comparison between the experiments. The grout pipe also allowed the use of flat-pack pressure gages, wall-motion gages, plasma-flow velocity measurements, and conductivity measurements. The flat-pack and wall-motion gages were installed at the same axial locations in the grout section as seven of the bar gages to help correlate experimental results.

The results obtained with fiber optics indicated that the shock front velocity attenuated from 43 to $4 \mathrm{~mm} / \mu \mathrm{s}$ over approximately $2.5 \mathrm{~m}$ of propagation. Unlike the steel experiment, no comparable study exists for a Voitenko-generated air shock to identify the mechanism of attenuation in a shock tube with grout walls. The only other relevant studies in the open literature are for the Marvel experiment, which indicated that the delayed entrainment of ablated wall material was the dominant mechanism for attenuation of the air shock. In Marvel, the 1-mdiam pipe was transite surrounded by a grout medium similar to the present experiment.
Pressure profiles indicate that peak pressures for the shock front decuyed from $2.28 \mathrm{GPa}$ at $0.10 \mathrm{~m}$ to $0.087 \mathrm{GPa}$ at $2.0 \mathrm{~m}$ from the diaphragm. The value at $0.10 \mathrm{~m}$ was obtained with a bar gage because (unlike the steel experiment) no piezoresistance gage was used at this location. In general, there was good agreement between the pressure profiles obtained with the bar gage and the flat-pack gages. The pressure profiles showed a larger and more rapid oscillatory behavior for gas flow in the grout experiment than in the steel experiment. This may have been caused by protrusions of the first two or three bar gages into the flow as radial wall expansion occurs. The entrainment of relatively cold wail material in the flow should have a rapid damping effect on such oscillations. But the persistance of the oscillation is a strong argument for the delayed entrainment of wall material into the flow. If we limit correlation of the pressure profiles to the first two oscillations. then mass entrainment does not appear to be an important factor for at least $4-6 \mu$ s behind the shock front. Radial wallmotion measurements in the grout experiment are consistent with the pressure profiles obtained. The rate of wall expansion is greatest during the first $10 \mu \mathrm{s}$ corresponding to the time of high-pressure oscillations behind the shock front. It then shows a uniform decrease with time that correlates with pressure decay behind the shock front. Postshot measurements of the bore diameter indicate that either the radial wall-motion measurements at $\mathbf{0 . 5 0}$ and $1.00 \mathrm{~m}$ are low, or significant wall motion occurred beyond the $100 \mu$ s duration of the wallmotion measurements. A combination of these alternatives is plausible. Postshot measurements indicate that radial expansion at $3.0 \mathrm{~m}$ was minimal $(<1 \mathrm{~mm})$. This suggests that significant attenuation occurred between 2.5 and $3.0 \mathrm{~m}$, since at $2.5 \mathrm{~m}$ a shock velocity of $\sim 4.5 \mathrm{~mm} / \mu \mathrm{s}$ was measured, with a peak shock-front pressure of $23.8 \mathrm{MPa}$.

The peak plasma flow velocity at $367 \mathrm{~mm}$ from the diaphragm was measured as $27.4 \mathrm{~mm} / \mu \mathrm{s}$. This is in good agreement with $29.0 \mathrm{~mm} / \mu \mathrm{s}$, which was obtained using the strong shock relation and the shock speed determined from other diagnostic sensors. Particularly interesting was the rate of decay behind the front. The flow velocity was reduced to one-half of its initial value by $9 \mu$ s following passage of the shock front. This may be of value in future 
numerical simulation studies. Plasma conductivity measurements were high, yielding a magnetic Reynolds number in excess of 60 . The high conductivity results required the use of a correction in experimental results for both the velocity and plasma resistance gages.

The close agreement of fiber optics TOA data and pressure histories over the first $2.5 \mathrm{~m}$ for the two experiments implies that propagation of the air shock is independent of the wall composition. This is surprising, since the density, material strength, atomic number, and atomic mass are signilicantly larger for steel than for grout. Such differences would be expected to affect the rate of radial wall motion, radiation diffusion, convective heat transfer, ablation and mass entrainment. Whether these phenomena combine in a positive or negative fashion will determine the effect on attenuation rate for the air shock. An example of a negative combination is radial wall motion. Although more rapid radial wall motion may attenuate the shock velocity by reducing pressures behind the shock front, it may increase the time for mass entrainment and thus reduce its effect as an attenuator.

Both the qualitative and quantitative results given here are more extensive than previous Voitenko studies of high-energy air shock propagation. In addition to shock TOA and velocity data, pressure profiles, wall motion, plasma flow velocity and conductivity histories, there are phenomena (e.g., condensation) not observed before. Previous studies assumed an instantaneous mixing of ablated wall material, but present results suggest that there is a $4-5 \mu$ s delay before significant mixing occurs. The most surprising result is that variation of wall material (i.e., steel vs grout) made little difference on the propagation of the shock front and subsequent gas flow over the $2.5 \mathrm{~m}$ of the comparison. Thus we feel that the results satisfied the experinental objectives. 


\section{APPENDIX A: GAGES}

The design, construction, and operation for three types of pressure gages and the will-motion gage are reviewed. The three pressure gages were the bar, piezoresistance, and nat-pack gages. Fifteen bar gages and four piezoresistance gages were used in the 6-m-long steel experiment (Table I). The 3-mi-long grout experiment used nine bar gages and seven flat-pack gages (Table 3). The grout experiment also used seven wallmotion gages at the same location as seven of the bar and flat-pack gages (Table 3 ).

\section{BAR GAGE}

Figure A-I shows a cross section of the bar gage. Each gage contained two 6.3-mm-dian rods (input and dump bars), with an X-cut quartz crystal mounted between the rods. A pressure pulse incident on the front of the input bar is transmitted down the bar through the quartz crystal and into the dump bar. As the pulse transits the quartz crystal, an electrical signal is generated proportional to the amplitude of the pressure. The pulse is reflected from the downstream end of the dump bar and transmitted bacl: to the crystal, thereby terminating the useful measurement time of the gage. The measurement period is determined by the length of the bars and the acoustic velocity in the bars. Both the input and dump bars were $\sim 152 \mathrm{~mm}$ ling. yielding a measurement period of $\sim 60 \mu \mathrm{s}$.

Bar gars can measure pressure pulses greater than the breaking stress of the quartzerysta! by using the acoustic mismatch of two dissimilar metals to reduce the pressure on the quartz transducer. ${ }^{15.16}$, If the inpedance of the input bar is greater than that of the dump bar, the pressure on the quarte crystal is iess than the pressure on the input bar. The first two gages in the steel experiment and the first three gages in the grout experiment had input bars of tungsten carbide and dump bars of titanium. These gages were capable of neasuring pressures in excess of $3.0 \mathrm{GPa}(30 \mathrm{~kb})$. The other gages had input bars of tungsten and dump bars of aluminum. These gages could measure pressures up to about $2.0 \mathrm{GPa}(20 \mathrm{~kb})$.

The bar assembly is supported on RTV washers in order to acoustically irolate the bars from the case. The electric signal is picked up from the quartz crystal by copper foil on the from face, and the dump bar on the back face. The Lucalox disk provides electrical isolation between the copper foii and input bar. The bars and crystals were assembled using epoxy at all the joints. Except for the stagnation gage in the two experiments, the front end of the input bars were machined to a $10 \mathrm{~mm}$ radius to conform to the pipe walls. The gages were positioned and adjusted so that the ends of the input bars were flush with the inside of the pipes.

The signal voltage is determined by the charge produced by the crystal and the capacitallee in parallel with the crystal. In the steel experiment, the bar gages were connected directly to oscilioscopes with approximately $\mathbf{4 6} \mathrm{m}$ of coaxial cable, with the cable itself (and the input capacitance of the oscilloscope) being the capacilance. To increase the signal levels (by decreasing the capacitance) on the last two gages in the grout experiment, voltage follower circuits were inserted in the signal cable near the experiment.

The gages were calibrated by dropping a steel ball bearing on the end of the input bar (with the axis of the gage vertical), then recording the rebound height of the ball bearing. The response of a gage was then determined from the heights of the fall and rebound, the mass of the ball bearing, the integral of the voltage pulse, and the capacitance across the crystal.

\section{PIEZORESISTANCE GAGE}

Figure A-2 is a cross section of the piezoresistance guge used in the steel experintent at $0.10,0.20$, 0.50 , and $1.00 \mathrm{~m}$ from the diaphragm. The sensor element consisted of a four-terminal piezoresistant grid operated in a current mode. The first two locations employed Manganin as the grid material and the last two 


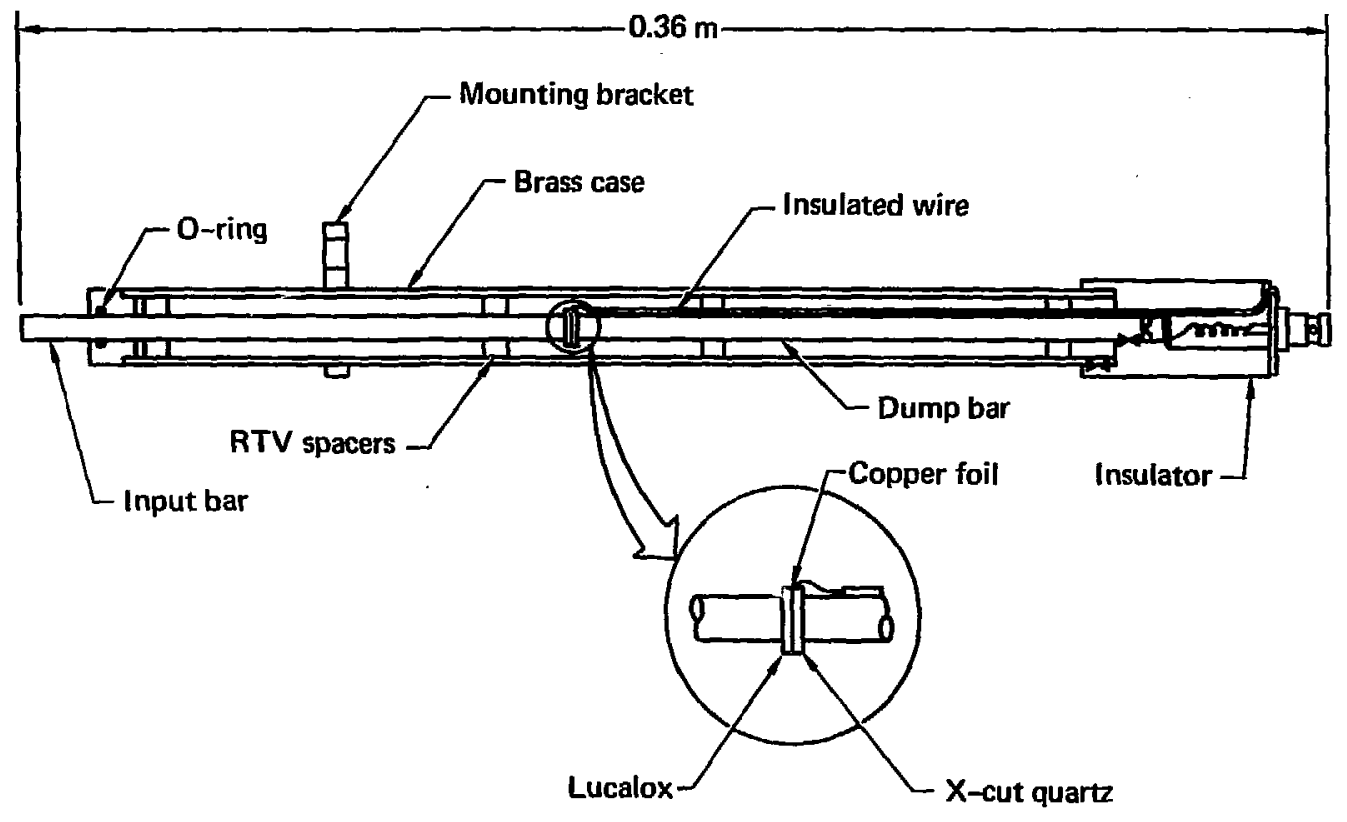

FIG. A-1. Cross section of bar gage. 


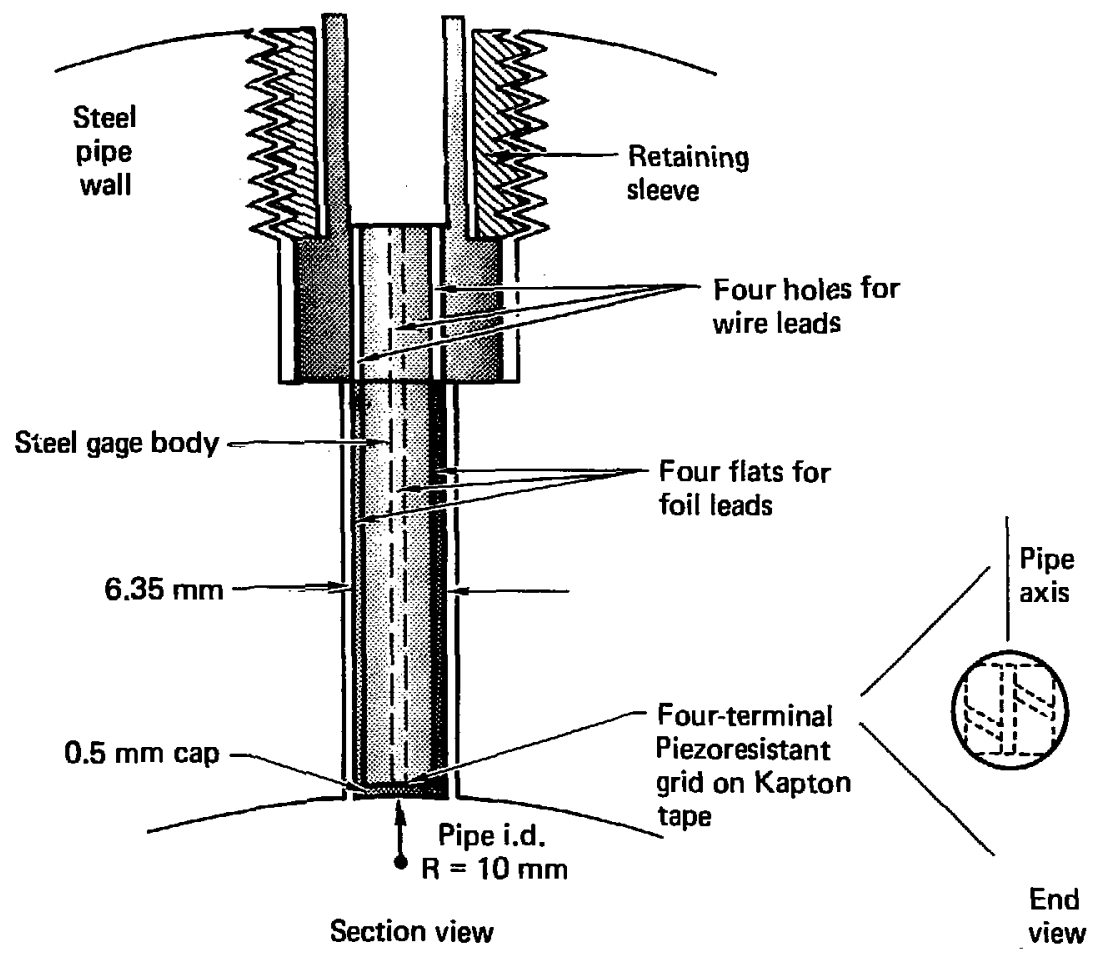

FIG. A-2. I-D Piezoresistant gage for steel pipe. 
Incations used ytterbium. The grids were sandwiched between Iwo layers of Kapton insulation and a $0.5-\mathrm{mm}$ thick steel cap was used over the end of the gage to provide temporary thermal protection in the high temperature flow. The end of the gage was ground to a $10 \mathrm{~mm}$ radius to match the $20 \mathrm{~mm}$ i.d. of the bore The cntire gage is secured in place by a threaded retaining sleeve, which prevents motion witt respect to the wall and acts as a gas seal. Failure of the gage to provide longer-duration pressure readings was caused by loss of continuity between the grid elements and cable leads.

\section{FLAT-PACK GAGE}

Figure A-3 shows a schematic of the flat-pack gage. This gage uses a piezoresistance element (Manganin or ytterbium) sandwiched between two 0.01 -mm-thick strips of Kapton insulation and two 0.60 mm-thick strips of steel. The steel strips are welded along their edges to provide a strong mechanical bond and act as a moisture seal for the grid area. The entire gage and junction with the cable are then epoxied for added moisture protection from the grout when it is added to the grout vessel. This appears to give adequate moisture protection since all gages functioned normally for the duration of the experiment.

The flat-pack gage was developed 'as a pressure sensor that would monitor the pressure associated with high-energy gas flow in a line-of-sight (LOS) pipe environment. Pressure associated with plasma flow in LOS pipes is sufficient to cause radial expansion of the pipe walls. The major problem is gage survival and reliable data recovery in an environment where the gage and cable are subject to high pressures, large radial displacements, and large tangential stresses that may induce significant strain effects. The three most vulnerable areas of the gage are thus the sensor, sensor-cable junction, and the cable itself. Each component must survive this environment and the system must minimize relative displacements that would disrupt the measurement. The flat-pack gage is designed ${ }^{14}$ to overcome these problems and has been used successfully in similar experiments.

\section{WALL-MOTION GAGE}

The mutual-inductance particle-velocity (wall-motion) gage consists of a number of closely wound primary and secondary turns of conducting wire forming a long rectangle. Consider a single primary and secondary loop as shown in Fig. A-4. Initially, the primary loop is excited with a large dc current. The secondary or sensor loop is linked by the magnetic field produced by the primary and develops the signal em 5 during gage operation. The gage is positioned in the material so that a longitudinal wave propagates along the long axis of the gage. As the wave propagates, material behind the wave front moves at the local particle velocity. The front of the gage (assumed to be in intimate contact with the medium) will also move at the particle velocity and the total length of the gage will decrease because of this motion.

The motion of the front of the sensor loop in the magnetic field produced by the current loop generates an emf, which can be related to the particle velocity at the front of the gage. In the present method, however, the front segment of the sensor loop moves in a nonuniform magnetic field. Since an identical motion of the current loop occurs and no relative motion of the two loops results, it is not immediately evident that an induced $\mathrm{em} \mathrm{f}$ will be developed. Careful consideration of the field contribution from current elements downstream from the gage front, however, reveals that magnetic flux is being cut.

With this type of magnetic gage it is easier to analyze the behavior in terms of the flux linkage or mutual inductance rather than from direct consideration of the magnetic field. A fundamental relation of electromagnetic theory, derivable directly from Maxwell's equations, relates the emf $\mathrm{\epsilon}$ developed in the sensor loop to the time rate of change of magnetic flux $\Phi$ linking the sensor loop (mks units are used throughout).

$$
\epsilon=-\frac{d \Phi}{d t} .
$$




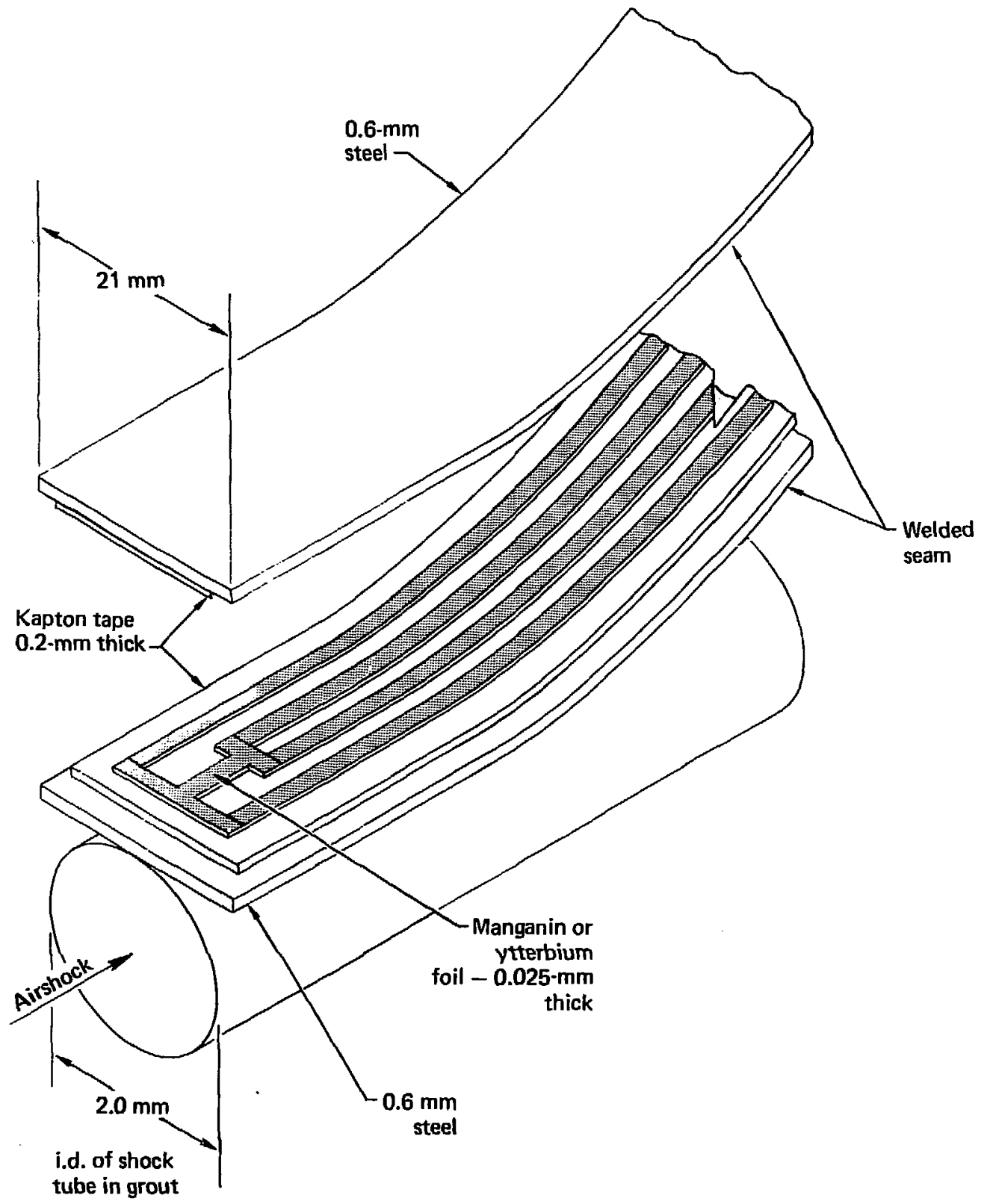

FIG. A-3. Flat-pack pressure gage for grout Voitenko experiment. 


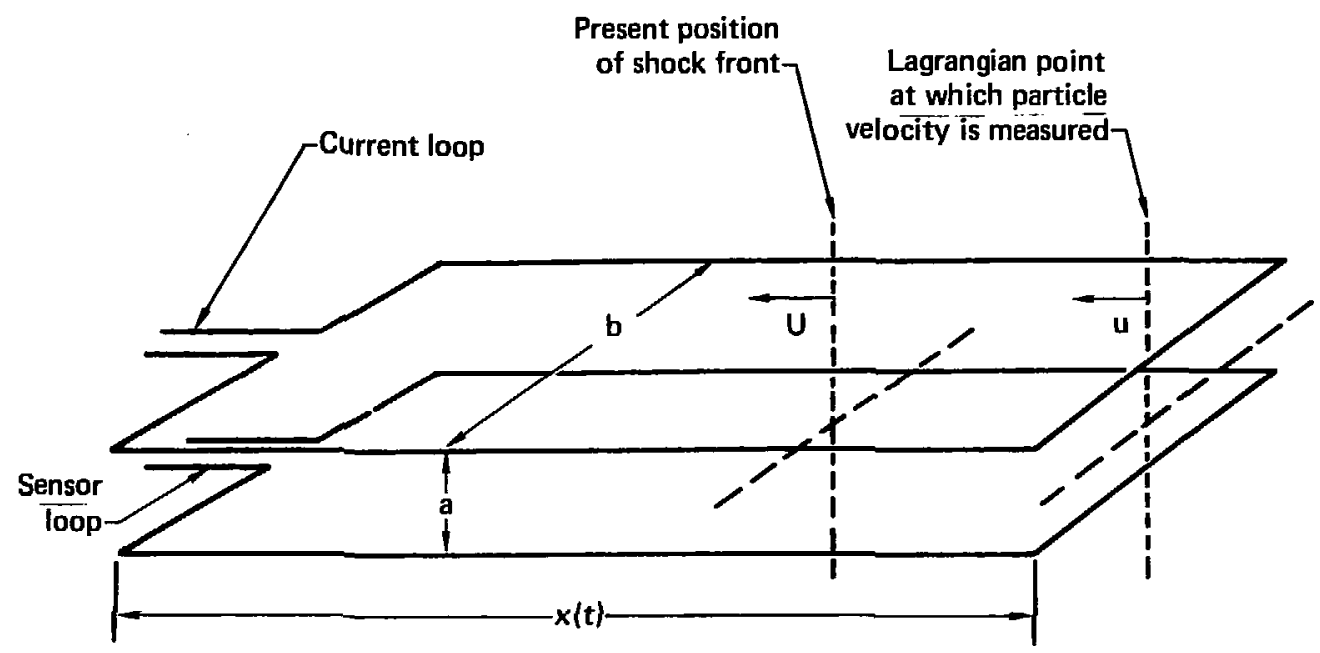

FIG. A-4. Idealized geometry for mutual inductance gage; $U$ is the shock velocity and $u$ is the particle velocity.

The magnetic flux $\Phi$ can be expressed as the product of the current in the primary I and the mutual inductance $M$ between the primary and secondary, resulting in

$$
\epsilon=-\frac{d(M I)}{d t} .
$$

The present transducer technique assumes that the gage is dc powered. Thus, 1 is time independent and

$$
E=-I \frac{d M}{d t} .
$$

Since the mutual inductance depends on time implicitly through the $x$ dependence of $M$ (see Fig. A-4), the emf becomes

$$
E=I \frac{d M}{d x} u,
$$

where $\mathrm{u}$ is the material particle velocity at the front plane of the gage and is assumed positive when directed as shown in Fig. A-4. When the gage is long compared to its lateral dimension, the term $\mathrm{dM} / \mathrm{dx}$ is nearly constarit and is equal to the total mutual inductance $M$ divided by the total length $\mathrm{x}_{\mathbf{0}}$.

When the necessary assumptions are satisfied, the quantity $1 \mathrm{dM} / \mathrm{dx}$ in Eq. (A-4) provides a constant gage factor that relates the induced emf to the instantaneous particle velocity at the front plane of the gage. Calibration requires measurement of this factor since in practice, the gage (Fig. A-5) contains a number of primary and secondary turns, making an analytic calculation of the factor impractical. 

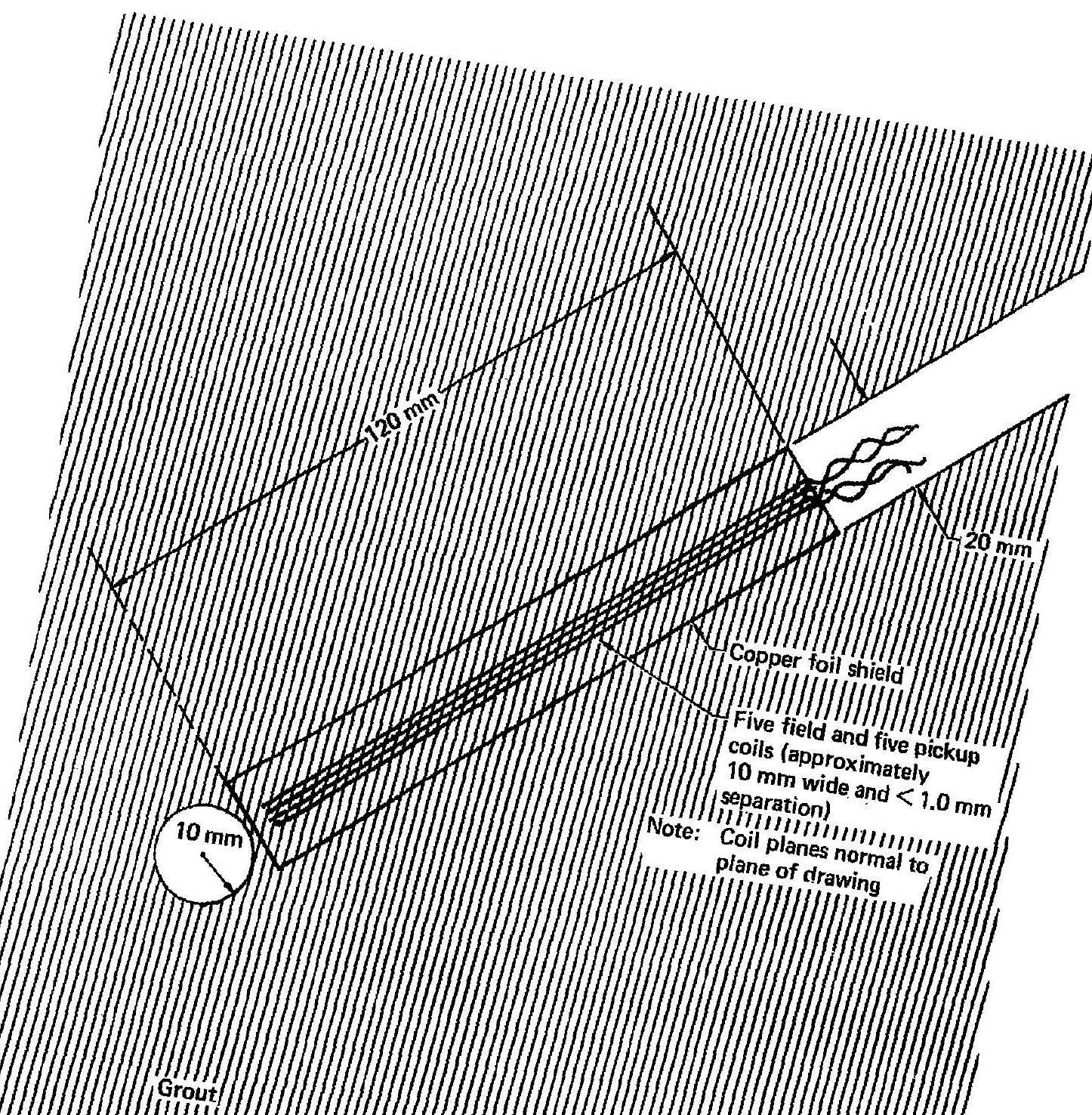


\section{APPENDIX B: GROUT SHOCK-TUBE CONSTRUCTION}

The grout shock tube was constructed in stages to accommodate the various sensors. A cylindrical steel frame is fabricated with four DR-1 grout disks in the center of the frame at regular intervals. Each disk is $19 \mathrm{~mm}$ thick, $152 \mathrm{~mm}$ o.d., with a $20 \mathrm{~mm}$ hole in the center. These disks are precast using Lucite forms and are kept wet prior to and after their installation in the steel frame. The grout disks ensure that no part of the steel frame comes within $66 \mathrm{~mm}$ of the $20-\mathrm{mm}$ bore wall. This eliminates any effect from the steel frame on wall motion induced by pressures in the plasma flow during the experimental times of interest. A 3-m-long, 19-mmo.d., 0.9-mm-thick copper tube covered with a $0.5-\mathrm{mm}$-thick heat-shrink plastic tube is then inserted through the four disks. This 20 -mm-o.d. copper and plastic tube, or bore tube, provides the form for the $20 \mathrm{~mm}$ bore through the grout section of the shock tube.

The magnets, coils, and copper probes for the particle velocity and conductivity measurements are then installed, supported by brackets mounted near the outer circumference of the steel frame. The flat-pack gages are then mounted, with the section containing the piezoresistant element in contact with and parallel to the bore tube. Figure B-I is a cross section of the over-all diagnostics emplacement plans. Steel brackets welded near the rim of the steel frame are used to support the flat-pack gages. All the cables for the sensors are tied to ribs of the steel frame and brought out the back of the frame where they are tied into a $\sim 80$-mm-diam bundle.
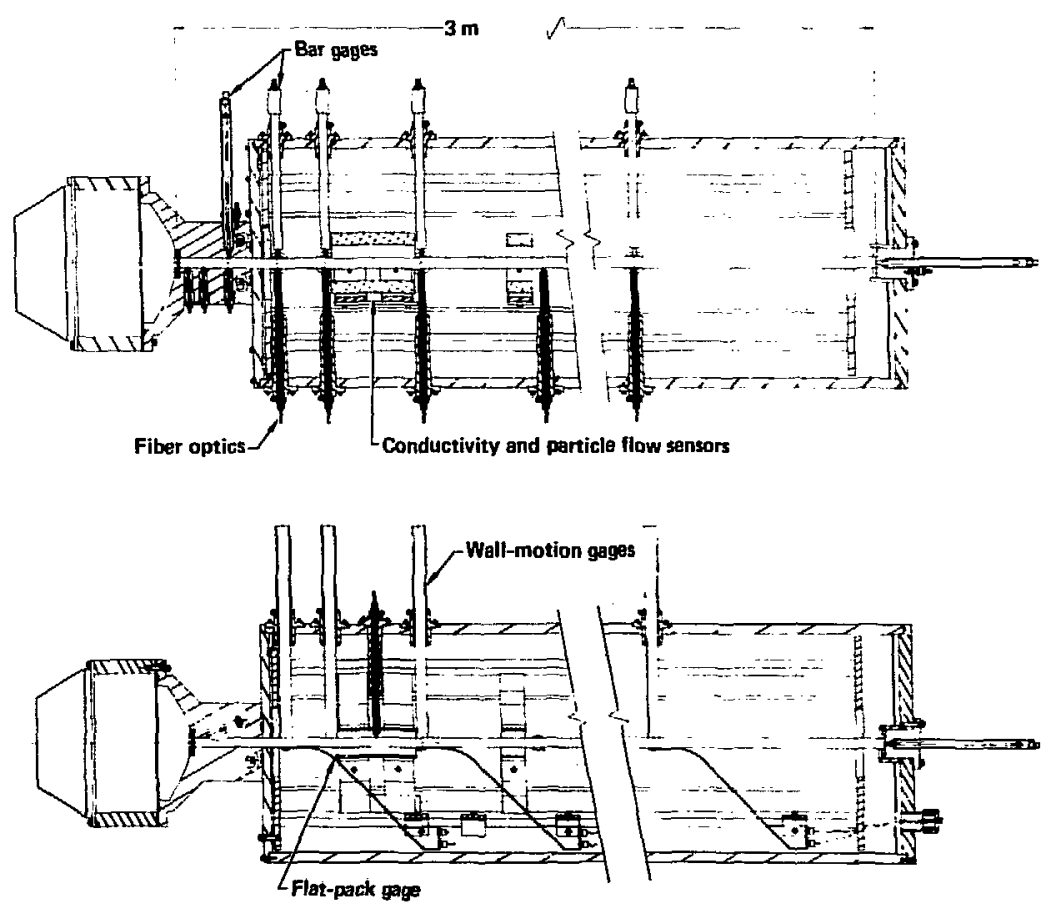

FIG. B-1. Compressor assembly, grout outlet pipe and diagnostics systems. 
Following installation of the sensors, the steel frame is inserted into a $0.508-\mathrm{m}$-o.d. steel pipe. Adjusting screws are used to center the $20-\mathrm{mm}$ bore tube. Then the fiber-optics assemblies and the bar- and wallmotion gages are inserted through ports in the steel pipe so the end of each sensor is in contact with the $20 \mathrm{~mm}$ bore tube. The cable bundle from the particle-velocity sensors, conductivity probes and fitt-pack gages are inserted through a $80-\mathrm{mm}$ hole in the rear end plate. Both the front and rear end plates are then mounted on the steel pipe and bolted in place, using $O$ rings to effect a seal. Then all sensor ports. :lignment ports, and the cable exit port are sealed with epoxy to provide an air-tight vessel. A vacuum roughing pump was altached to the vessel and any leaks detected were sealed with epoxy.

The vessel is then ready to be filled with DR-1 grout. A mixing tank ( $2.1 \mathrm{~m}$ high, $1 \mathrm{~m}$ diam) was constructed, and an electric motor with a 2-m-long shaft extending through the cover plate is mounted on the top of the mixing tank. Blades at the bottom of the shaft are used for mixing the DR-1 ingredients, which are added in proportions shown in Table B-1. To remove the entrained air, the grout is mixed at a reduced pressure of $0.5 \mathrm{MPa}$ for $2 \mathrm{~h}$. Al the same time a roughing pump reduces pressure in the shock vessel to less than $0.016 \mathrm{MPi}$.

Mixing and pouring the grout under reduced pressure added to the design complexity, fabrication time, and expense of the grout-tube experiment, but is necessary because the entrained air in the grout tends to migrate to the surface of the bore tube. This results in numerous air pockets of up $101 \mathrm{~mm}$ diam accumulating along the $20 \mathrm{~mm}$ bore wall of the grout section. A large number of air pockets in the bore wall would have a significant but unaccountable effect on the plasma flow. Preliminary tests showed that reducing the air pressure during the mixing and pouring phases removes entrained air.

For the filling operation, the mixing tank is lifted $1 \mathrm{~m}$ and the shock vessel is monitored with a stud pipe at the top of the shock vessel and Tygon tubing attached between the bottom and top of the front end plate. The grout is then allowed to cure for 6 wecks.

A week prior to the shot date a $0.33 \mathrm{~N}$ solution of nitric acid is circulated for $\sim 16 \mathrm{~h}$ through the bore tube to dissolve the copper tubing. The heat-shrink tubing is left in place to prevent drying out of the surface of the $\mathbf{2 0} \mathrm{mm}$ grout bore. Four days prior to the shot date the grout tube was transported to the Bunker 850 firing table at Site 300 of the Lawrence Livermore Laboratory. Final assembly of the shock tube and other test preparations then proceeded as described in the text.

TABLE B-1. DR-1 grout composition.21

\begin{tabular}{lcr}
\hline \multicolumn{1}{c}{ Ingredient } & \multicolumn{1}{c}{${\mathbf{b} / \mathrm{ft}^{3}}^{3}$} & $\%$ \\
\hline Calaveras I and II cement & 43.86 & 36.28 \\
Lone Star Lapis Lustre \#60M & 29.22 & 24.17 \\
Tamnsco silica Hour & 15.19 & 12.56 \\
Aqua Gel [baroid gel] & 1.75 & 1.45 \\
CFR-2 & 0.175 & 0.15 \\
Water & $\underline{30.70}$ & $\underline{25.39}$ \\
Total & 120.895 & 100.00 \\
\hline
\end{tabular}




\section{APPENDIX C: PLASMA FLOW VELOCITV AND CONDUCTIVITY GAGES}

An over-all view of the plasma flow and conductivily diagnostics is given in Fig. C-I. Two pairs of barium ferrite permanent magnets are used to provide a transverse magnetic field for the three meisurentent stations. The first pair is made of two rectangular pieces of barium ferrite, $178 \mathrm{~mm}$ long. $50.8 \mathrm{~mm}$ thick, and $25.4 \mathrm{~mm}$ wide, polarized to prodluce a uniform magnetic field transverse to the outlet pipe. The magnets were located $25.4 \mathrm{~mm}$ from the surface of the outlet pipe. The magnetic field of this configuration is $47.5 \mathrm{mT}$, as measured inside the outlet pipe, and provides the magnetic field for both the plas na velocity gage and the plasma resistance gage at 367 and $427 \mathrm{~mm}$ from the diaphragm, respectively.

The second pair of magnets, $100 \mathrm{~mm}$ long, $50.8 \mathrm{~mm}$ thick, and $25.4 \mathrm{~mm}$ wide, extend from 0.60 to $0.70 \mathrm{~m}$ along the outlet pipe. This magnet pair is closer to the outlet pipe, being only $12.7 \mathrm{~mm}$ from the surface of the pipe. The conductivity gage consists of a pickup loop $25 \mathrm{~mm}$ in diam and centered at $732.5 \mathrm{~mm}$, which is $32.5 \mathrm{~mm}$ from the end of the second pair of magnets and in the region of the exil magnetic field gradient.

\section{OPERATING PRINCIPLES}

Each electrode pair along the channel operates as a simple Faraday generator (Fig. C-2) with the conductive plasma nowing through a transverse magnet ic fiesd inducing a mutually orthogonal electric field. Electrodes in contact with the plasma sense the voltage difference across the channel and produce a current in an external circuit. The induced voltage $V_{0}$ seen by the electrodes is equal to the product of the magnetic field strength $B$, plasma flow velccity $u$, and the electrode separation $b$. When a current is allowed to flow in an external circuit the measured electrode voltage is reduced by the $\mathrm{i}_{\mathrm{i}}$ voltage caused by the internal plasma resistance $\mathbf{R}_{i}$. Thus the output voltage $V$ of a Faraday generator $c$ an be written as

$$
\mathbf{v}=\mathbf{v}_{0}-\mathbf{i} \mathbf{R}_{\mathbf{i}}
$$

where $\mathrm{V}_{0}=\mathrm{Bbu}$.

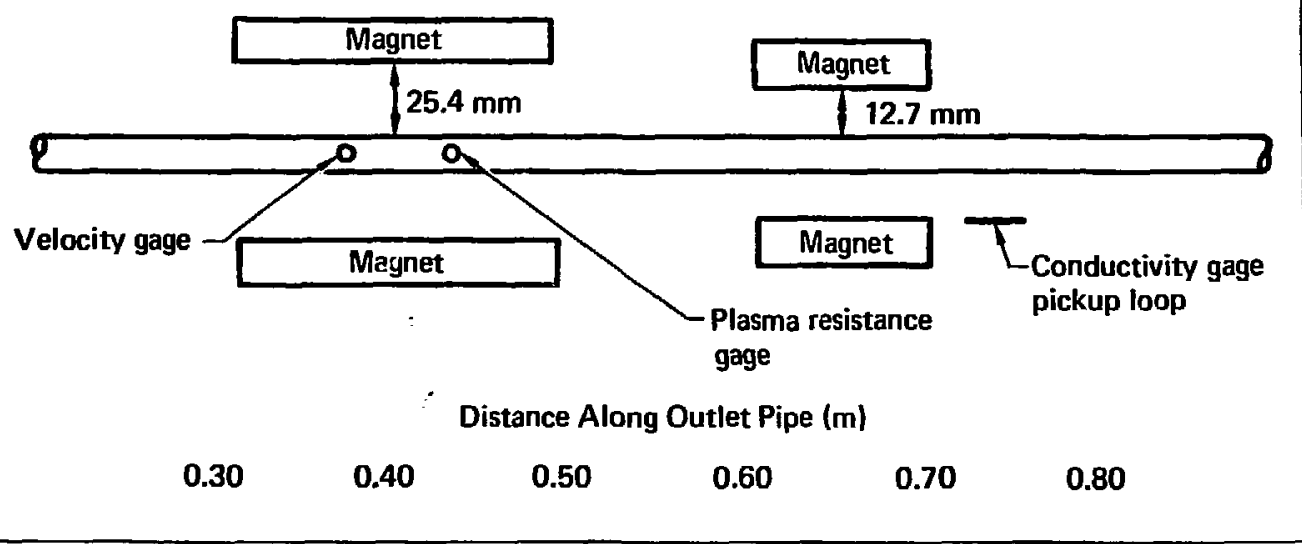

FIG. C-I. Configuration and layout of diagnostics for Voitenko compressor grout experiment. 


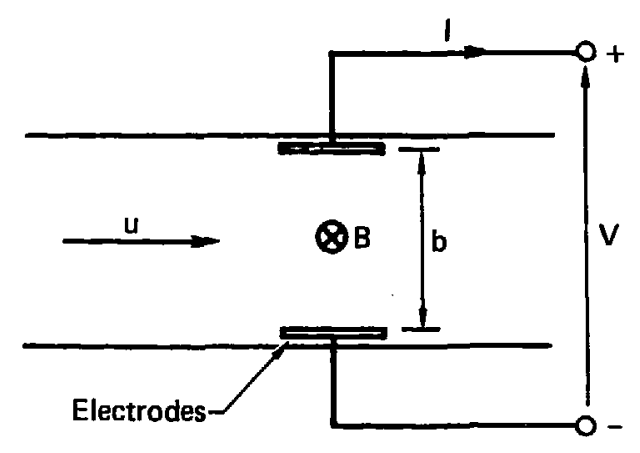

FIG. C-2. Simplified schematic of Faraday mhd
generator.

The velocity-gage configuration used at the $367 \mathrm{~mm}$ location is operated as a simple open-circuit generator. For an extcrnal circuit load such that $\mathrm{i} \rightarrow 0$, the internal plasma voltage drop $\mathrm{iR}_{\mathbf{i}}$ becomes much less than $V_{0}$, and then $V=V_{0}=B b u$. The time-dependent plasma velocity can then be determined directly from

$$
u(t)=\frac{v_{0}(t)}{B b}
$$

where $B$ and $b$ have constant values. In the experiment an external cable termination of $50 \Omega$ serves as the load and by comparison with the plasma resistance (on the order of $10 \mathrm{~m} \Omega$ ) satisfies the negligible internal voltagedrop requirement.

The electrode pair at $\mathbf{4 2 7} \mathrm{mm}$ is operated as a Faraday generator having an external electrical load of approximately the same resistance as the plasma. A thin strip of stainless steel is connected between the electrodes to provide a resistance load of $10 \mathrm{~m} \Omega$. The voltage $V$ across the electrodes is measured directly and the load current is measured independently by a search coil inside the open loop in the stainless-steel load. Fronı Eq. (C-1) the plasma resistance history can be determined from independent measurements of $V, v_{0}$, and $i$. The measurement of $V_{0}$ is taken from an open-circuit velocity gage. The time difference between the two diagnostic locations in this measurement is taken into account.

To relate the plasma resistance to the effective conductivity, a factor $\mathbf{r}$ must be determined for the electrode and channel geometry. This factor was determined in the laboratory using a channel mockup and electrolytic solution of known conductivity. The plasma effective conductivity $\sigma$ is then determined from plasma resistance by $\sigma=\Gamma / \mathbf{R}_{\mathbf{i}}$.

The third diagnostic in the outlet pipe determined the plasma conductivity from an eddy-current measurement. When the piasma flows through an axial gradient in the magnetic field, there will also be an axial gradient in the MHD voltage, resulting in circulating currents in the vicinity of the gradient as shown. in Fig. C-3. A search coil outside the channel has an induced voltage from the variations in the magnetic fields produced by these eddy currents.

Output of the search coil is electronically integrated, so that it directly measures the field perturbation caused by the eddy currents

$$
\mathrm{V}=\mathrm{NA} \triangle \mathrm{B} / \boldsymbol{\tau},
$$



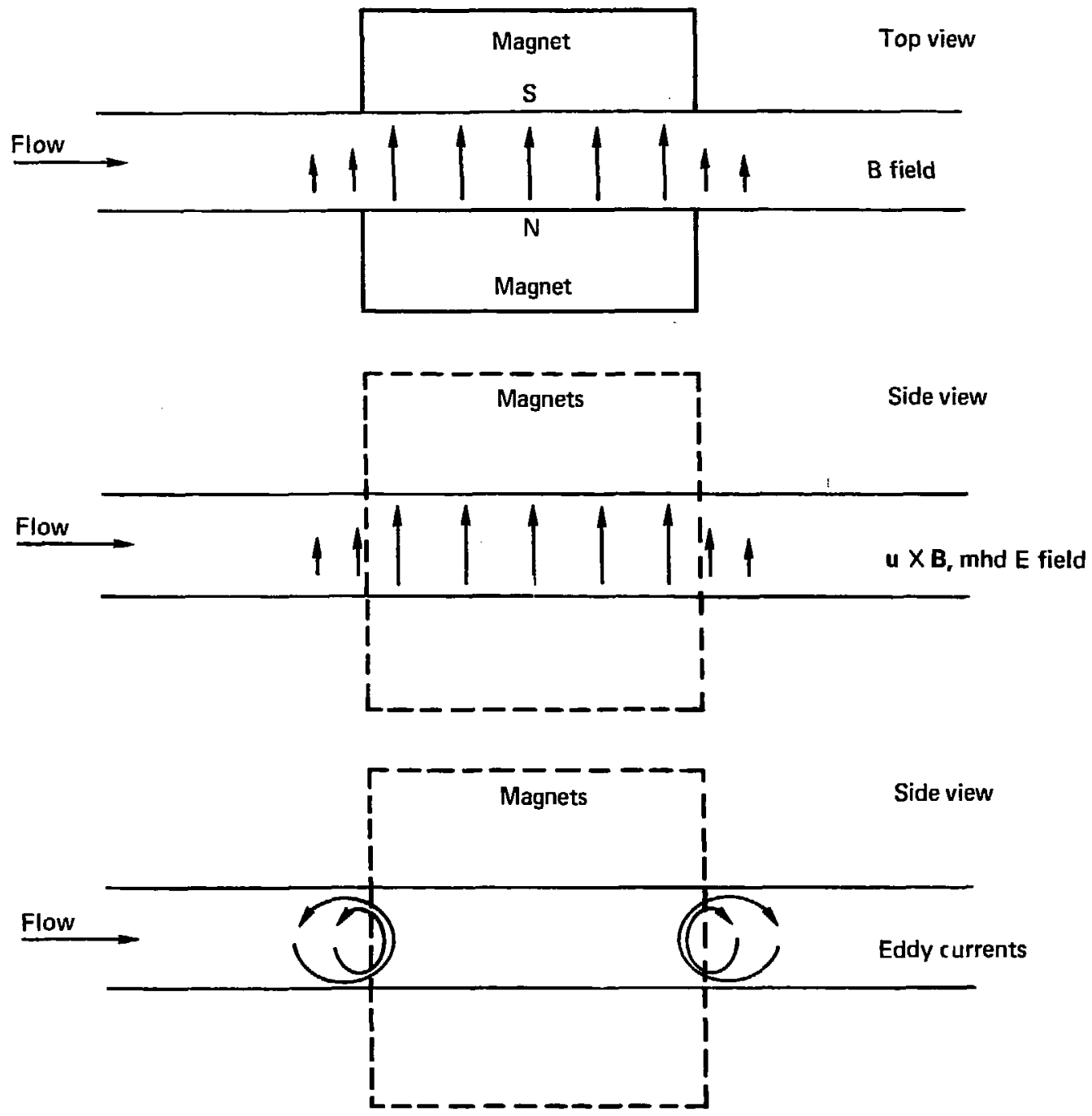

FIG. C-3. Illustration of eddy currents arising in plasma flow due to magnetic field gradient. 
where $A$ is the coil area, $\mathbf{N}$ is the number of turns, and $\tau$ is the integrator time constant. The magnetic field perturbation $\Delta B$ is a function of magnetic Reynolds number $R_{m}$ and is theoretically linear with $R_{m}$ at low values: Thus

$$
\Delta \mathrm{B}=\mathrm{f}\left(\mathbf{R}_{\mathrm{m}}\right)=\mathrm{f}\left(\mu_{0} \sigma \mathrm{ub}\right)
$$

The conductivity gage is calibrated in the laboratory by firing a compressed-air-driven aluminum rod through a mockup of the gage configuration. A Lexan tube serves as the channel, with the magnets and the search coil set up in the geometry to be used on the shot. The rod is propelled through the mockup at different speeds and the integrated search-coil output is measured.

From the measured rod speed a plot is made of the search-coil output vs rod speed. Since the same output signal levels imply the same magnetic Reynolds number, or $\sigma u$, the plasma conductivity is obtained from

$$
\sigma_{p}=\frac{\sigma_{L} \mathbf{u}_{L}}{u_{p}},
$$

where the subscripts $L$ and p refer to laboratory rod and plasma parameters, respectively.

\section{PLASMA-VELOCITY GAGE}

The electrodes used to measure the plasma velocity are located at $367 \mathrm{~mm}$ along the outlet pipe. An end view of the gage and magnet configuration is shown in Fig. C-4. The barium ferrite magnets are held in place by two pieces of slotted Lexan. Two electrodes fabricated from brass rods are positioned normal to the magnetic field. Each electrode is $50.8 \mathrm{~mm}$ long, with a $6.37 \mathrm{~mm}$ diam at the outlet pipe surface. The electrodes are ground to a $10 \mathrm{~mm}$ radius so they are flush with the wall of the outlet pipe. The edges of the electrodes exposed to the plasma flow are rounded to a radius of $0.75 \mathrm{~mm}$. The design of the electrodes resulted from an attempt to minimize motion of the electrode during the time of the experiment, which was expected to occur for several tens of microseconds after shock arrival. The high pressure of the plasma flowing through the outlet pipe can cause significant expansion of the grout wall during times of interest. Because the velocity-gage calibration is dependent on a known spatial separation between the electrodes, it is important that the electrodes maintain that spacing during the experiment. Thus the electrodes were made long to given them a large areal density and thereby minimize their radial motion caused by the high-pressure plasma.

The voltage lead wires were attached to screws threaded into the end of each electrode. The signal was fired on RG58 coaxial cable through an isolation transformer and into an oscilloscope terminated with $50 \Omega$.

\section{PLASMA-RESISTANCE GAGE}

The plasma-resistance gage and the plasma-velocity gage operate in a similar manner. The difference is that a low-resistance electrical load is placed across the electrodes in the plasmaresistance gage. The electrodes shown in Figs. C-4 and C-5 are identical in size. But for the plasma-resistance gage, they are fabricaled from two lengths of different diameter brass held together with a pin. This allows the electrical load to be made from a thin piece of stainless steel inserted between the two lengths of brass. Good electrical contact is ensured by soldering the stainless steel to the brass. The stainless-steel strip is $0.25 \mathrm{~mm}$ thick and $10 \mathrm{~mm}$ wide. The resistance of the stainless-steel strip as measured between the two electrodes is $10 \mathrm{~m} \Omega$. As shown in Fig. C-5, a section of the stainless-steel strip is bent into a loop of nearly $360^{\circ}$. A search 


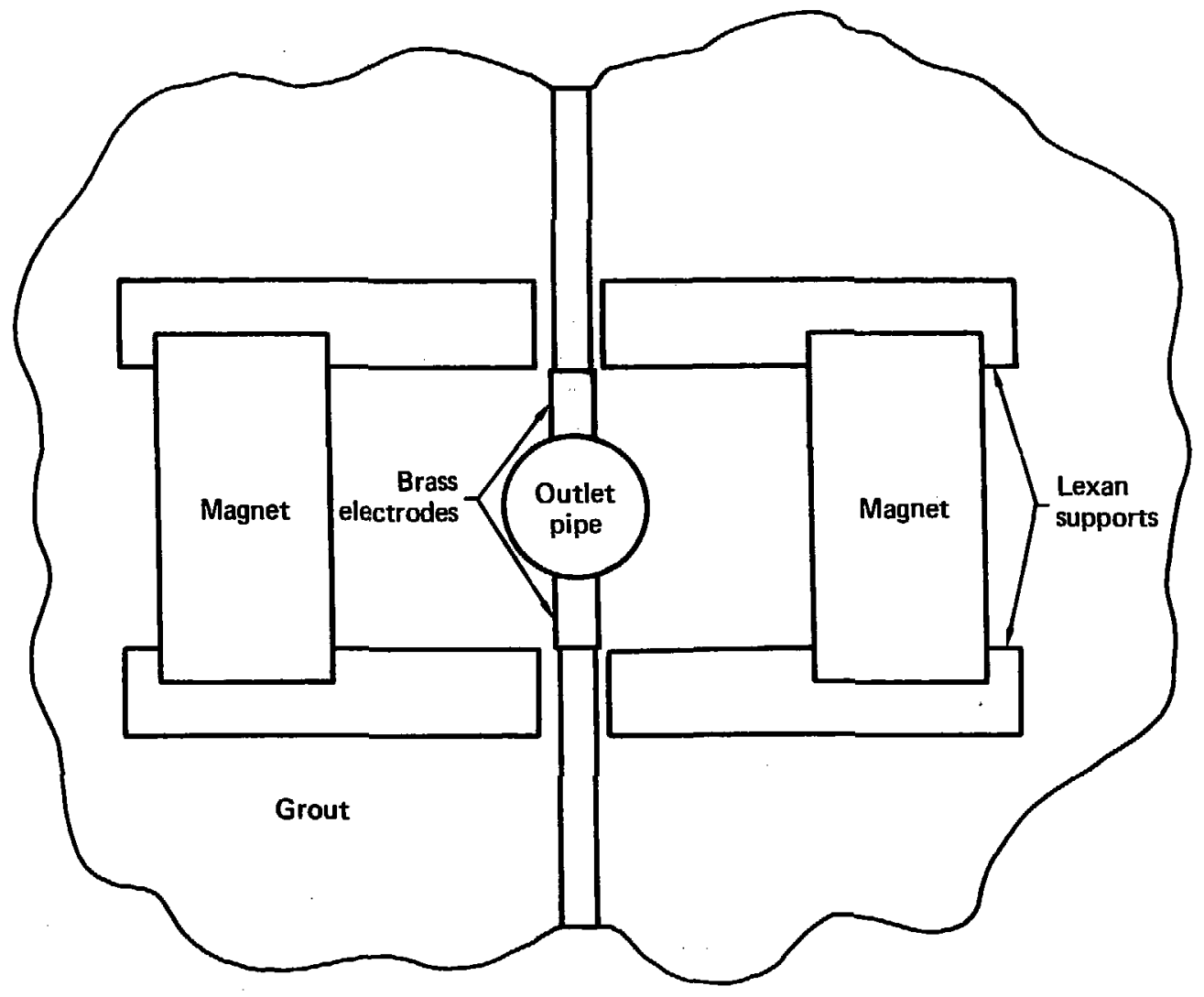

FIG. C-4. End view of layout for plasma-velocity gage. 


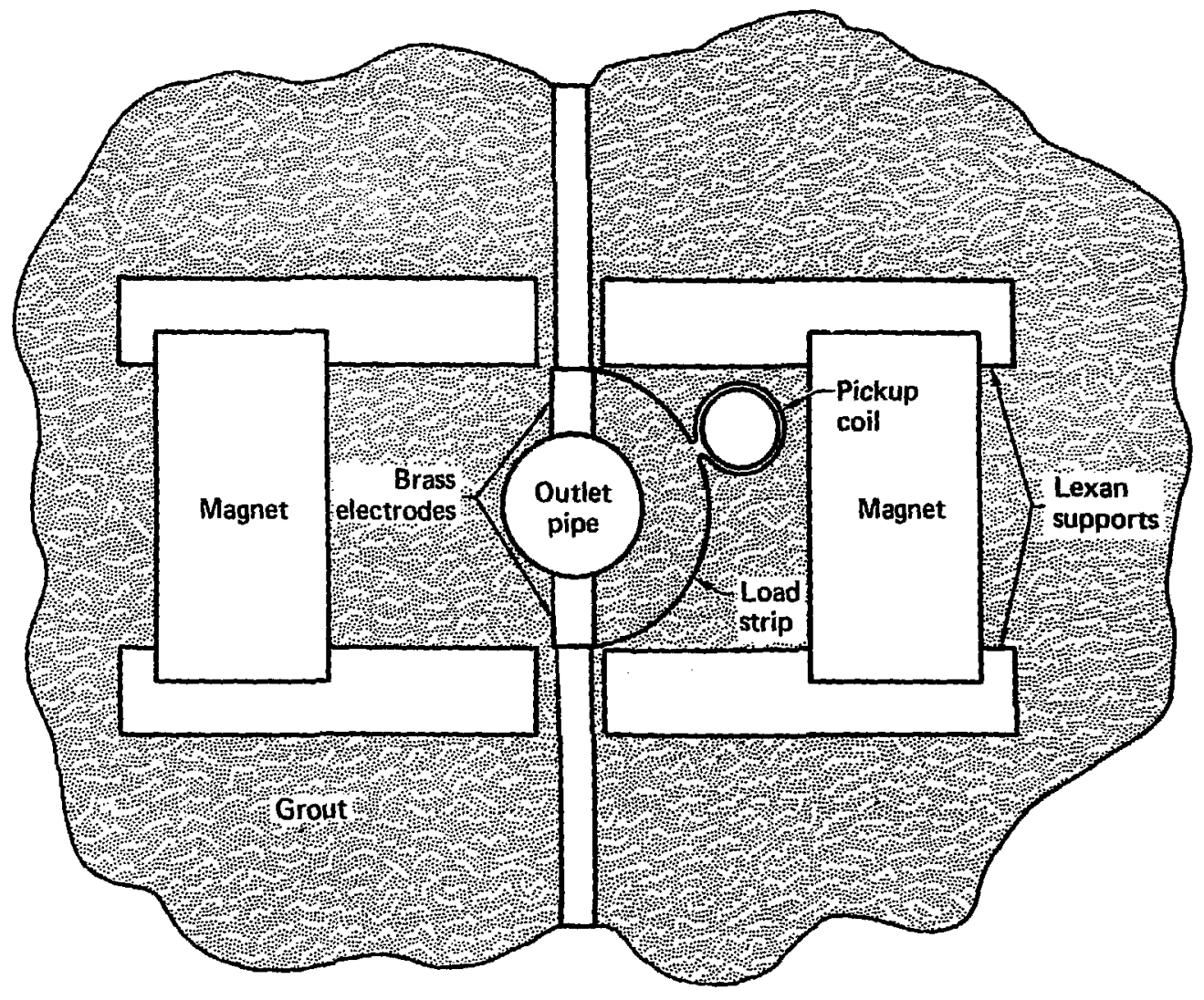

FIG. C-5. End view of layout for plasma-resistance gage. 
coil placed inside the loop measures the current flowing through the load. The voltage across the load is also measured by contacts directly on the electrodes. Independent measurements of load current and load voltage when combined with the open-circuit velocity gage measurement are sufficient to yield the plasma resistance. Figures $\mathbf{C}-4$ and $\mathrm{C}-5$ are plan views of the magnet and support structure at different axial locations.

Coaxial cable RG58 is used for the voltage and current measurements. The load voltage cable is run through an isolation transformer "then into an oscilloscope and terminated with $50 \Omega$. The cable from the load current pickup coil is run into an integrator with a built-in $50 \Omega$ terminator. The integrator allows the load current to be displayed directly as a function of time on the oscilloscope.

\section{PLASMA-CONDUCTIVITY GAGE}

The plasma-conductivity gage is based on an eddy-current principle. The pickup coil consists of 50 turns of wire wrapped around a $31.8-\mathrm{mm}$-diam rod. For mounting on the experiment, the rod is removed from the coil; the coil is then flattened to a minor diameter of $10 \mathrm{~mm}$. The upstream edge of the coil is placed $20 \mathrm{~mm}$ downstream of the barium ferrite magnets. The coil output is run through RG58 cable into an integrator with a $50 \Omega$ termination and then displayed on an oscilloscope. The use of the integrator allows the direct time history to be observed on the scope. The integrator used on the conductivity gage and on the load current is simple RC integrator circuits with time constants sufficient such that no correction is needed during the experiment.

\section{ACKNOWLEDGMENTS}

The authors are grateful to $G$. W. Ullich for his advice and support throughout the program and is C. Knowles, B. Hartenbaum, B. K. Killian, K. Pyatt, H. L. Brode, J. Thomsen, and G. R. Abrahamsor for their many valuable suggestions that contributed to the design of both experiments.

The authors are also deeply indebted to A. M. Ban for drafting support, N. W. Stewart for assistance in mechanical assembly of the shock tubes, C. H. Dittmore for processing and digital reduction of the films, L. F. Simmons and the 850 bunker crew for their excellent field support during both high-explosive tests. 


\section{REFERENCES}

1. B. K. Crowley and H. D. Glenn, "Numerical Simulation of a High-Energy (Mach 120 to 40) Air-Shock Experiment," in Proc. Seventh Intern. Shock Tube Symp., Toronto, Canada (23-25 June, 1969), pp. 314-342.

2. B. K. Crowley, H. D. Glenn, and R. E. Marks, "An Analysis of Marvel-A Nuclear Shock Tube Lxperiment," J. Geophys. Res. 76, 3356 (1971).

3. H. D. Glenn and B. K. Crowley, "Comparison of High-Energy Gas Flow Experiments," J. Appl. Phys. 42, 5517 (1971).

4. A. E. Voitenko, "Generation of High Speed Jets," Sov. Phys. Dokl, 9, 860 (1966).

5. H. D. Glenn, J. R. Barthel, and E. A. Day, Ablation Phenomena Associated with Line-of-Sight Pipes in Nuclear Tests, Defense Nuclear Agency Report, Systems, Science, and Software, La Jolia, CA, DNA$3015 T$ (S/RD) (1972).

6. D. C. Pound, Measurement of Tunnel Environment and Early Energy, Gulf Radiation Technology, La Jolla, CA, DASA POR 6464 (1971).

7. J. R. Barthel and D. F. Patch, Condensation Modeling in the FLIP Code, Systems, Science and Software, La Jolla, CA, SSS-R-75-2535 (1975).

8. J. R. Barthel, A Computational Model for Flow in Line-of-Sight Pipes, Systems, Science and Soltware, La Jolla, CA, DASA-2554 (1970).

9. D. Sawle, "Characteristics of the Voitenko High Explosive Driven Gas Compressor," in First Imtern. Colloq. of Gas Dynamics of Explosions, Brussels (18-21 Sept., 1967).

10. H. D. Glenn and B. K. Crowley, Optical Technique for Monitoring High Energy (Mach 35-130) Shocks in Steel Pipes Containing Ambient Atmospheric Air, Lawrence Livermore Laboratory, Livermore, CA, UCRL-71007 (1968).

11. H. D. Glenn and B. K. Crowley, "High-Speed (4-6 cm/ $\mu \mathrm{sec})$ Gas-Jet Propagation," J. Appl. Phys 41, 4157 (1970).

12. H. D. Glenn and B. K. Crowley, "An Analysis of a High-Explosive Shock-Tube Experiment," J. Appl. Phys. 42, 5 (1971).

13. H. R. Kratz, An Experimental Investigation of the Flow of a High-Velocity, High-Density Iron Plasma in Pipes and Muffers; Defense Atomic Support Agency Report, Gulf General Atomic, La Jolla, CA, DASA-2319 (1970).

14. H. D. Glenn, Development of Diagnostic Techniques for Application to Underground Nuclear Tests, Defense Nuclear Agency Report, Systems, Science and Software, La Jolla, CA, DNA 3257F (1973).

15. A. W. Blackstock, H. R. Kratz, and M. B. Feeney, "Piezoelectric Gauges for Measuring Rapidly Varying Pressures up to Seven Kilobars," Rev. Sci. Inst. 35, 105 (1964).

16. B. Hartenbaum, A Piezoelectric Transducer for Measuring Sub-millisecond Pressure Pulses with Amplitudes up to 30 Kilobars, Gulf General Atomic Report, La Jolla, CA, GAMD-8474 (1968).

17. H. D. Glenn, Diagnostics Techniques Improvement Program, Defense Nuclear Agency Report, Systems, Science and Software, La Jolla, CA, DNA 2978 T (1972).

18. K. D. Pyatt, Systems, Science and Software, La Jolla, CA, private communication (1978).

19. H. D. Glenn, "High Energy Oxygen Jet Propagation," J. Appl. Phys. 44, 2585 (1973).

20. P. S. Brown and M. L. Lohmann, "Computer Modeling of the Voitenko Tube Generator," in Proc. Sixth Intern. Symp. on Military Applications of Blast Simulations, Cahors, France (25-29 June, I979).

21. T. L. Ellis, U.S. A rmy Engineer Waterways Experiment Station, Vicksburg, MS, private communicution (April 1978).

22. W. L. Danek, D. J. Shooley, and F. A. Jerogal, Particle Velocimeter for Use Close in to Underground Explosions, Engineering Physics Co., Rockville, MD, Final Report DASA-1431-3 (1967).

23. D. E. Grady, C. W. Smith, and L. Seaman, In Situ Constitutive Relations of Rocks, SRI International, Menlo Park, CA, DNA 3172 Z (1973). 
24. J. T. Rosenberg, C. W. Smith, and D. R. Curran, In Situ Constitutive Relations of Soils and Rocks, SRI International, Menlo Park, CA, Final Report DNA 4097F (1976).

25. S. P. Gill, D. W. Baum, W. L. Shimmin, and D. Mukherjee, Explosive MHD Research, Artec Associates Inc., Annual Report 119, Navy Contract N0001475-C-0822 (1977).

26. D. W. Baum, S. P. Gill, L. W. Shimmin and D. Mukherjee, Research on Nonideal Plasmas, Artec Associates Inc., Hayward, CA, Final Report 126, Navy Contraet NR00014-77-C-0463 (1978).

27. D. W. Baum, S. P. Gill, W. L. Shimmin, D. Mukherjee, F. Flagg, and J. D. Watson, Shock Physics of Nonideal Plasmas, Artec Associates, Inc., Hayward, CA, Annual Report 130, Navy Contract 0001478C-0354 (1979).

28. S. P. Gill, D. Mukherjee, and D. W. Baum, MHD Velocity Gage Study, Artec Associates Inc., Hayward, CA, Final Report 128, DN:i Contract DNA001-78-C-0130 (1979).

29. T. R. Butkovich, The Gas Equation of State for Natural Materials, Lawrence Livermore Laboratory, Livermore, CA, UCRL-14729 (1967).

30. M. J. Ginsberg, D. E. Grady, P. S. Dicarli, and J. T. Rosenberg, Effects of Stress an the Electrical Resistance of Ytterbium and Calibration of Ytterbium Stress Transducers, SRI International, Menlo Park. CA, Defense Nuclear Agency Report DNA 3577F (1973). 